\author{
UNIVERSIDADE DE SÃO PAULO \\ ESCOLA DE ENGENHARIA DE SÃO CARLOS \\ DEPARTAMENTO DE ENGENHARIA MECÂNICA
}

Avaliação da Metodologia Udwadia-Kalaba para o Controle Ativo de Vibrações em Sistemas Rotativos

Raphael Pereira Spada

Orientador: Prof. Dr. Rodrigo Nicoletti

São Carlos

2015 

Raphael Pereira Spada

\section{Avaliação da Metodologia Udwadia-Kalaba para o Controle Ativo de Vibrações em Sistemas Rotativos}

Dissertação apresentada à Escola de Engenharia de São Carlos da Universidade de São Paulo, como parte dos requisitos para obtenção do título de mestre em Engenharia Mecânica.

Área de Concentração: Dinâmica de Máquinas e Sistemas.

ESTE EXEMPLAR TRATA-SE DA VERSÃO CORRIGIDA.

A VERSÃO ORIGINAL ENCONTRA-SE DISPONÍVEL JUNTO AO DEPARTAMENTO DE ENGENHARIA MECANICA DA EESC-

USP.

Orientador: Prof. Dr. Rodrigo Nicoletti

São Carlos

2015 


\section{AUTORIZO A REPRODUČ̃̃ TOTAL OU PARCIAL DESTE TRABALHO, POR QUALQUER MEIO CONVENCIONAL OU ELETRÔNICO, PARA FINS DE ESTUDO E PESQUISA, DESDE QUE CITADA A FONTE.}

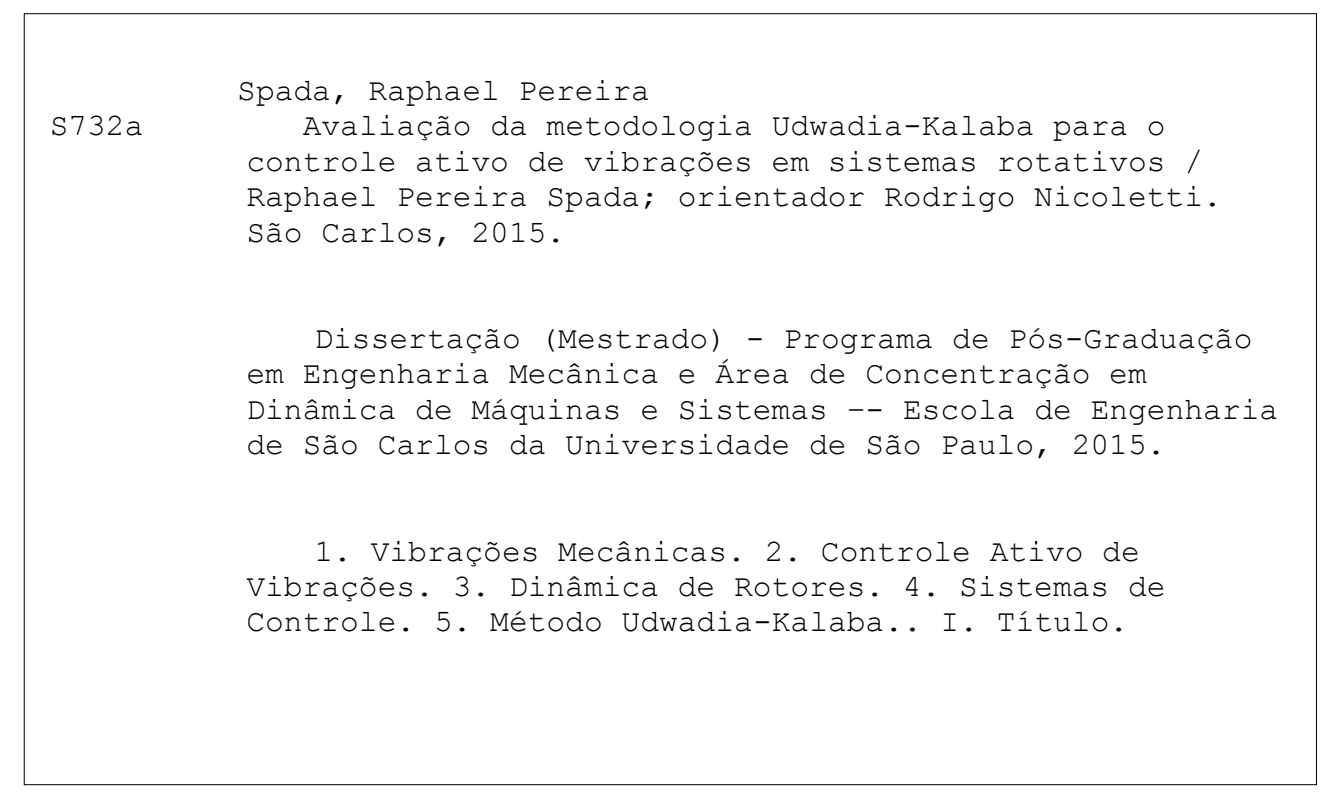


FOLHA DE JULGAMENTO

Candidato: Engenheiro RAPHAEL PEREIRA SPADA.

Título da dissertação: "Avaliação da metodologia Udwadia-Kalaba para o controle ativo de vibrações em sistemas rotativos".

Data da defesa: 05/03/2015

Comissão Julgadora:

Prof. Associado Rodrigo Nicoletti

(Orientador)

(Escola de Engenharia de São Carlos/EESC)

Prof. Dr. Valder Steffen Junior

(Universidade Federal Uberlândia/UFU)

Profa. Dra. Kátia Lucchesi Cavalca Dedini

(Universidade Estadual de Campinas/UNICAMP)
Resultado:
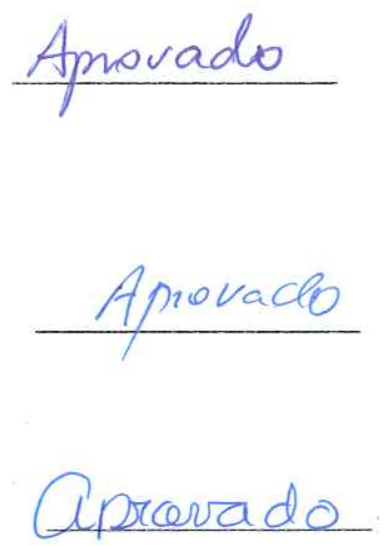

Coordenador do Programa de Pós-Graduação em Engenheira Mecânica: Prof. Associado Marcelo Areias Trindade

Presidente da Comissão de Pós-Graduação:

Prof. Associado Paulo César Lima Segantine 



\section{Dedicatória}

Dedico este trabalho à minha mãe, Maria Isabel, e ao meu irmão Ricardo, pelo incondicional apoio, amor e carinho, que foram fundamentais para a realização deste trabalho. 



\section{Agradecimentos}

Ao Prof. Dr. Rodrigo Nicoletti, pela oportunidade, confiança, amizade e orientação constante ao longo deste trabalho.

Aos professores do departamento de Engenharia Mecânica da EESC-USP pelas disciplinas ministradas e conselhos dados ao longo do projeto.

Ao colega pesquisador Henry Viveros pelo auxílio e colaboração.

Aos amigos do espaço de Coworking de São Carlos pela amizade e convivência.

Aos meus familiares, pelo constante apoio e incentivo.

À CAPES, Coordenação de Aperfeiçoamento de Pessoal de Nível Superior, pelo suporte financeiro. 



\section{Resumo}

SPADA, R. P. Avaliação da metodologia Udwadia-Kalaba para o controle ativo de vibrações em sistemas rotativos. 2015. Dissertação de Mestrado, Escola de Engenharia de São Carlos, Universidade de São Paulo, São Carlos, 2015.

Máquinas rotativas são sempre sujeitas à vibrações mecânicas, em menor ou maior grau, e para garantir um correto funcionamento destas máquinas, evitando falhas de operação, é necessário realizar o controle destas vibrações. Uma das frentes que vem se destacando nesta área é o controle ativo de vibrações. Neste tipo de abordagem as vibrações são controladas ativamente através de um sistema de atuação e de uma técnica de controle a ser empregada de forma satisfatória. Neste contexto, existem inúmeras abordagens da teoria de controle que podem ser aplicadas, e aqui é avaliada a aplicação da metodologia proposta por Udwadia e Kalaba para o controle de trajetória de sistemas não lineares, uma técnica de controle ainda não utilizada no controle ativo de vibrações em sistemas rotativos. Em um primeiro momento a avaliação do desempenho e potencial de aplicação desta metodologia é realizada em sistemas com quatro graus de liberdade através de comparação com controladores do tipo proporcional-integralderivativo e regulador linear-quadrático. Os resultados obtidos pelo controlador avaliado são similares aos resultados obtidos pelo controlador proporcional-integralderivativo com melhorias em termos de erro de posicionamento. A metodologia também é avaliada em um sistema rotativo com um maior número de graus de liberdade, no qual é possível compreender o comportamento do controlador em um sistema flexível. Por fim realiza-se um exemplo de aplicação da técnica em um sistema com um eixo rígido e mancal hidrodinâmico ativo de atuação eletromagnética. Os resultados de simulação obtidos mostram que a metodologia possui potencial de aplicação para sistemas que apresentam eixo rígido, no qual uma drástica redução na amplitude de vibração do sistema foi observada por toda faixa de operação avaliada, enquanto que a sua aplicação em sistemas com eixo flexível se tornou restrita aos dois primeiros modos de vibrar do sistema flexível utilizado, modelado através do método dos elementos finitos.

Palavras chave: Vibrações Mecânicas, Controle Ativo de Vibrações, Dinâmica de Rotores, Sistemas de Controle, Método Udwadia-Kalaba. 



\begin{abstract}
SPADA, R. P. Evaluation of the Udwadia-Kalaba methodology for the active vibration control of rotating machinery. 2015. Master's Dissertation, Escola de Engenharia de São Carlos, Universidade de São Paulo, São Carlos, 2015.
\end{abstract}

Rotating machinery are always subject to mechanical vibration to a lesser or greater degree, and to ensure proper operation of these machines, avoiding faulty operation, it is necessary to carry out the control of these vibrations. One of the fronts that stood out in this area is the active vibration control. In this type of approach, vibrations are actively managed through an actuation system and a control technique to be used satisfactorily. In this context, there are numerous approaches to control theory that can be applied, and here the application of the methodology proposed by Udwadia and Kalaba for trajectory control of nonlinear systems is evaluated, a control technique not yet used in active vibration control in rotating systems. At first the evaluation of the performance and potential application of this methodology is performed on systems with four degrees of freedom by comparison with controllers of the proportionalintegral-derivative and linear-quadratic regulator type. The results of the evaluated controller are similar to results obtained by proportional-integral-derivative controller with improvements in positioning error. The methodology is also evaluated in a rotating system with a larger number of degrees of freedom, wherein we can understand the controller's behavior in a flexible system. Finally, an application example of the technique on a system with a rigid shaft and hydrodynamic bearing with electromagnetic actuators is presented. The obtained simulation results show that the method has application potential to systems having rigid shaft, in which a dramatic reduction in the amplitude of vibration of the system was observed at all the operating range evaluated, whereas their application in systems with flexible shaft became restricted to the first two vibration modes of the flexible system used, modeled by the finite element method.

Keywords: Mechanical Vibrations, Active Vibration Control, Rotor Dynamics, Control Systems, Udwadia-Kalaba Method. 



\section{Lista de figuras}

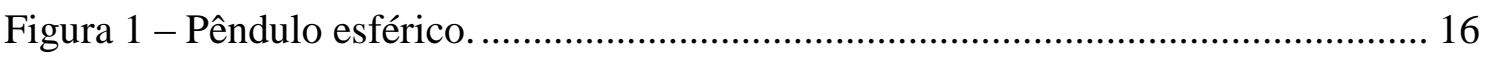

Figura 2 - Deslocamentos do pêndulo esférico no tempo.......................................... 18

Figura 3 - Trajetória tridimensional do pêndulo esférico. .......................................... 19

Figura 4 - Configuração do rotor (a) de Laval e (b) rotor não simétrico........................ 21

Figura 5 - Sistemas de coordenadas utilizados na modelagem no (a) plano YZ e (b) no

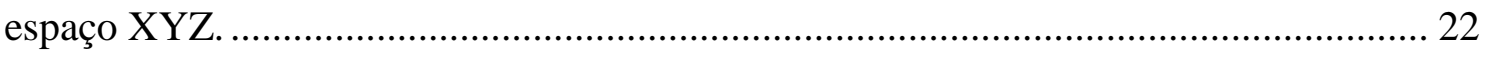

Figura 6 - Raio da trajetória em função da rotação do eixo. Fonte: (CHILDS, 1993). .. 24

Figura 7 - Diagrama de Campbell para o rotor de Laval. .......................................... 26

Figura 8 - Diagrama de Campbell para o rotor não simétrico. ................................... 26

Figura 9 - Diagrama de blocos do controlador PID................................................ 30

Figura 10 - Parâmetros de ganho do controlador PID para rotor de Laval.................... 31

Figura 11 - Parâmetros de ganho do controlador PID para rotor não simétrico............ 31

Figura 12 - Diagrama de blocos do controlador LQR. .......................................... 32

Figura 13 - Resposta do rotor de Laval em 3 situações de ganhos com $\Sigma>\mathrm{K}$, nas

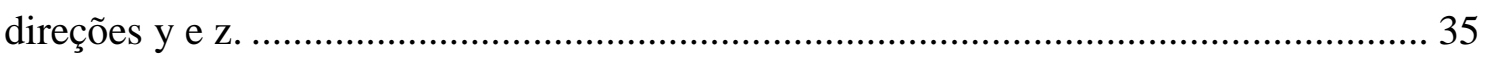

Figura 14 - Resposta do rotor de Laval em 3 situações de ganhos com $\Sigma=\mathrm{K}$, nas

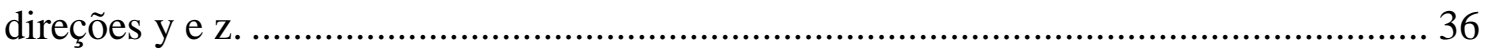

Figura 15 - Resposta do rotor de Laval nos 4 graus de liberdade utilizando o controlador Udwadia-Kalaba.

Figura 16 - Ação de controle e sinal de erro para o rotor de Laval utilizando o

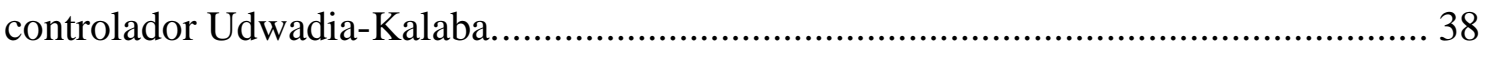

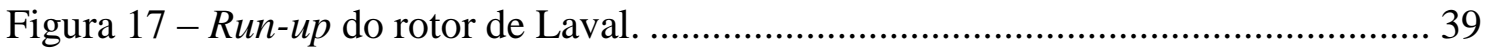

Figura 18 - Resposta do rotor de Laval nos 4 graus de liberdade utilizando o controlador PID. 40 
Figura 19 - Ação de controle e sinal de erro para o rotor de Laval utilizando o controlador PID.

Figura 20 - Resposta do rotor de Laval nos 4 graus de liberdade utilizando o controlador LQR.

Figura 21 - Ação de controle e sinal de erro para o rotor de Laval utilizando o controlador LQR.

Figura 22 - Resposta do rotor não simétrico nas condições de ganho avaliadas, para as direções y e z.

Figura 23 - Resposta do rotor não simétrico nos 4 Graus de liberdade, utilizando o controlador Udwadia-Kalaba

Figura 24 - Ação de controle e sinal de erro para o rotor não simétrico, utilizando o controlador Udwadia-Kalaba 46

Figura 25 - Run-up do rotor não simétrico. 46

Figura 26 - Ação de controle em run-up do controlador Udwadia-Kalaba para o rotor não simétrico.

Figura 27 - Resposta do rotor não simétrico nos 4 Graus de liberdade, utilizando o controlador PID. 48

Figura 28 - Ação de controle e sinal de erro para o rotor não simétrico, utilizando o controlador PID. 48

Figura 29 - Resposta do rotor não simétrico nos 4 graus de liberdade, utilizando o controlador LQR.

Figura 30 - Ação de controle e sinal de erro para o rotor não simétrico, utilizando o controlador LQR. 50

Figura 31 - Comparativo do RMS da ação de controle e sinal erro para todas as configurações de rotores e controladores. 
Figura 32 - Desenho esquemático do modelo em elementos finitos.

Figura 33 - Diagrama de Campbell do modelo em MEF. 55

Figura 34 - Resposta vibratória do mancal nas direções y e z. ...................................... 57

Figura 35 - Resposta vibratória do disco nas direções y e z....................................... 57

Figura 36 - Resposta vibratória no mancal aplicando atuação nas 4 direções............... 58

Figura 37 - Resposta vibratória do disco para as direções y e z até 5.000 rpm............. 59

Figura 38 - Ação de controle nas 4 direções no mancal. ................................................59

Figura $39-1^{\circ}$ modo de vibrar nas direções y e z nas condições livre e controlado. ..... 60

Figura 40 - $2^{\circ}$ modo de vibrar nas direções y e z nas condições livre e controlado. ....... 61

Figura $41-3^{\circ}$ modo de vibrar nas direções y e z nas condições livre e controlado. ..... 62

Figura $42-4^{\circ}$ modo de vibrar nas direções y e z nas condições livre e controlado. ..... 63

Figura $43-5^{\circ}$ modo de vibrar nas direções y e z nas condições livre e controlado. ..... 64

Figura 44 - Desenho esquemático do mancal hidrodinâmico segmentado. 66

Figura 45 - Relação entre a razão de excentricidade e o número de Sommerfeld do mancal. 66

Figura 46 - Relação entre o número de Sommerfeld e rigidez e amortecimento do mancal.

Figura 47 - Magnitude e fase da força eletromagnética do atuador. 68

Figura 48 - Diagrama de blocos no Simulink® do atuador inverso.

Figura 49 - Resposta do eixo rígido em run-up para ambas as direções, nas condições livre e controlada. 70

Figura 50 - Tensão elétrica nos quatro atuadores. 71

Figura 51 - Corrente aplicada nos quatro atuadores. 72

Figura 52 - Potência consumida pelos atuadores. 72

Figura 53 - Força de atuação produzida pelos atuadores eletromagnéticos. 73 
Figura 54 - Resposta do eixo rígido em run-up para ambas as direções, nas condições livre e controlada, sem limitações do atuador. ..... 


\section{Lista de tabelas}

Tabela 1 - Propriedades dos modelos com quatro graus de liberdade.......................... 25

Tabela 2 - Relação de ganhos avaliada para o rotor de Laval. ..................................... 34

Tabela 3 - Relação de ganhos avaliada para o rotor não simétrico............................... 43

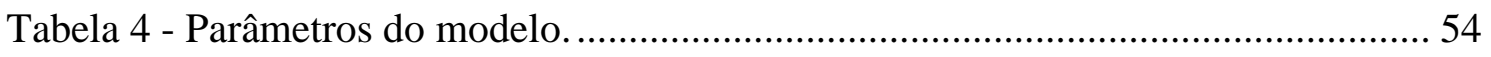

Tabela 5 - Frequências críticas do modelo. …........................................................... 54

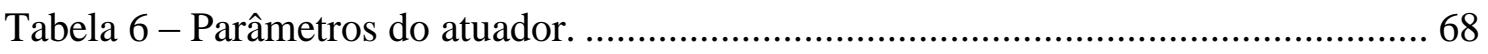





\section{Sumário}

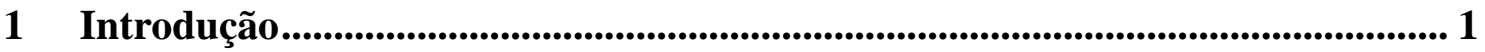

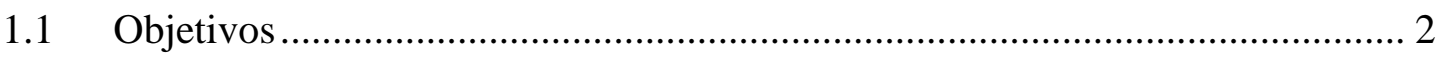

1.2 Organização da Dissertação ....................................................................... 3

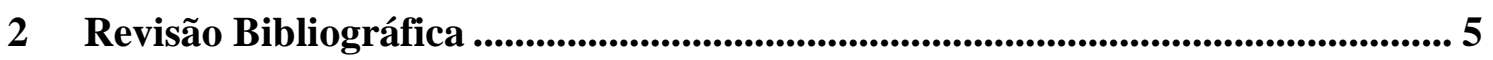

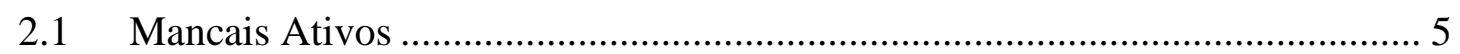

2.2 Controle Ativo de Vibrações Laterais em Rotores ........................................... 7

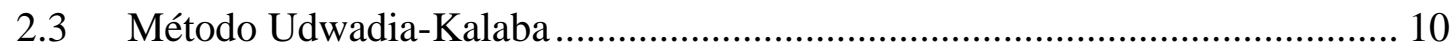

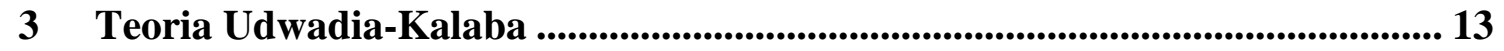

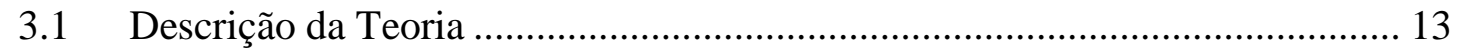

3.2 Aplicação em um Pêndulo Esférico................................................................. 16

4 Avaliação do Controlador em Sistemas Rotativos com 4 Graus de Liberdade21

4.1 Modelo com Quatro Graus de Liberdade ..................................................... 21

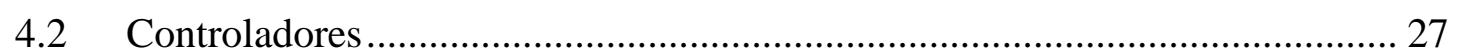

4.2.1 Controlador Udwadia-Kalaba........................................................... 27

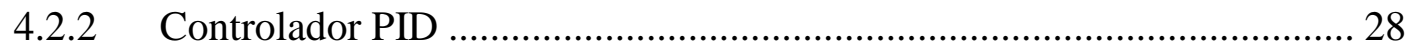

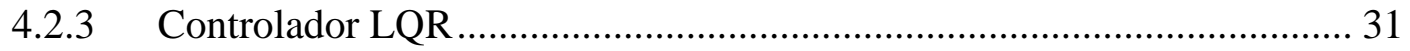

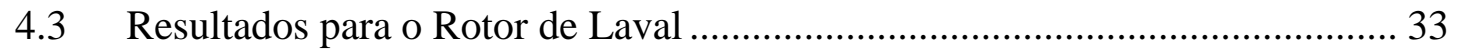

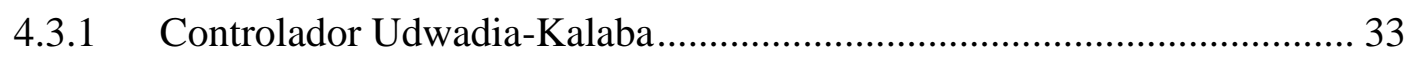

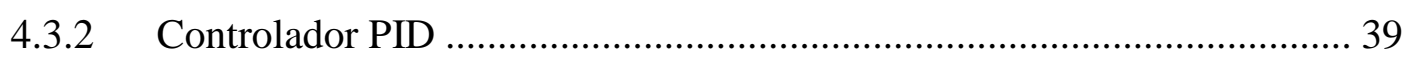

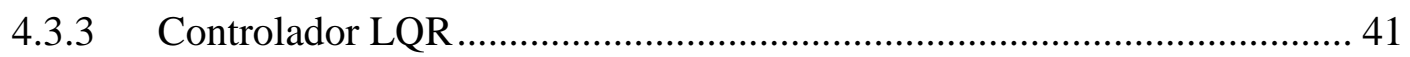

4.4 Resultados para o Rotor não Simétrico............................................................. 42

4.4.1 Controlador Udwadia-Kalaba ............................................................... 43

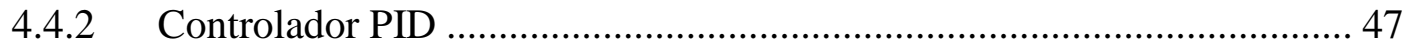

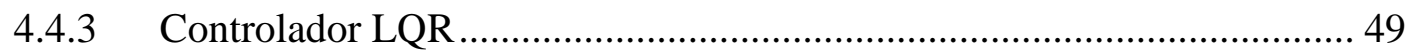

4.5 Comparação do Valor RMS da Ação de Controle e Sinal de Erro ................... 50

5 Avaliação do Controlador em Sistema Rotativo Modelado pelo Método dos Elementos Finitos...............................................................................................53

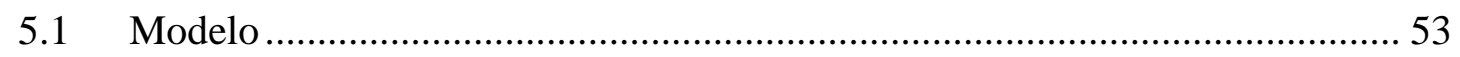

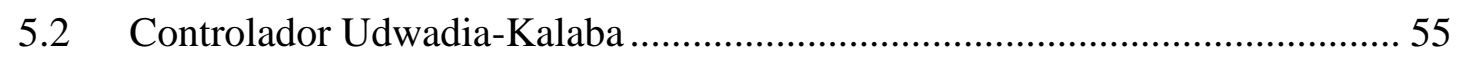

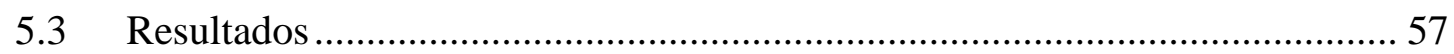


6 Exemplo de Aplicação ......................................................................................... 65

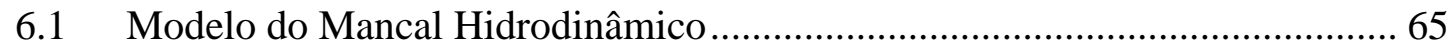

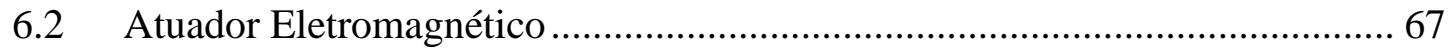

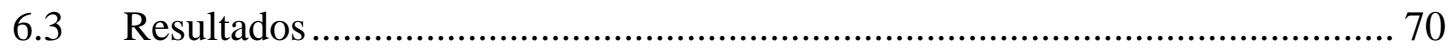

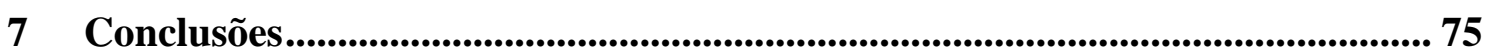

7.1 Trabalhos Futuros ......................................................................................... 76

Referências Bibliográficas ............................................................................................. 79 


\section{Capítulo 1}

\section{Introdução}

Máquinas rotativas possuem uma vasta aplicação, desde equipamentos cotidianos até imensas turbinas de hidroelétricas. Todos estes sistemas rotativos estão sujeitos às vibrações, em menor ou maior grau, devido à impossibilidade de se obter um balanceamento perfeito das suas partes rotativas. Esta massa residual desbalanceada pode gerar uma energia suficiente para excitar modos de vibrar da estrutura em questão. Assim, é de fundamental importância que se tenha níveis aceitáveis de vibração para um sistema rotativo desbalanceado, tendo em vista que tais vibrações podem comprometer o desempenho da máquina.

Para atenuar os problemas de vibração em um sistema rotativo algumas abordagens podem ser adotadas (DOUBRAWA FILHO, 2008):

- Agir sobre a excitação - diminuindo a excitação (desbalanceamento) diminuise a amplitude de vibração, porém a melhoria no balanceamento do sistema exige a utilização de equipamentos sofisticados e de alta precisão na maioria dos casos, constituindo em uma forma de controle nem sempre viável.

- Modificações estruturais - alterações estruturais no sistema buscam alterar propriedades como rigidez e amortecimento, que modificam as rotações características do sistema e seu comportamento dinâmico. Porém restrições mecânicas e dimensões padronizadas podem impedir a aplicação desta técnica.

- Operar o sistema longe de suas rotações características - com o sistema atuando acima das rotações características, também denominadas por velocidades críticas, os problemas de vibrações se tornam mais brandos em função da baixa amplitude de vibração. Esta aplicação é bem específica para casos em que o sistema pode atuar em faixas de rotação elevadas.

- Controle de vibrações - neste tipo de técnica procura-se atenuar as vibrações do sistema de duas formas, o controle passivo e o ativo. O controle passivo exige algumas modificações estruturais seja na forma de isolamento de vibração ou até neutralizadores dinâmicos. Já no controle ativo existe a 
necessidade da inclusão de um atuador, sensores para capturar o comportamento do sistema e de uma técnica da teoria de sistemas de controle a ser empregada de maneira satisfatória.

Com os crescentes avanços no campo da tecnologia e a busca pelo desenvolvimento de sistemas inteligentes, o controle ativo de vibrações (CAV) vem ganhando destaque no contexto de redução de vibrações em sistemas rotativos.

O CAV permite a aplicação de diversas técnicas de controle encontradas na literatura, incluindo técnicas de controle ótimo e robusto. Com isso, a motivação deste trabalho consiste em avaliar o desempenho de uma abordagem de controle ativo ainda não empregada no contexto de redução de vibrações em sistemas rotativos, avaliando então, a possibilidade de aplicação de mais uma técnica no âmbito do CAV.

\subsection{Objetivos}

A técnica de controle ativo a ser avaliada neste trabalho consiste em um controlador de trajetória realizado através da comparação entre a dinâmica do sistema livre com o seu comportamento restrito pelas definições de trajetória desejadas, da mesma forma como a natureza lida com sistemas que possuem uma restrição de movimento definida, tal como um pêndulo esférico. (UDWADIA, 2008).

Assim, a evolução do projeto consistiu nas seguintes etapas:

- Implementar o controlador em sistema simples (rotor de Laval) e aplicar controladores proporcional-integral-derivativo (PID) e regulador quadrático linear (LQR - do inglês linear quadratic regulator) para realizar comparativo de desempenho;

- Implemetar o controlador em sistema com efeito giroscópico (rotor não simétrico) e aplicar controladores PID e LQR para realizar comparativo de desempenho;

- Aplicar o controlador em sistema com mais graus de liberdade (GDL) através do Método dos Elementos Finitos (MEF);

- Exemplo de aplicação em um sistema com mancal hidrodinâmico e atuadores eletromagnéticos. 


\subsection{Organização da Dissertação}

Após este capítulo de introdução, o capítulo 2 apresenta uma revisão bibliográfica dos principais temas relativos a este trabalho, como mancais ativos, controle ativo de vibrações em sistemas rotativos, assim como o histórico para obtenção da metodologia de controle aqui avaliada além de exemplos de sua aplicação na literatura.

Na sequência, o capítulo 3 apresenta a descrição desta metodologia para obtenção da dinâmica de um sistema multicorpos que apresenta restrições cinemáticas e a analogia entre a aplicação desta técnica em uma visão de controle de sistemas. Para ilustrar o emprego da metodologia é realizada a obtenção da dinâmica de um pêndulo esférico.

No capítulo 4, o controlador é empregado em sistemas rotativos mais simples, que apresentam quatro graus de liberdade, e é realizada a comparação de seus resultados aos obtidos por controladores PID e LQR.

Para estender a avaliação deste controlador, no capítulo 5 se aumenta o número de graus de liberdade do sistema rotativo em questão, aumentando, então, a complexidade do sistema.

Para avaliar a aplicação da técnica em um sistema mais próximo do real, no capítulo 6 é realizado o controle através desta metodologia em um sistema que apresenta um mancal hidrodinâmico com atuadores eletromagnéticos.

Por fim, o capítulo 7 apresenta as conclusões obtidas neste trabalho, assim como as limitações encontradas no emprego desta técnica no âmbito de CAV em sistemas rotativos e etapas futuras que podem ser realizadas. 


\section{Capítulo 2}

\section{Revisão Bibliográfica}

Nesta seção é apresentada uma revisão bibliográfica dos principais temas relacionados a este trabalho: mancais ativos, controle de vibrações laterais em sistemas rotativos e um histórico da criação da teoria proposta por Udwadia e Kalaba (1992), assim como aplicações da técnica nos últimos anos.

\subsection{Mancais Ativos}

Os primeiros mancais utilizados para o $\mathrm{CAV}$ foram os mancais magnéticos, com Schweitzer e Lange (1976) investigando experimentalmente as características deste tipo de mancal na aplicação de controle ativo de vibrações de um rotor. Classicamente, os mancais magnéticos ativos (MMAs) podem ser empregados em rotores que operam a altas velocidades para reduzir o atrito ou desgaste do eixo-mancal e podem gerar uma força transversal sem contato para realizar o controle de vibrações (SCHWEITZER, 1990).

O motivo pelo qual os MMAs são amplamente utilizados no CAV consiste em seu acionamento elétrico e a possibilidade de alteração de suas características dinâmicas com a máquina em funcionamento (ADAMS; McCLOSKEY, 1990). Além disso, estes apresentam vantagens em termos de limpeza, faixa de frequência de operação e atuação sem contato, uma vez que não há necessidade de lubrificação ou fluido para sustentação do eixo (ULBRICH, 1993).

Ainda segundo Adams e McCloskey (1990), apesar das inúmeras vantagens apresentadas pelos MMAs, estes estão limitados às aplicações em sistemas de pequeno porte, uma vez que o custo envolvido na adoção de MMAs em sistemas de grande porte torna-se muito elevado, em conjunto com as forças de atuação envolvidas na sustentação do sistema, aumentado complexidade e tornando-se menos compactos. Outra desvantagem que pode ser citada é o consumo de potência contínua apresentada pelos MMAs (HORST; WOLFEL, 2004).

Outro fator a ser considerado em sistemas que utilizam MMAs é a necessidade da inclusão de um sistema de proteção, usualmente mancais auxiliares, em caso de possíveis 
sobrecargas ou falha do sistema de atuação, que seriam catastróficas sem a presença deste sistema auxiliar (KASARDA, 2000).

Em virtude das limitações apresentadas pelos MMAs, surgem algumas soluções de novos mancais ativos, conhecidos como mancais híbridos, nos quais o mancal é responsável pela sustentação do eixo enquanto que os atuadores se responsabilizam unicamente pelo CAV do eixo.

Uma das primeiras opções de mancais híbridos avaliadas foram os mancais com atuadores piezelétricos, cujo princípio de funcionamento consiste na aplicação de uma tensão elétrica que gera uma força mecânica na estrutura onde os atuadores são aplicados. Os trabalhos de Palazzolo et al. (1991) e Palazzolo et al. (1993) foram os primeiros envolvendo a utilização de atuadores piezelétricos no conceito de mancais híbridos. Como resultado, obteve-se redução satisfatória nas amplitudes de vibração para rotações elevadas, enquanto que seu comportamento em baixas frequências foi menos eficaz. Palazzolo et al. (1993) levantaram as principais desvantagens dos atuadores piezelétricos, entre elas a baixa faixa de deslocamento que o atuador pode aplicar na estrutura, recomendando, assim, a sua utilização em sistemas que não apresentem grandes níveis de vibração quando não controlados.

Nos últimos anos, mancais híbridos com atuadores eletromagnéticos tem se destacado. Nicoletti (2006) apresentou um mancal hidrodinâmico segmentado juntamente com sapatas magnéticas móveis. Neste caso, o filme de óleo entre eixo e sapatas é responsável pela sustentação do eixo, enquanto que os atuadores eletromagnéticos realizam somente o CAV, mesma configuração utilizada no trabalho de Viveros e Nicoletti (2014). Desta forma, é possível atacar as desvantagens de baixa carga apresentadas pelos MMAs de mesma dimensão ao mesmo tempo em que não se perde a possibilidade de realização do CAV, tendo em vista que a capacidade de carga dos MMAs são cerca de dez vezes menores do que as de um mancal hidrodinâmico de mesma dimensão (BURROWS; KEOGH; SAHINKAYA, 2009).

Dentro da linha de mancais híbridos com atuação eletromagnética destaca-se também o trabalho de Morais (2010), que consistiu no controle de fechamento de trincas, e o trabalho de Koroishi (2013), envolvendo o controle de vibrações em sistemas rotativos através de atuação eletromagnética. Neste caso, o mancal híbrido consistia em um mancal de rolamento em conjunto a quatro atuadores eletromagnéticos.

Para garantir a eficácia da utilização de atuadores eletromagnéticos para o CAV, é necessário possuir um bom modelo dos atuadores. No trabalho de Morais et al. (2013), atuadores deste tipo são caracterizados através de métodos de solução de problemas inversos, 
tendo como resultado a função transferência entre a força produzida pelos atuadores em função da corrente e do gap existente entre o eixo e o atuador. Já no trabalho de Viveros e Nicoletti (2014), os atuadores são modelados empiricamente a partir de curvas experimentais de força versus tensão elétrica de entrada.

As principais vantagens de um mancal híbrido com atuação eletromagnética, também empregado neste trabalho, consistem na estrutura eletromecânica simples do atuador associada a uma ação de controle sem contato mecânico, além do consumo energético reduzido, uma vez que os atuadores não são responsáveis pela sustentação do eixo (KOROISHI et al., 2014).

\subsection{Controle Ativo de Vibrações Laterais em Rotores}

Conforme citado anteriormente, os MMAs foram os primeiros mancais utilizados no CAV. Segundo Burrows, Keogh e Sahinkaya (2009) os MMAs são frequentemente controlados através de controladores PID, que em uma perspectiva de vibração de rotores seria similar ao controle passivo de um sistema mola-amortecedor.

As aplicações deste tipo de controlador para sistemas com MMAs tem sido extensivas. Lei e Palazzolo (2009) realizaram a avaliação de estabilidade e controle de vibrações em um volante de motor suportado por MMAs, obtendo bons resultados até mesmo com controladores relativamente mais simples, como o caso do controlador PID. Em outra abordagem, Jeon et al. (2002) também utilizam um controlador PID para realizar a estabilização do sistema e com isso realizam a avaliação da resposta em frequência do conjunto estabilizado para criar um controlador LQG que obteve redução significativa nas amplitudes de vibração lateral para os dois primeiros modos de vibrar do sistema.

Apesar de o controlador PID ser o mais utilizado para o CAV em MMAs, outros tipos de controladores foram estudados. Lin e Yu (2004) realizaram um controle modal ótimo através da realimentação de estados do rotor flexível e obtiveram excelentes resultados de atenuação de vibração para os primeiros modos de corpo rígido. Em continuação ao trabalho anterior, $\mathrm{Yu}$, Lin e $\mathrm{Chu}$ (2007) produziram um controlador robusto de norma $\mathrm{H}_{\infty}$ com o intuito de deixá-lo menos suscetível às incertezas da planta, como perda de massa no disco e alterações na velocidade de rotação. Já Chen, Ji e Liu (2010) fizeram o CAV de um volante suportado por MMAs através de uma rede neural artificial treinada pelo algoritmo de back propagation, apresentando bons resultados em termos de controle da posição do eixo, rejeição a distúrbios e redução na amplitude de vibração do sistema. Recentemente, Defoy, Alban e 
Mahfoud (2014) desenvolveram uma abordagem diferente no controle por lógica Fuzzy, através de entradas em coordenadas polares de velocidade tangencial e radial associadas ao regime permanente e regime transiente. A avaliação deste controlador foi realizada através de comparação com um controlador PID e um controlador fuzzy single-input single-output (SISO), constatando-se melhorias em redução de vibrações enquanto a estabilidade era mantida no mesmo patamar, mostrando que esta nova abordagem consiste em uma boa metodologia para o CAV em MMAs.

Tendo em vista que os MMAs possuem restrições quanto à sua aplicação em máquinas de grande porte, o estudo de controle de vibrações em sistemas rotativos com mancais híbridos vem sendo propulsionado. Com relação aos atuadores piezelétricos, Palazzolo et al. (1993) e Simões e Steffen (2007) realizaram o CAV através da utilização de atuadores piezelétricos do tipo pilha, constituídos por cerâmicas piezelétricas empilhadas e conectadas por eletrodos em paralelo. A técnica de controle empregada foi a de um controlador modal ótimo pela fácil aplicabilidade. Os resultados mostraram-se satisfatórios com relação à atenuação de vibrações nas ressonâncias dos primeiros modos de vibrar, não sendo eficiente em rotações mais baixas, caso em que as vibrações inclusive aumentaram. Horst e Wolfel (2004) investigaram um controlador LQR em adotaram uma abordagem diferente, realizando a aplicação das cerâmicas piezelétricas diretamente em contato com o eixo, porém obtiveram resultados inferiores quando comparados aos obtidos pelas cerâmicas piezelétricas empilhadas. Tuma et al. (2013) utilizaram um mancal hidrodinâmico com atuadores piezelétricos do tipo pilha para ganhar mais estabilidade em altas rotações. Para isso, foi utilizado um controlador proporcional, que resultou no ganho de cerca de $3.000 \mathrm{rpm}$ na margem de estabilidade do mancal.

Em função das limitações apresentadas pelos atuadores piezelétricos, o CAV utilizando atuação eletromagnética vem se destacando, pois, como dito anteriormente, apresentam vantagens semelhantes às apresentadas pelos MMAs sem as desvantagens de baixa carga e elevado consumo de potência elétrica. Neste contexto, Das et al. (2010) e Das, Dutt e Ray (2011) desenvolveram um controlador PD utilizando atuadores eletromagnéticos em um rotor suportado por mancais hidrodinâmicos. Ambos os trabalhos consideraram apenas simulações numéricas e avaliaram parâmetros como posicionamento dos atuadores ao longo do eixo, uma vez que neste caso os atuadores não se encontravam nos mancais do sistema.

De um ponto de vista mais experimental, Buttini e Nicoletti (2012a) realizaram um controlador PD através da avaliação no domínio da frequência do comportamento do sistema em malha aberta. Os resultados mostraram redução no pico de ressonância do sistema. Em 
sequência, Buttini e Nicoletti (2012b) implementaram um controlador PD utilizando um algoritmo de auto identificação dos ganhos, através da resposta em frequência de malha aberta do sistema e agora avaliando um critério de desempenho desejado, como minimização da amplitude de vibração na ressonância, redução da vibração ao longo do eixo ou de minimização da ação de controle. Escolhido o critério, o controlador PD é ligado, com os ganhos determinados de acordo com o critério escolhido, consistindo assim em um conceito de máquina inteligente, em que o sistema é capaz de identificar as condições operacionais e tomar decisões autônomas com o objetivo de atender critérios ótimos definidos pelo projetista.

Considerando agora mancais híbridos com atuação eletromagnética, o controlador PD também é utilizado por Viveros e Nicoletti (2014) para realizar o CAV em um mancal hidrodinâmico com atuadores eletromagnéticos. Os resultados experimentais deste trabalho, no domínio da frequência, mostraram redução no nível de vibração de 10 a $20 \%$ para uma faixa de rotação entre 600 e 1100 rpm. No trabalho de Koroishi, Steffen e Mahfoud (2012) outros tipos de técnica de CAV são aplicados, realizando a comparação entre um controlador Fuzzy que leva em consideração a não linearidade do atuador eletromagnético com controladores $\mathrm{H}_{\infty}$ e LQR considerando um modelo linear dos atuadores. Pelas simulações numéricas foi visto que o controlador obtido utilizando lógica Fuzzy gerou uma força de controle maior, possivelmente devido às não linearidades do atuador consideradas nesta situação. Apesar das forças envolvidas serem maiores, a utilização de um modelo não linear do atuador permite maior confiabilidade ao sistema, tendo em vista que a linearização ocorre ao redor de um ponto de operação e se as condições de operação da máquina alterarem bruscamente, a região linear de comportamento do atuador pode ser comprometida, sendo necessária a redefinição dos ganhos para os controladores LQR e $\mathrm{H}_{\infty}$.

Koroishi et al. (2014) realizaram um CAV modal de um rotor flexível através de duas abordagens de controle, um controlador LQR resolvido por desigualdades matriciais lineares e utilizando todos os modos de vibrar do rotor simultaneamente, resultando em uma matriz de ganho fixa para todas as situações, e um controlador por lógica Fuzzy que leva em conta cada modo separadamente, ou seja, um controlador para cada modo de vibrar da estrutura. Os resultados experimentais dos dois controladores foram bons em termos de redução da amplitude de vibração, com resultados ligeiramente superiores obtidos pelo controlador LQR. 


\subsection{Método Udwadia-Kalaba}

O problema geral de se obter equações de movimento para sistemas que apresentam restrição de movimento tem sido uma área de interesse comum entre cientistas e engenheiros, sendo considerado um dos problemas centrais na dinâmica de multicorpos. Segundo Zhao, Zhen e Chen (2013) o tema vem sendo atacado por renomados cientistas, engenheiros e matemáticos desde a sua formulação por Lagrange, que para lidar com sistemas que apresentam restrição de movimento criou o método multiplicador de Lagrange, e passando por Gauss, Jacobi, Gibbs e Poincaré. Entretanto, os multiplicadores são difíceis de ser encontrados em situações com alto número de graus de liberdade.

Udwadia e Kalaba (1992) conseguiram obter de forma precisa a expressão que determina o comportamento de um sistema que apresenta restrições de movimento. Zhao, Zhen e Chen (2013) apontam três vantagens apresentadas pelo método Udwadia-Kalaba. A primeira consiste em não necessitar adição de novas variáveis no sistema, como os multiplicadores de Lagrange. A segunda permite abordar problemas com matriz de massa singular com diferentes restrições cinemáticas, sejam elas holonômicas ou não holonômicas. E por fim o método permite dividir o sistema em subsistemas para obter as equações de movimento e assim combinar estas equações para obter o comportamento do sistema como um todo, de forma simples.

A metodologia proposta por Udwadia-Kalaba será apresentada de forma detalhada no próximo capítulo, restringindo esta seção ao histórico para obtenção do método assim como suas aplicações nos últimos anos.

As pesquisas realizadas nos últimos anos utilizando esta metodologia podem ser divididas em duas categorias, uma para a obtenção das equações de movimento para sistemas que apresentam algum tipo de restrição cinemática e outra para a realização de controle de trajetória de um sistema a partir da comparação entre a dinâmica do sistema sem restrições com a sua dinâmica restrita, foco deste trabalho.

Do ponto de vista da obtenção das equações de movimento, Pennestri, Valentini e de Falco (2010) realizam uma comparação entre o método Udwadia-Kalaba e o método de partição de coordenadas (outra metodologia utilizada nesta área) para modelar a dinâmica de uma manivela deslizante, considerando elementos flexíveis para a estrutura e testando condições de elementos de viga Euler-Bernoulli e Timoshenko. O método Udwadia-Kalaba obteve resultados mais precisos com menor tempo de processamento, para os dois tipos de vigas. Zhao, Zhen e Chen (2013) utilizaram esta metodologia para realizar a modelagem 
multicorpos de uma corrente engastada nas duas extremidades, com o campo gravitacional atuando sobre cada elo da corrente. Para realizar o modelo, os autores consideraram as restrições cinemáticas entre os elos da corrente e as condições de engaste, obtendo resultados numéricos precisos. Além disto, os autores utilizaram a metodologia para obter a dinâmica de um peixe robô, modelando torso, cabeça e cauda do animal. Como resultado, as simulações numéricas apresentaram um comportamento muito similar ao animal estudado.

Ainda com relação à obtenção das equações de movimento do sistema, Oprea (2013) obteve a dinâmica de um trem em colisão empregando a metodologia Udwadia-Kalaba nos acoplamentos dos vagões, obtendo as forças de restrição envolvidas neste cenário de múltiplas colisões entre vagões. Por fim, destaca-se o trabalho de Huang, Cheng e Zhong (2013) que utilizam a metodologia para obter a dinâmica de um manipulador paralelo através da separação do sistema em subsistemas interligados por restrições cinemáticas. Utilizando esta abordagem, foi possível obter um modelo tanto para cinemática direta quanto para a inversa, sem a utilização de variáveis adicionais como os multiplicadores de Lagrange.

Voltando-se agora para a aplicação de interesse deste trabalho, o controle de sistemas, destacam-se alguns trabalhos teóricos utilizando a metodologia Udwadia-Kalaba. Lam, Schutte e Udwadia (2006) realizaram o controle de trajetória de satélites em função da trajetória de um satélite líder. Esta aplicação possibilita a utilização de satélites menores e mais leves com aparelhamento mais simples, de tal forma que o conjunto destes se comporte como um satélite mais complexo, executando com mesma eficiência a tarefa do satélite líder. O trabalho de Cho e Udwadia (2013) também é voltado para o controle de trajetória de satélites e neste trabalho obtiveram todas as forças e torques de controle a ser empregados para que os requerimentos de trajetória impostos pela movimentação do satélite líder fossem obtidos, sem utilizar qualquer artifício de linearização no modelo.

Em uma abordagem semelhante, Mylapili e Udwadia (2012) realizaram a sincronização de giroscópios acoplados, que apresentam movimentação caótica, em relação à movimentação de um giroscópio mestre. Os resultados mostraram sinais de erro de cumprimento da trajetória insignificantes, na ordem da tolerância de integração numérica.

Por fim, destaca-se a aplicação da metodologia feita por Peters et al. (2008), que obtiveram uma estrutura unificada para obtenção de controladores de trajetória ótimos para robôs com graus de liberdade redundantes. Estes controladores ótimos foram obtidos de duas maneiras, impondo a trajetória das juntas do robô e em uma segunda abordagem definindo a trajetória da ferramenta. Para validar o trabalho, foi utilizado um manipulador hidráulico antropomórfico com sete graus de liberdade, simulando os principais graus de liberdade de 
um braço humano. Os resultados mostraram o cumprimento dos requisitos de trajetória impostos satisfatoriamente, com valores de rms do erro de trajetória pequenos. Este foi o único trabalho com validação experimental realizado utilizando a metodologia proposta por Udwadia-Kalaba (do conhecimento do autor desta dissertação).

Tendo em vista que este tipo de técnica ainda não foi avaliada no âmbito de CAV em sistemas rotativos, a importância do presente trabalho consiste na verificação da viabilidade de aplicação desta técnica, para que, se possível, mais uma técnica de controle possa ser empregada numa área de conhecimento que vem ganhando destaque ao longo dos anos. 


\section{Capítulo 3}

\section{Teoria Udwadia-Kalaba}

Neste capítulo, a teoria proposta por Udwadia e Kalaba (1992) para obtenção das equações de movimento de sistemas multicorpos não lineares que apresentam restrições cinemáticas é apresentada. Ao descrever esta teoria, mostra-se uma analogia no emprego desta técnica no âmbito de controle de trajetória de um sistema através da imposição de restrições cinemáticas virtuais. Para ilustrar o emprego da técnica, realiza-se um exemplo de aplicação para obtenção das equações dinâmicas de um pêndulo esférico.

\subsection{Descrição da Teoria}

Conforme discutido no Capítulo 2, a teoria proposta por Udwadia e Kalaba (1992) apresenta uma forma de obter as equações dinâmicas para sistemas que apresentam algum tipo de restrição cinemática sem utilizar o artifício de incluir novas variáveis como os multiplicadores de Lagrange e sem realizar qualquer tipo de aproximação ou linearização no modelo, para o caso de sistemas não lineares.

Considera-se um sistema com movimentação livre (não restrita) como o da Equação (1).

$$
[M]\{\ddot{q}\}=\{Q\}
$$

Onde $\mathrm{M}$ representa a matriz de inércia do sistema, $\ddot{q}$ o vetor de acelerações e $\mathrm{Q}$ o vetor de forças associadas ao comportamento livre do sistema.

A primeira etapa a ser realizada é a definição das restrições cinemáticas a serem impostas no sistema da Equação (1), sendo elas restrições holonômicas (quando as restrições são definidas em termos de posição e tempo), não holonômicas (envolvendo termos de velocidade), ideais (restrições sem atrito) ou não ideais (algum tipo de atrito está envolvido na restrição cinemática).

Definindo as restrições no formato da Equação (2), para restrições holonômicas, e da Equação (3), para restrições não holonômicas, o próximo passo é o de derivar estas restrições 
até chegarmos à mesma ordem do sistema livre da Equação (1), no caso um sistema de segunda ordem.

$$
\begin{gathered}
\varphi(q, t)=0 \\
\psi(q, \dot{q}, t)=0
\end{gathered}
$$

Assim, é necessário derivar duas vezes com relação ao tempo a Equação (2) que não envolve termos de velocidade, e uma vez a Equação (3) para chegarmos à mesma ordem do sistema original representado na Equação (1). Realizando este procedimento, é possível rearranjar estas equações no formato da Equação (4).

$$
A(q, \dot{q}, t)\{\ddot{q}\}=b(q, \dot{q}, t)
$$

A Equação (4) é equivalente às Equações (2) e (3) somente se as condições iniciais $q(0)$ e $\dot{q}(0)$ satisfazem as Equações (2) e (3) e suas respectivas derivadas. Entretanto, do ponto de vista de controle, as condições iniciais não serão idênticas às restrições desejadas, uma vez que queremos levar o sistema de um comportamento livre para um comportamento controlado, ou seja, o sistema não está inicialmente nos estados desejados. Assim, a restrição final pode ser aplicada como uma combinação das restrições originais, na forma das Equações (5) e (6), de tal maneira que os ganhos $\Sigma, K$ e $\Lambda$ influenciam na convergência da resposta do sistema livre para a resposta controlada. A avaliação da influência destes ganhos será apresentada no próximo capítulo.

$$
\begin{gathered}
\ddot{\varphi}+\Sigma \dot{\varphi}+K \varphi=0 \\
\dot{\psi}+\Lambda \psi=0
\end{gathered}
$$

Estas equações são, então, rearranjadas no formato da Equação (4).

Se definirmos a aceleração do sistema livre como na Equação (7), a força de restrição, ou força de controle, necessária a ser aplicada ao sistema da Equação (1) para que o sistema atenda as restrições impostas é dada pela Equação (8). 


$$
\begin{gathered}
\{\mathrm{a}\}=[\mathrm{M}]^{-1}\{Q\} \\
\left\{Q_{c}\right\}=-[M]^{1 / 2}\left([A][M]^{-1 / 2}\right)^{+}([A]\{a\}-\{b\})
\end{gathered}
$$

$\mathrm{Na}$ Equação (8) os termos envolvidos foram definidos nas Equações (1), (4) e (7) e o sinal de $X^{+}$indica a pseudoinversa da matriz $X$, também conhecida como a inversa de MoorePenrose, utilizada para determinação da matriz inversa de matrizes não quadradas.

Segundo Udwadia (2008), esta força de restrição é aquela que minimiza o funcional da Equação (9) a cada instante de tempo, se diferenciando assim dos controladores usualmente utilizados, que buscam minimizar um funcional do tipo $\int_{0}^{T} J(t) d t$.

$$
J(t)=\left[Q^{c}\right]^{T}[M]^{-1}\left[Q^{c}\right]
$$

Ainda segundo Udwadia (2008), a vantagem de se utilizar a matriz de ponderação do funcional da Equação (9) como sendo a inversa da matriz de inércia do sistema consiste no fato de que o controlador está favorecendo a aplicação de forças nas menores massas e, uma vez que, considerando um sistema multicorpos, para movimentar massas menores é necessária a aplicação de uma força menor, o controlador busca uma solução de mínima força de atuação.

Olhando a força de restrição exibida na Equação (8) podemos estabelecer uma analogia com as formas de controle convencionais de tal forma que tenhamos na Equação (10) uma ação de controle com ganho proporcional variável e um sinal de erro.

$$
\left\{Q_{c}\right\}=-K(q, \dot{q}, t) e(q, \dot{q}, t)
$$

Onde:

$$
\begin{gathered}
K(q, \dot{q}, t)=[M]^{1 / 2}\left([A][M]^{-1 / 2}\right)^{+} \\
e(q, \dot{q}, t)=[A]\{a\}-\{b\}=[A](\{a\}-\{\ddot{q}\})
\end{gathered}
$$

Pela Equação (12) é possível observar que o sinal de erro utilizado pelo controlador é uma comparação entre a aceleração desejada a partir das restrições cinemáticas impostas e a 
aceleração do sistema, ou seja, o controle é realizado através da avaliação da aceleração do sistema.

Se incluirmos a Equação (10) no sistema livre (não controlado) da Equação (1) tem-se uma realimentação negativa de um sinal de erro de aceleração, dada pela Equação (13), que define o comportamento dinâmico do sistema, que agora passa a ser restringido (controlado).

$$
[M]\{\ddot{q}\}=\{Q\}-K(q, \dot{q}, t) e(q, \dot{q}, t)
$$

\subsection{Aplicação em um Pêndulo Esférico}

Para ilustrar a teoria apresentada neste capítulo, realiza-se o emprego da técnica para a obtenção das equações dinâmicas para um sistema que possui movimentação restrita, um pêndulo esférico, como o da Figura 1, constituído por uma barra de comprimento $L$ com massa desprezível e uma massa pontual $m$ localizada na extremidade da barra.

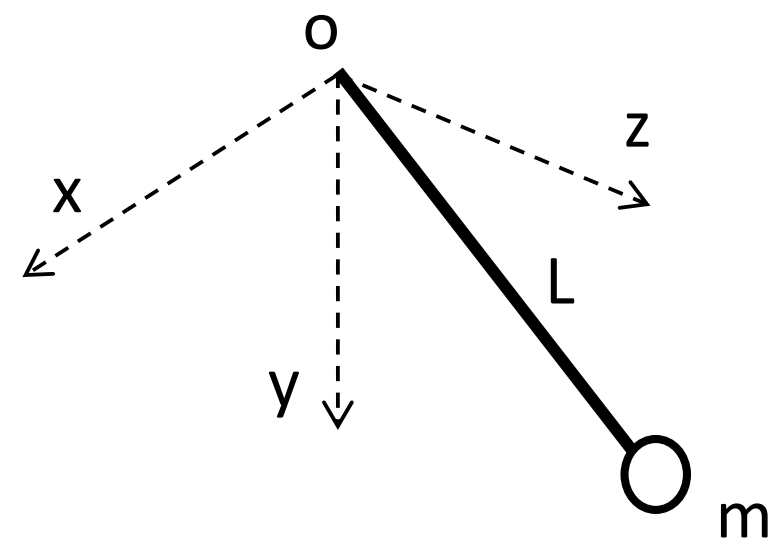

Figura 1 - Pêndulo esférico.

A dinâmica livre da massa é dada pela Equação (14), na qual removemos a força de tração da barra, que é responsável pela geração da restrição de movimento da massa pontual. Vale ressaltar que aqui não é considerando a resistência do ar.

$$
[M] \ddot{q}=\left[\begin{array}{ccc}
m & 0 & 0 \\
0 & m & 0 \\
0 & 0 & m
\end{array}\right]\left\{\begin{array}{l}
\ddot{x} \\
\ddot{y} \\
\ddot{z}
\end{array}\right\}=\left\{\begin{array}{c}
0 \\
m g \\
0
\end{array}\right\}=\{Q\}
$$


Definem-se agora as restrições impostas ao sistema na Equação (15), que define uma esfera centrada na origem do sistema de coordenadas com raio L.

$$
\varphi=x^{2}+y^{2}+z^{2}-L^{2}=0
$$

Realizando a diferenciação relativa ao tempo da Equação (15) obtemos a Equação (16) que diferenciada mais uma vez é equivalente a Equação (17).

$$
\begin{gathered}
\dot{\varphi}=x \dot{x}+y \dot{y}+z \dot{z}=0 \\
\ddot{\varphi}=x \ddot{x}+y \ddot{y}+z \ddot{z}+\dot{x}^{2}+\dot{y}^{2}+\dot{z}^{2}=0
\end{gathered}
$$

Rearranjando a Equação (17) no formato da Equação (4), obtêm-se a relação exibida na Equação (18).

$$
[A]\{\ddot{q}\}=\left[\begin{array}{lll}
x & y & z
\end{array}\right]\left\{\begin{array}{l}
\ddot{x} \\
\ddot{y} \\
\ddot{z}
\end{array}\right\}=-\dot{x}^{2}-\dot{y}^{2}-\dot{z}^{2}=b
$$

Conforme comentado na seção anterior, para um conjunto de condições iniciais que respeitem as Equações (15) e (16), a Equação (18) é equivalente a Equação (15) que representa a restrição de trajetória original. Neste caso, considera-se que as condições iniciais atendem as Equações (15) e (16), não sendo necessário realizar a combinação proposta na Equação (5).

Aplicando, então, a Equação (8) para obtenção da força de restrição aplicada na massa a cada instante de tempo, têm-se a dinâmica final do comportamento do pêndulo esférico, considerando condições iniciais $\mathrm{q}(0)$ e $\dot{q}(0)$ que satisfaçam as Equações (15) e (16), como por exemplo as condições iniciais $\mathrm{q}(0)=\left[\begin{array}{lll}\mathrm{L} & 0 & 0\end{array}\right]^{T}$ e $\dot{q}(0)=\left[\begin{array}{lll}0 & 0 & 0\end{array}\right]^{T}$.

$$
[M] \ddot{q}=\left[\begin{array}{ccc}
m & 0 & 0 \\
0 & m & 0 \\
0 & 0 & m
\end{array}\right]\left\{\begin{array}{l}
\ddot{x} \\
\ddot{y} \\
\ddot{z}
\end{array}\right\}=\left\{\begin{array}{c}
0 \\
m g \\
0
\end{array}\right\}-\left\{\begin{array}{l}
\frac{m x\left(\dot{x}^{2}+\dot{y}^{2}+\dot{z}^{2}+y g\right)}{x^{2}+y^{2}+z^{2}} \\
\frac{m y\left(\dot{x}^{2}+\dot{y}^{2}+\dot{z}^{2}+y g\right)}{x^{2}+y^{2}+z^{2}} \\
\frac{m z\left(\dot{x}^{2}+\dot{y}^{2}+\dot{z}^{2}+y g\right)}{x^{2}+y^{2}+z^{2}}
\end{array}\right\}
$$


Resolvendo esta equação no MATLAB® ${ }^{\circledR}$ com o comando ode45, considerando o comprimento da barra $L=1 \mathrm{~m}$, massa $m=1 \mathrm{~kg}$, gravidade $g=9.81 \mathrm{~m} / \mathrm{s}^{2}$ e condições iniciais definidas anteriormente, foi possível constatar o comportamento esperado, o da restrição de movimento da massa, de acordo com a restrição imposta pela Equação (15).

A Figura 2 apresenta a resposta no tempo para as três coordenadas. Identifica-se o movimento oscilatório do pêndulo nas direções x (entre -1 e $1 \mathrm{~m})$ e y (entre 0 e $1 \mathrm{~m}$ ), enquanto em z não apresenta qualquer alteração. Percebe-se que a resistência do ar não ter sido considerada implica em uma amplitude de oscilação constante para estas direções. Com relação ao movimento em z, como as condições iniciais nesta direção eram nulas, o esperado era que não fosse visto qualquer deslocamento nesta direção, uma vez que a gravidade atua somente em y. Assim, os resultados se mostraram coerentes com o comportamento de um pêndulo esférico no vácuo.
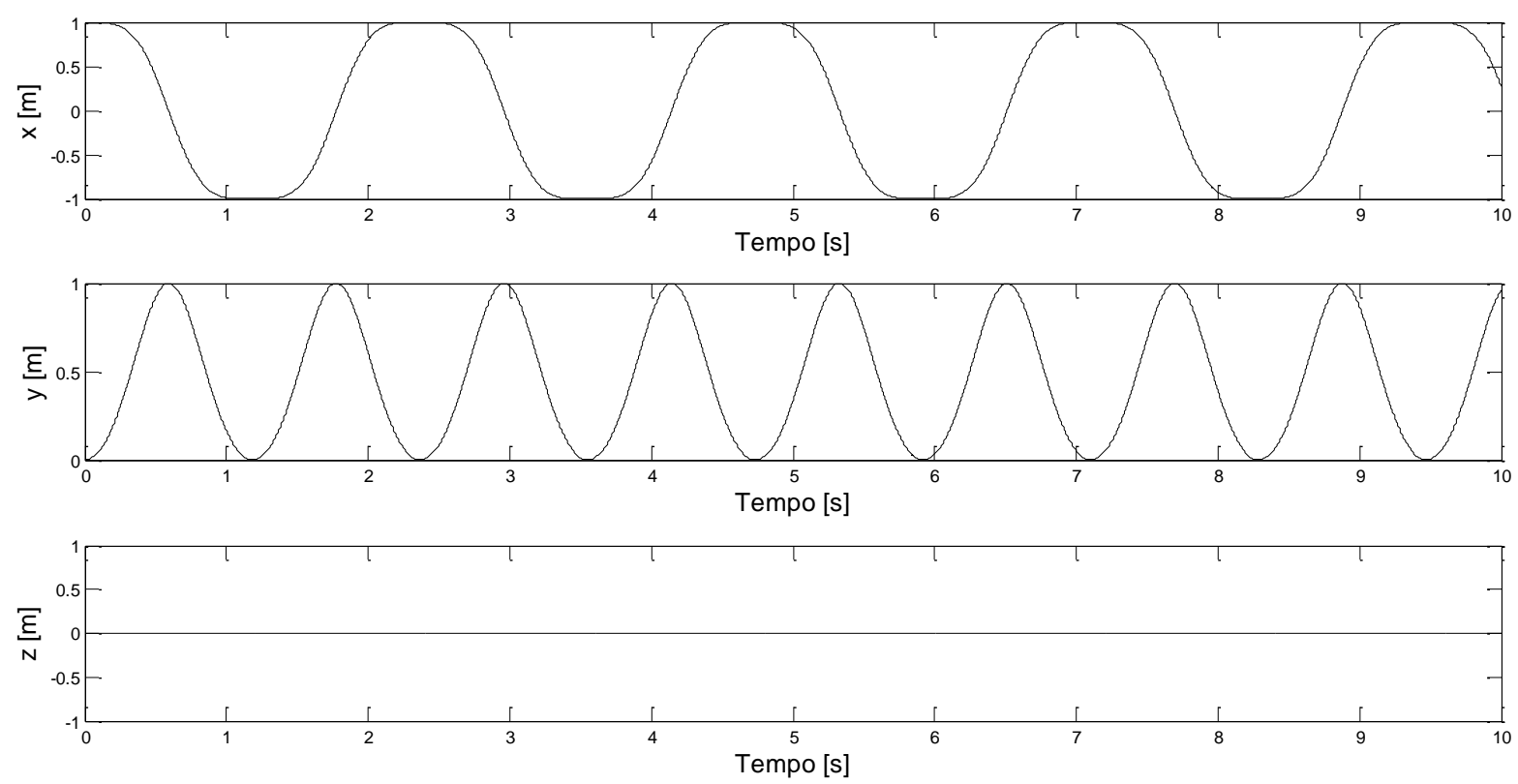

Figura 2 - Deslocamentos do pêndulo esférico no tempo.

A Figura 3 exibe um gráfico em três dimensões do sistema, no qual o comportamento do pêndulo em função das condições iniciais aplicadas pode ser visto de forma mais clara.

A partir destes resultados, conclui-se que a técnica consiste em uma ferramenta simples e poderosa para realização da modelagem de sistemas que possuem algum tipo de restrição cinemática. 
No próximo capítulo, inicia-se a investigação desta abordagem para a realização de um controle ativo de vibrações em sistemas rotativos, no qual a aplica-se uma força de controle baseada em restrições cinemáticas virtuais.

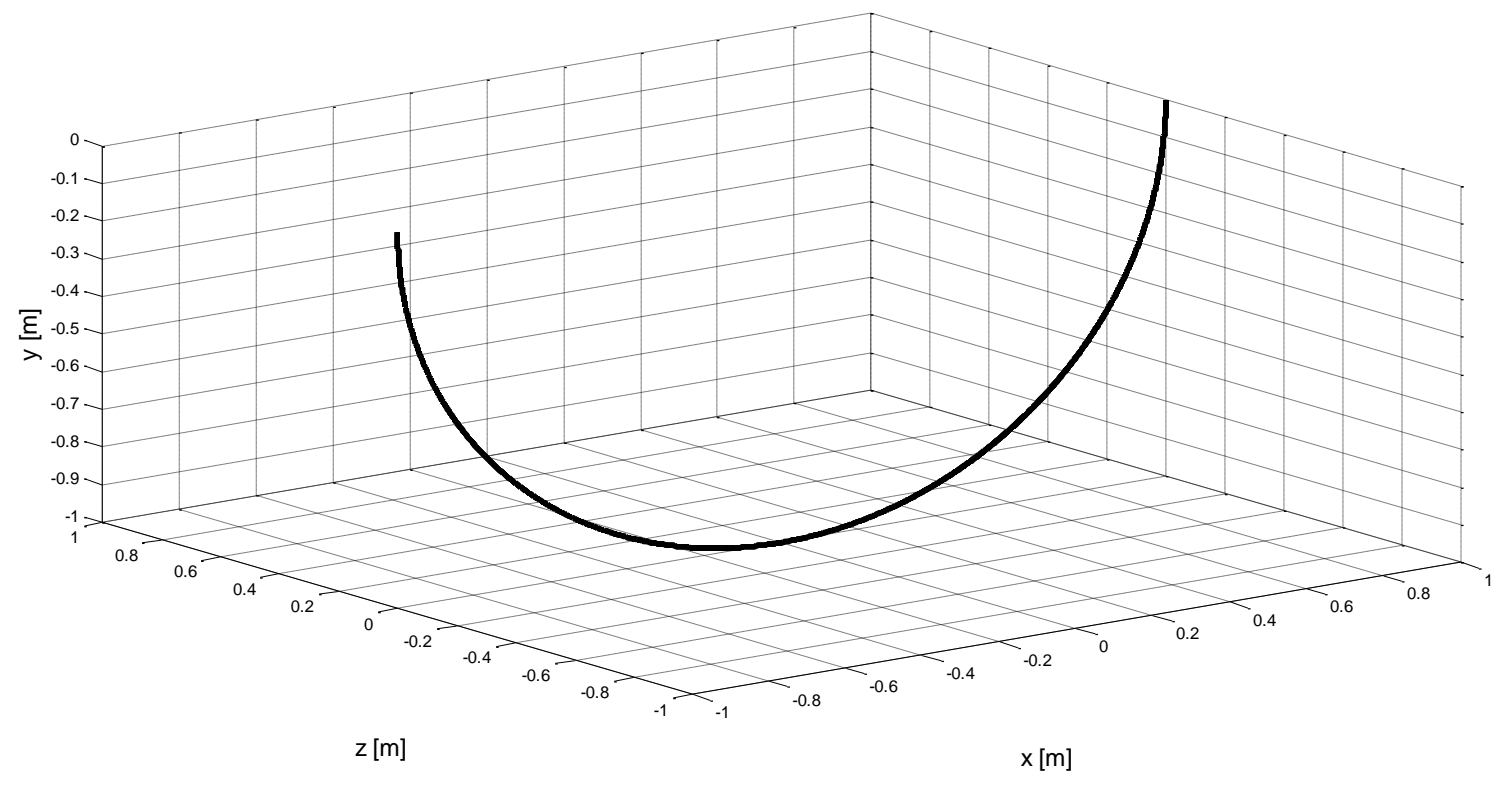

Figura 3 - Trajetória tridimensional do pêndulo esférico. 


\section{Capítulo 4}

\section{Avaliação do Controlador em Sistemas Rotativos com 4 Graus de Liberdade}

Neste capítulo são apresentadas a modelagem e o comportamento dos sistemas utilizados neste trabalho para avaliação do emprego da teoria Udwadia-Kalaba no âmbito de redução de vibrações em sistemas rotativos. São utilizados primeiramente modelos mais simples com poucos graus de liberdade, nos quais o desempenho do controlador proposto por Udwadia-Kalaba é comparado com controladores convencionais PID e LQR.

\subsection{Modelo com Quatro Graus de Liberdade}

Como o objetivo deste estudo é avaliar o desempenho de um método de controle ainda não aplicado aos sistemas rotativos, se faz necessária, primeiramente, a utilização de um sistema que seja conhecido, com um modelo já consagrado e de comportamento dinâmico já definido. Desta forma é adotado um sistema rotativo mais trivial, conhecido como o rotor de Laval (ou rotor de Jeffcott), exibido na Figura 4(a), na qual temos um rotor (disco) centrado em um eixo flexível, equidistante dos mancais (suportes do eixo) que são considerados rígidos para a faixa de operação da máquina.

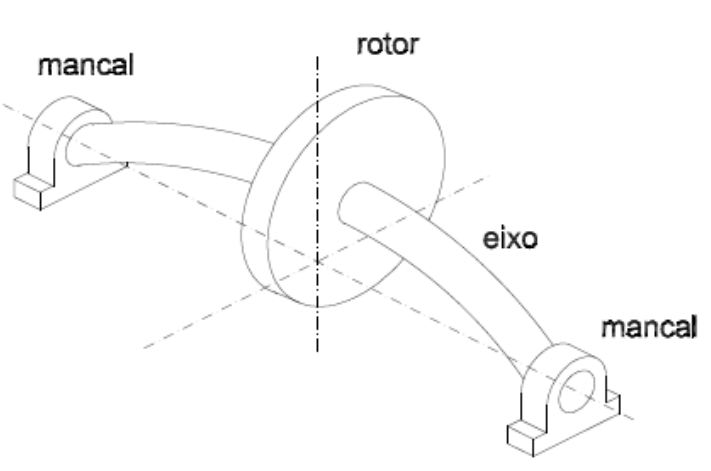

(a)

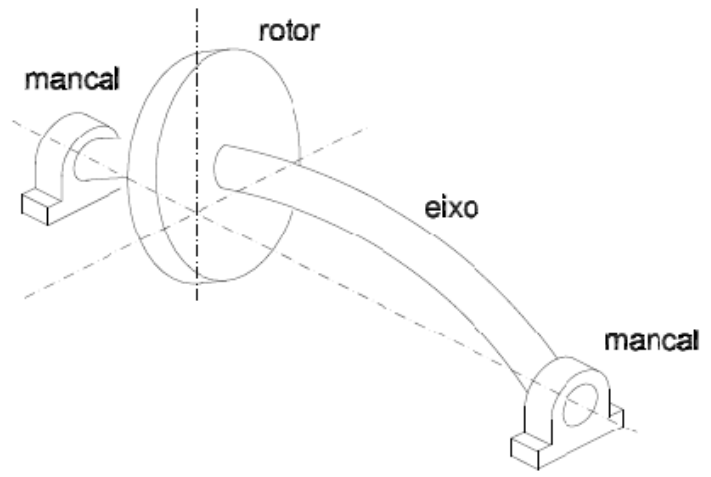

(b)

Figura 4 - Configuração do rotor (a) de Laval e (b) rotor não simétrico. 
A segunda configuração de rotor, apresentada na Figura 4(b), se distingue do rotor de Laval unicamente pelo fato do disco não estar mais equidistante dos mancais, o que produz o efeito giroscópico do rotor.

$\mathrm{Na}$ Figura 5(a), apresentam-se os sistemas de coordenadas no plano YZ, o que é suficiente para representar o rotor de Laval, que por estar equidistante dos mancais, considerados rígidos, não apresenta efeito giroscópico (JEFFCOTT, 1919). Neste caso o disco se movimenta somente no plano YZ (não ocorre inclinações do disco) que possui a origem alinhada ao centro dos mancais. No segundo sistema de coordenadas, Figura 5 (b), surgem dois novos movimentos do disco, uma inclinação em Y e uma em Z.

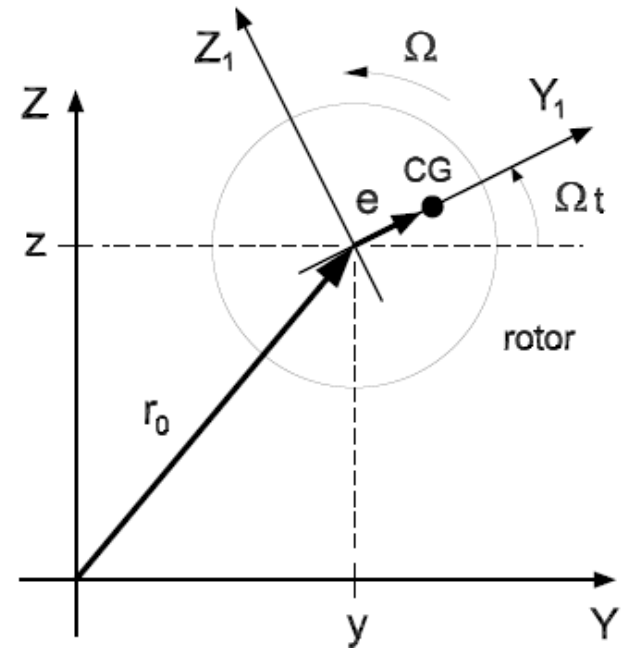

(a)

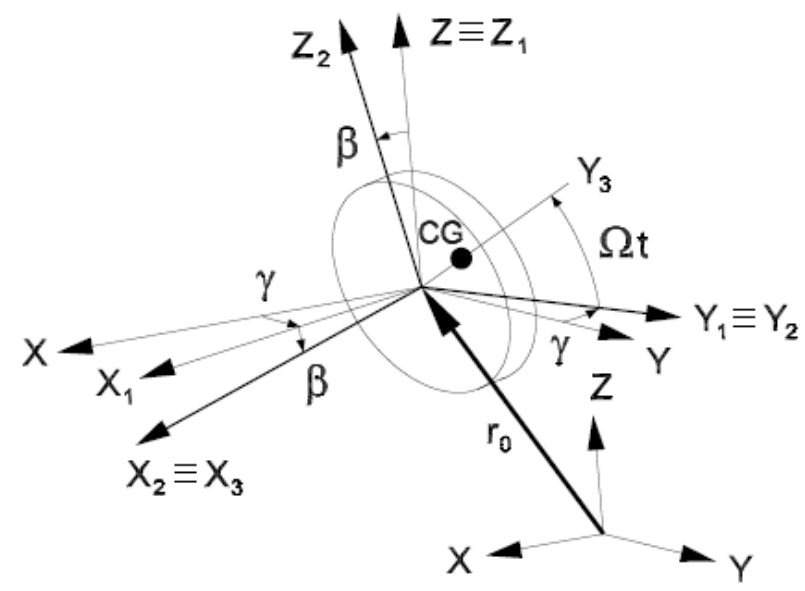

(b)

Figura 5 - Sistemas de coordenadas utilizados na modelagem no (a) plano YZ e (b) no espaço $\mathrm{XYZ}$

No caso mais geral, o sistema de equações que define o comportamento do sistema em função da força produzida pelo desbalanceamento da massa do disco é exibido na Equação (20). 


$$
\begin{gathered}
{\left[\begin{array}{ccccc}
m & 0 & 0 & 0 & -m e \operatorname{sen} \Omega t \\
0 & m & 0 & 0 & m e \cos \Omega t \\
0 & 0 & I_{t} & 0 & 0 \\
0 & 0 & 0 & I_{t} & -I_{p} \dot{\beta} \\
-m e \operatorname{sen} \Omega t & m e \cos \Omega t & 0 & -I_{p} \dot{\beta} & I_{p}
\end{array}\right]\left\{\begin{array}{c}
\ddot{y} \\
\ddot{z} \\
\ddot{\beta} \\
\ddot{\gamma} \\
\dot{\Omega}
\end{array}\right\}=} \\
\\
\left\{\begin{array}{l}
m e \Omega^{2} \cos \Omega t-d \dot{y} \\
m e \Omega^{2} \operatorname{sen} \Omega t-d \dot{z}-m g \\
-I_{p} \Omega \dot{\gamma}-d_{\theta} \dot{\beta} \\
I_{p} \Omega \dot{\beta}-d_{\theta} \dot{\gamma} \\
T-m e g \cos \Omega t+I_{p} \dot{\gamma} \dot{\beta}+m e \dot{y} \Omega \cos \Omega t+m e \dot{z} \Omega \operatorname{sen} \Omega t
\end{array}\right\}
\end{gathered}
$$

Em uma condição de velocidade de rotação constante do rotor, a dinâmica do sistema pode ser definida pela Equação (21), que será utilizada para realizar a comparação do desempenho do controlador Udwadia-Kalaba com os controladores PID e LQR.

$$
\begin{aligned}
& {\left[\begin{array}{cccc}
m & 0 & 0 & 0 \\
0 & m & 0 & 0 \\
0 & 0 & I_{t} & 0 \\
0 & 0 & 0 & I_{t}
\end{array}\right]\left\{\begin{array}{c}
\ddot{y} \\
\ddot{z} \\
\ddot{\beta} \\
\ddot{\gamma}
\end{array}\right\}+\left[\begin{array}{cccc}
d & 0 & 0 & 0 \\
0 & d & 0 & 0 \\
0 & 0 & d_{\theta} & I_{p} \Omega \\
0 & 0 & -I_{p} \Omega & d_{\theta}
\end{array}\right]\left\{\begin{array}{c}
\dot{y} \\
\dot{z} \\
\dot{\beta} \\
\dot{\gamma}
\end{array}\right\}+} \\
& {\left[\begin{array}{cccc}
k & 0 & 0 & -\mu \\
0 & k & \mu & 0 \\
0 & \mu & k_{\theta} & 0 \\
-\mu & 0 & 0 & k_{\theta}
\end{array}\right]\left\{\begin{array}{l}
y \\
z \\
\beta \\
\gamma
\end{array}\right\}=\left\{\begin{array}{l}
m e \Omega^{2} \cos \Omega t \\
m e \Omega^{2} \operatorname{sen} \Omega t-m g \\
0 \\
0
\end{array}\right\}}
\end{aligned}
$$

Como resultado da Equação (21), quando a velocidade de rotação é constante, o centro geométrico do disco executa basicamente uma trajetória circular, em torno da posição de equilíbrio estático do sistema em z, com raio da trajetória dependente da velocidade angular do sistema. A Figura 6 apresenta o comportamento do sistema quando $\mu=0$ na Equação (21), configurando o modelo do rotor de Laval, demonstra-se que para valores de rotação bem acima da frequência natural do sistema, o raio da trajetória tende ao valor do desbalanceamento residual, fenômeno conhecido como autocentragem. Assim, o intuito do controlador proposto é então o de reduzir este raio de trajetória. 

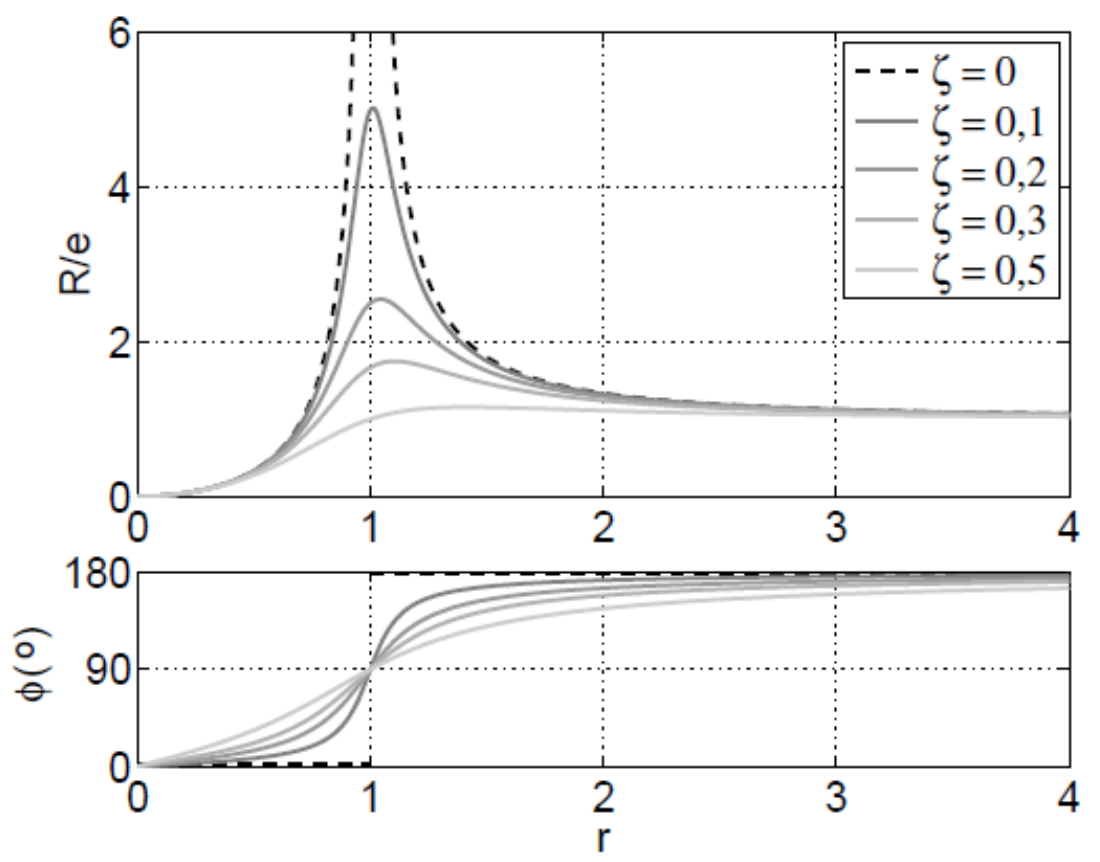

Figura 6 - Raio da trajetória em função da rotação do eixo. Fonte: (CHILDS,1993).

Assim, definem-se na Tabela 1 os parâmetros de ambos os modelos com quatro graus de liberdade utilizados neste trabalho, obtidos através das características geométricas de um sistema real. Ressalta-se que o valor de $\mu$ (rigidez de acoplamento linear-angular) é obtido através do tipo de material do eixo, de sua seção transversal e das distâncias entre disco e mancais.

As velocidades de rotação exibidas na Tabela 1 foram escolhidas a partir da análise dos diagramas de Campbell dos rotores de Laval e não simétrico, Figura 7 e Figura 8 respectivamente. Os diagramas de Campbell permitem visualizar as frequências naturais dos graus de liberdade do sistema em função da rotação em que o mesmo se encontra. $O$ valor de rotação adotado no modelo consiste em 1,5 vezes o valor das frequências em rotação nula, definido por ser um valor que se localiza em uma região entre rotações críticas, estas caracterizadas por ser uma situação em que o rotor apresenta rotação igual à frequência natural do sistema. Graficamente as rotações críticas são observadas pelo cruzamento da reta preta $45^{\circ}$ com as curvas em cinza.

Pela Figura 7 identificam-se as rotações críticas do rotor de Laval que ocorrem até uma velocidade de rotação de $4.000 \mathrm{rpm}$. Nesta configuração de rotor, os dois primeiros modos não apresentam alteração na frequência natural em função da velocidade de rotação do sistema, desta forma, a velocidade crítica ocorre em cerca de $1.800 \mathrm{rpm}$. Já a segunda velocidade crítica se encontra ao redor de $3.800 \mathrm{rpm}$. 
Já pela Figura 8, observa-se a ocorrência das frequências críticas na mesma faixa de operação anterior, agora para o rotor não simétrico. Nesta configuração, nota-se a separação na evolução da frequência natural dos dois primeiros modos de vibrar do sistema, relativos aos modos de translação, algo que não ocorre com o rotor de Laval. Em regime estacionário, as velocidades críticas ocorrem ao redor de 2.500, 3.000 e $5200 \mathrm{rpm}$.

Tabela 1 - Propriedades dos modelos com quatro graus de liberdade.

\begin{tabular}{|c|c|c|c|c|}
\hline \multicolumn{5}{|c|}{ Valor } \\
\hline Parâmetro & Descrição & Laval & Não Simétrico & Unidade \\
\hline L1 & Distância mancal 1 e disco & 0,2 & 0,1 & $\mathrm{~m}$ \\
\hline $\mathrm{L} 2$ & Distância mancal 2 e disco & 0,2 & 0,3 & $\mathrm{~m}$ \\
\hline $\mathrm{m}$ & Massa do disco & 1,0419 & 1,0419 & $\mathrm{~kg}$ \\
\hline $\mathrm{I}_{\mathrm{t}}$ & $\begin{array}{l}\text { Momento inercia transversal } \\
\text { do disco }\end{array}$ & 0,0011 & 0,0011 & $\mathrm{~kg} \cdot \mathrm{m}^{2}$ \\
\hline $\mathrm{I}_{\mathrm{p}}$ & $\begin{array}{l}\text { Momento de inércia polar do } \\
\text { disco }\end{array}$ & 0,0022 & 0,0022 & $\mathrm{~kg} \cdot \mathrm{m}^{2}$ \\
\hline$\Omega$ & Velocidade de rotação & 2809 & 4835 & rpm \\
\hline $\mathrm{d}$ & Amortecimento dos mancais & 100 & 100 & N.s/m \\
\hline $\mathrm{d}_{\theta}$ & $\begin{array}{l}\text { Amortecimento angular dos } \\
\text { mancais }\end{array}$ & 100 & 100 & N.m.s/rad \\
\hline $\mathrm{k}$ & Rigidez dos elementos de eixo & $4,0079 \times 10^{4}$ & $1,6625 \times 10^{5}$ & $\mathrm{~N} / \mathrm{m}$ \\
\hline $\mathrm{k}_{\theta}$ & $\begin{array}{l}\text { Rigidez angular dos } \\
\text { elementos de eixo }\end{array}$ & 534,3849 & 712.5132 & N.m/rad \\
\hline$\mu$ & $\begin{array}{l}\text { Rigidez de acoplamento } \\
\text { linear-angular }\end{array}$ & 0 & $-7,1251 \times 10^{3}$ & $\mathrm{~N} / \mathrm{rad}$ \\
\hline $\mathrm{e}$ & $\begin{array}{l}\text { Desbalanceamento residual do } \\
\text { disco }\end{array}$ & $3 \times 10^{-4}$ & $3 \times 10^{-4}$ & kg.m \\
\hline $\mathrm{g}$ & Gravidade & 9,81 & 9,81 & $\mathrm{~m} / \mathrm{s}^{2}$ \\
\hline
\end{tabular}




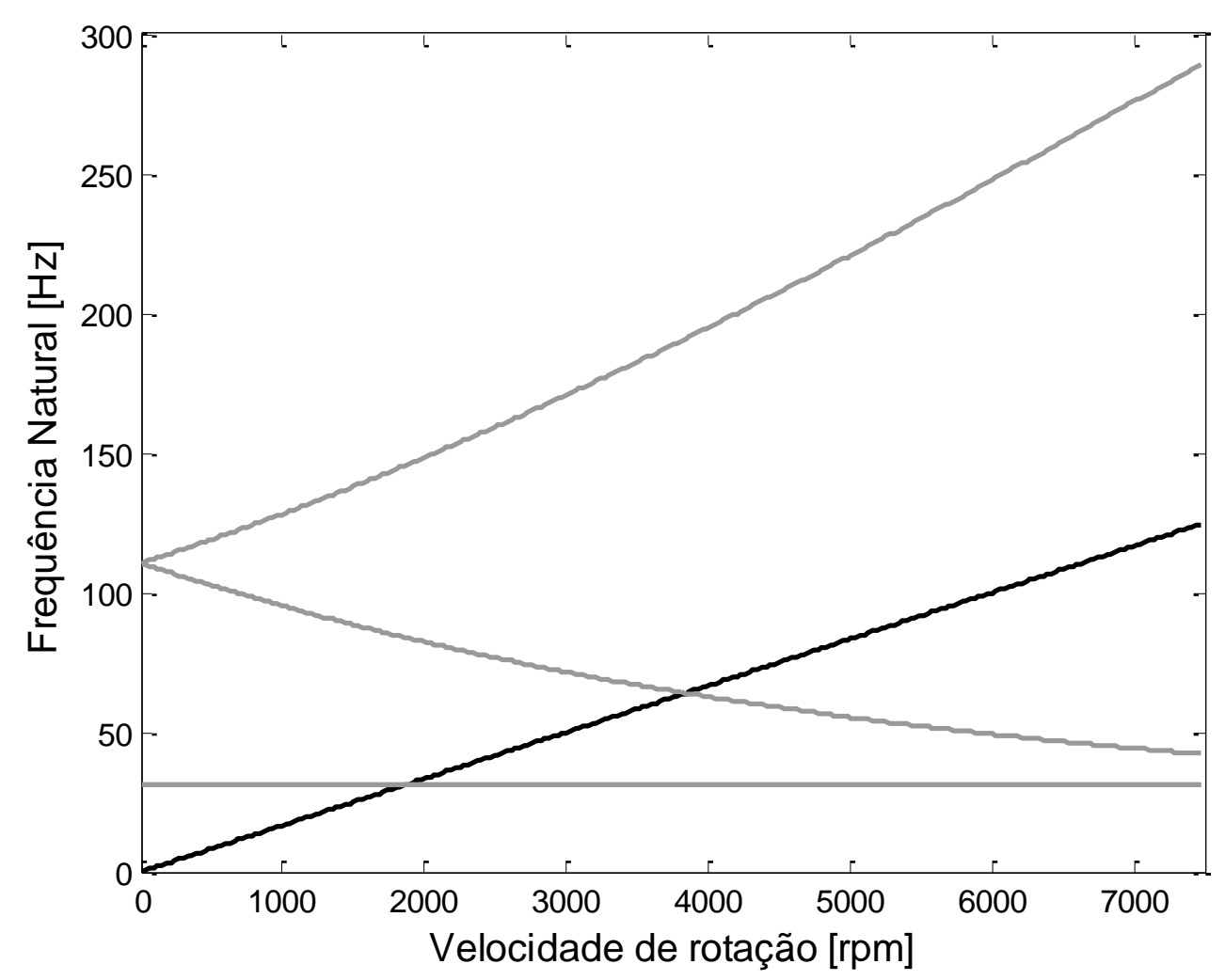

Figura 7 - Diagrama de Campbell para o rotor de Laval.

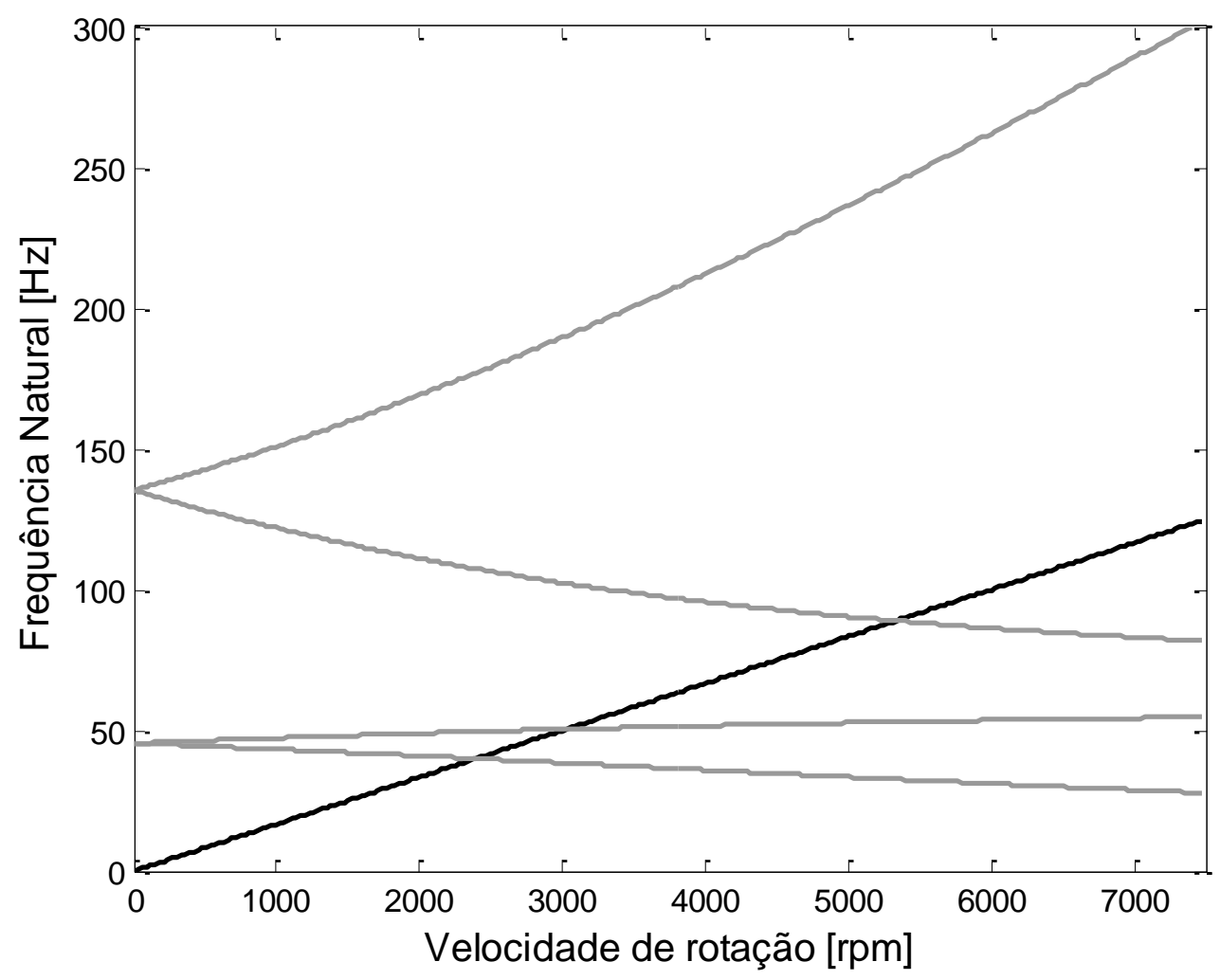

Figura 8 - Diagrama de Campbell para o rotor não simétrico. 


\subsection{Controladores}

Nesta seção é apresentada a metodologia para aplicação do controlador UdwadiaKalaba nos modelos definidos anteriormente, e os controladores PID e LQR utilizados para comparação.

\subsubsection{Controlador Udwadia-Kalaba}

O intuito deste controlador é o de restringir a movimentação em yz do disco e para isto, é necessário definir, primeiramente, a restrição desejada. Como mostrado anteriormente, a resposta do sistema consiste em uma trajetória circular com raio dependente da velocidade de rotação em que o sistema se encontra. Assim, define-se a restrição cinemática desejada como uma trajetória circular em yz em torno do equilíbrio estático do sistema, com um raio definido $\mathrm{R}_{\text {máx }} \mathrm{O}$ intuito desta abordagem é impor um $\mathrm{R}_{\text {máx }}$ pequeno de tal forma que a amplitude de vibração final do sistema seja atenuada. Assim, a Equação (22) define a restrição imposta ao sistema livre.

$$
\varphi=y^{2}+\left(z+\delta_{\text {est }}\right)^{2}-R_{\max }^{2}=0
$$

Conforme discutido no capítulo anterior, é necessário diferenciar esta equação em relação ao tempo até obtermos as mesma ordem do sistema a ser controlado (segunda ordem). Assim, a Equação (23) apresenta a primeira derivada e a Equação (24) a segunda.

$$
\begin{gathered}
\dot{\varphi}=y \dot{y}+\left(z+\delta_{\text {est }}\right) \dot{z}=0 \\
\ddot{\varphi}=\dot{y}^{2}+y \ddot{y}+\dot{z}^{2}+\left(z+\delta_{\text {est }}\right) \ddot{z}=0
\end{gathered}
$$

O próximo passo seria o de rearranjar a Equação (24) na forma da Equação (4), entretanto, como discutido anteriormente, a Equação (24) só é equivalente à restrição original (Equação (22)) para certas condições iniciais. Como o intuito do controlador é aplicar a restrição ao sistema que não se encontra em condições iniciais que atendem a restrição, é necessário aplicar uma combinação das Equações (22), (23) e (24), conforme apresentado no capítulo anterior pela Equação (5). Assim, aplicando a Equação (4) ao resultado da combinação das Equações (22), (23) e (24), obtém-se a Equação (25) que representa as 
condições de restrição cinemática impostas ao sistema. $\mathrm{O}$ impacto dos ganhos $\Sigma$ e $\mathrm{K}$ no desempenho do controlador serão avaliados na seção de resultados.

$$
[A]\{\ddot{q}\}=\left[\begin{array}{cccc}
y & z+\delta_{\text {est }} & 0 & 0 \\
0 & 0 & 1 & 0 \\
0 & 0 & 0 & 1
\end{array}\right]\left\{\begin{array}{c}
\ddot{y} \\
\ddot{z} \\
\ddot{\beta} \\
\ddot{\gamma}
\end{array}\right\}=\left\{\begin{array}{c}
-\dot{y}^{2}-\dot{z}^{2}-\Sigma \dot{\varphi}-K \varphi \\
\ddot{\beta}_{s c} \\
\ddot{\gamma}_{s c}
\end{array}\right\}=\{b\}
$$

Para garantir a atuação de controle somente nas direções y e z (não é desejada a atuação de torques em $\beta$ e $\gamma$ ) é necessário realizar um passo adicional, deve-se requerer que as acelerações impostas pela restrição sejam iguais às acelerações não controladas para as direções $\beta$ e $\gamma$. Por isto, foram adicionados os termos $\ddot{\beta}=\ddot{\beta}_{s c}$ e $\ddot{\gamma}=\ddot{\gamma}_{s c}$, onde as acelerações não controladas podem ser obtidas pela Equação (7), considerando que o sistema da Equação (21) esteja no formato da Equação (1).

Assim, a ação de controle exigida pelo controlador é obtida através da aplicação da Equação (8). Em virtude da grande quantidade de parâmetros e variáveis que são envolvidas na geração da ação de controle, esta não é obtida analiticamente.

Com a ação de controle definida, a dinâmica do sistema controlado é expressa pela Equação (26), uma equação diferencial não linear (devido à força de controle $\left\{Q_{c}\right\}$ ), o que requer a resolução numérica do problema.

$$
\{\ddot{q}\}=[M]^{-1}\left(\{Q\}+\left\{Q^{c}\right\}\right)
$$

Para resolver esta equação, foi utilizada a função ode15s de resolução de equações diferenciais de forma numérica do software MATLAB®, com tolerância de erro relativo de $10^{-9}$ e absoluto de $10^{-13}$, com parâmetros do sistema definidos na Tabela 1 e $\mathrm{R}_{\max }=1 \times 10^{-4}$.

\subsubsection{Controlador PID}

O controlador PID consiste na aplicação de uma ação de controle proporcional, integral e derivativa do sinal de erro apresentado no sistema, ou seja, dada uma resposta desejada, é feita a comparação com a resposta atual, gerando o sinal de erro que é realimentado à planta do sistema para que a resposta tenda àquela desejada (OGATA, 2001).

O modelo apresentado na Figura 9 foi produzido através do software Simulink®, integrado ao MATLAB $®$ com todos os parâmetros do sistema exibidos na Tabela 1, passando 
a formulação do sistema da Equação (21) para o espaço de estados. Este controlador foi projetado de tal forma que a atuação de controle só começa a agir a partir dos 4 segundos, tempo para termos uma comparação direta entre resposta não controlada versus controlada. Vale destacar que a ação de controle é aplicada somente nas direções y e z, como no controlador Udwadia-Kalaba.

Os ganhos aplicados no controlador são exibidos na Figura 10 e Figura 11 para o controlador do rotor de Laval e para o rotor não simétrico, respectivamente. Estes são obtidos através da função de Automatic Tuning do Simulink®, que realiza um algoritmo para determinação dos ganhos levando em consideração desempenho e robustez do controlador. $\mathrm{O}$ algoritmo consiste em primeiramente realizar uma linearização da planta e em seguida determinar ganhos iniciais baseados na resposta em frequência de malha aberta do sistema. Após este passo, o usuário avalia qual critério de desempenho a ser otimizado, acompanhamento de referência ou rejeição a distúrbios da planta. Neste caso, foi escolhido o acompanhamento de referência uma vez que este é um dos critérios de avaliação a serem adotados. Os ganhos são determinados levando em consideração um critério de margem de fase mínima.

Para ambas as direções (y e z) o controlador apresenta os mesmos ganhos e as referências utilizadas correspondem a uma trajetória circular com raio equivalente a $R_{\max }$, como definido para o controlador Udwadia-Kalaba. As tolerâncias da função de integração numérica do Simulink ${ }^{\circledR}$ foram ajustadas para os mesmos valores utilizados no controlador de trajetória. 


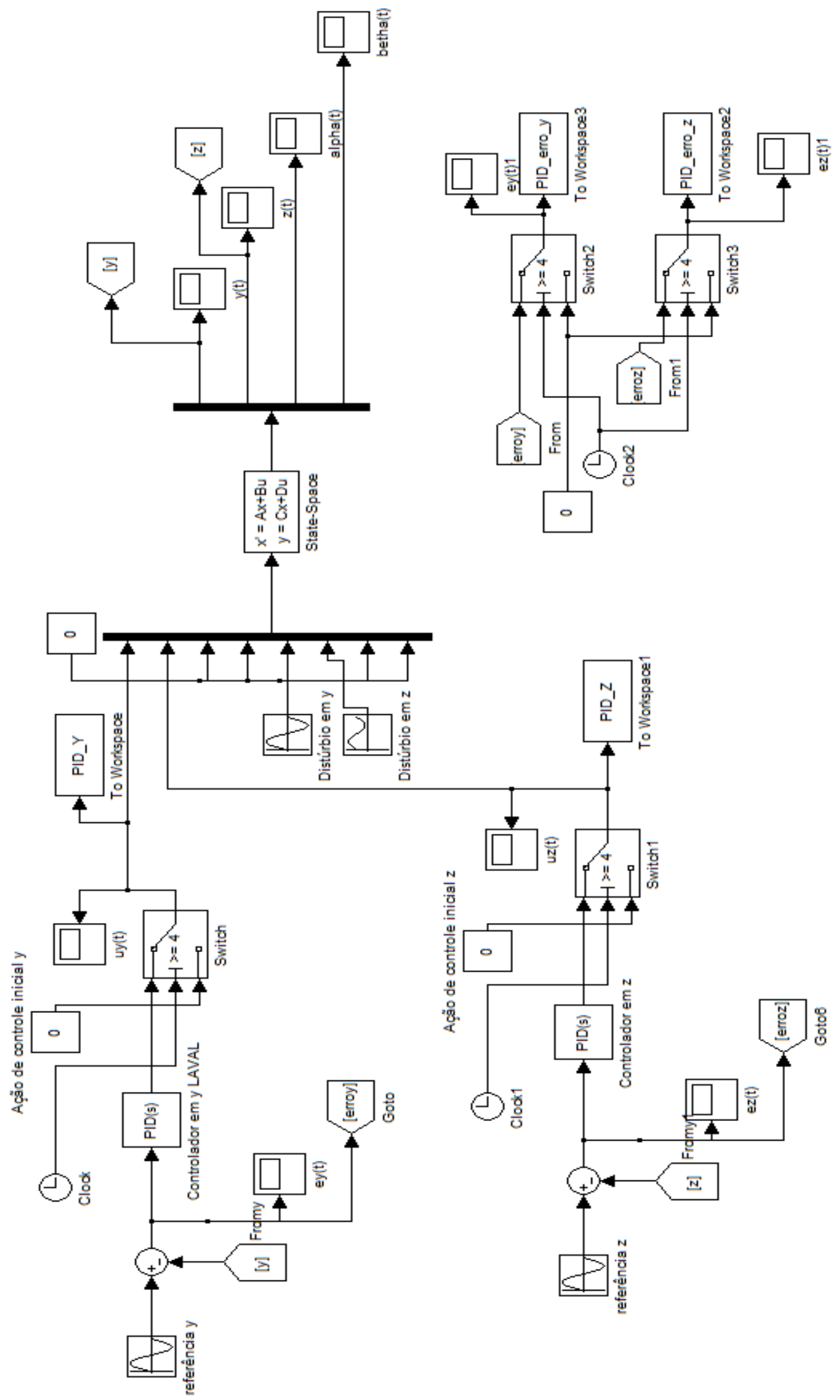

Figura 9 - Diagrama de blocos do controlador PID. 


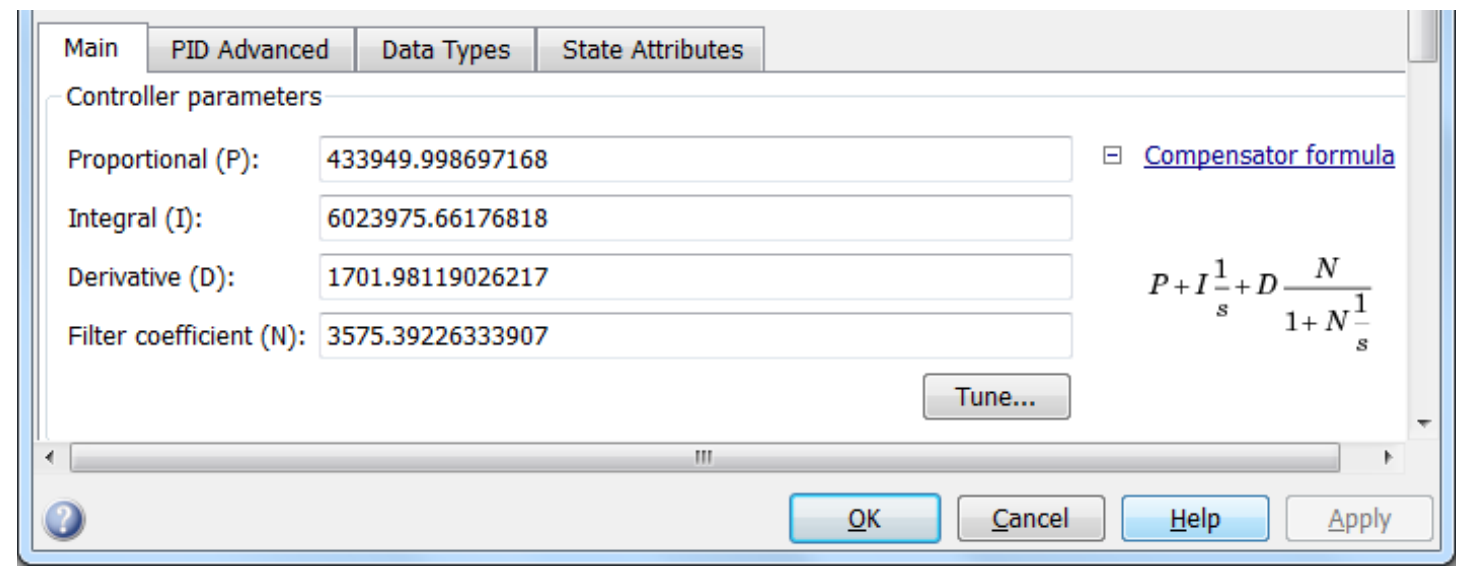

Figura 10 - Parâmetros de ganho do controlador PID para rotor de Laval.

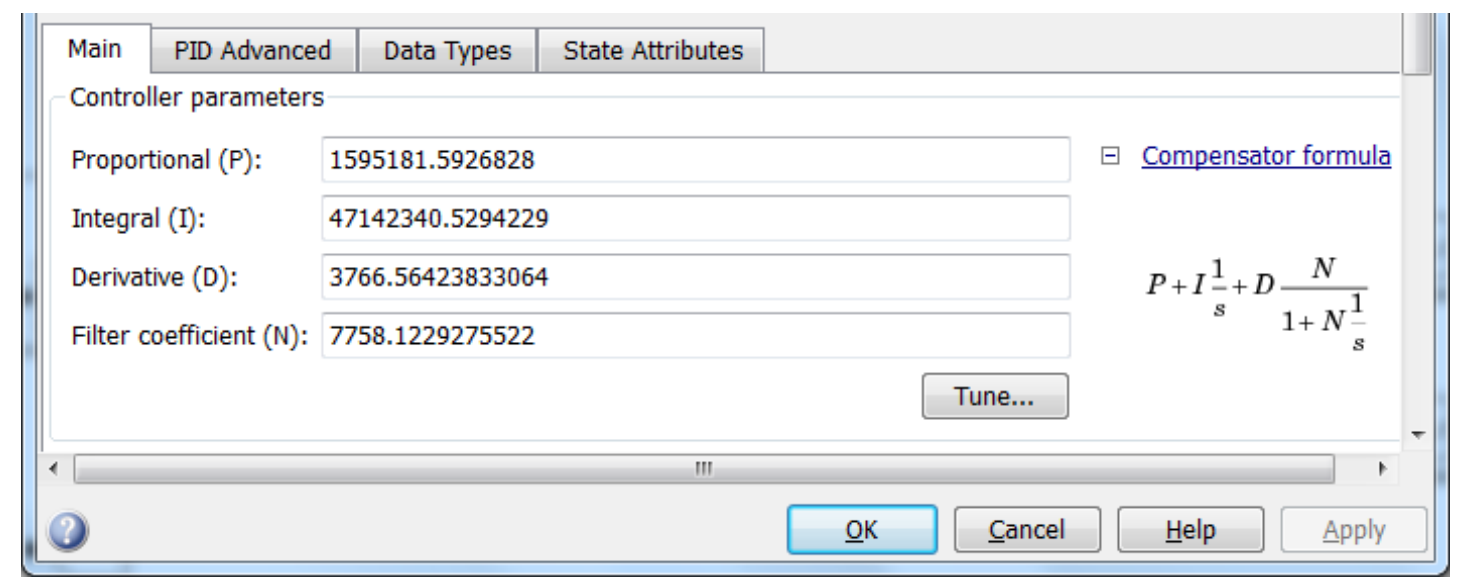

Figura 11 - Parâmetros de ganho do controlador PID para rotor não simétrico.

\subsubsection{Controlador LQR}

O controle LQR busca levar os estados de um sistema para valores nulos, através de uma realimentação proporcional dos estados do sistema, distinguindo-se do controle PID que utiliza os sinais de erro. O diagrama de blocos no Simulink® é exibido na Figura 12. 


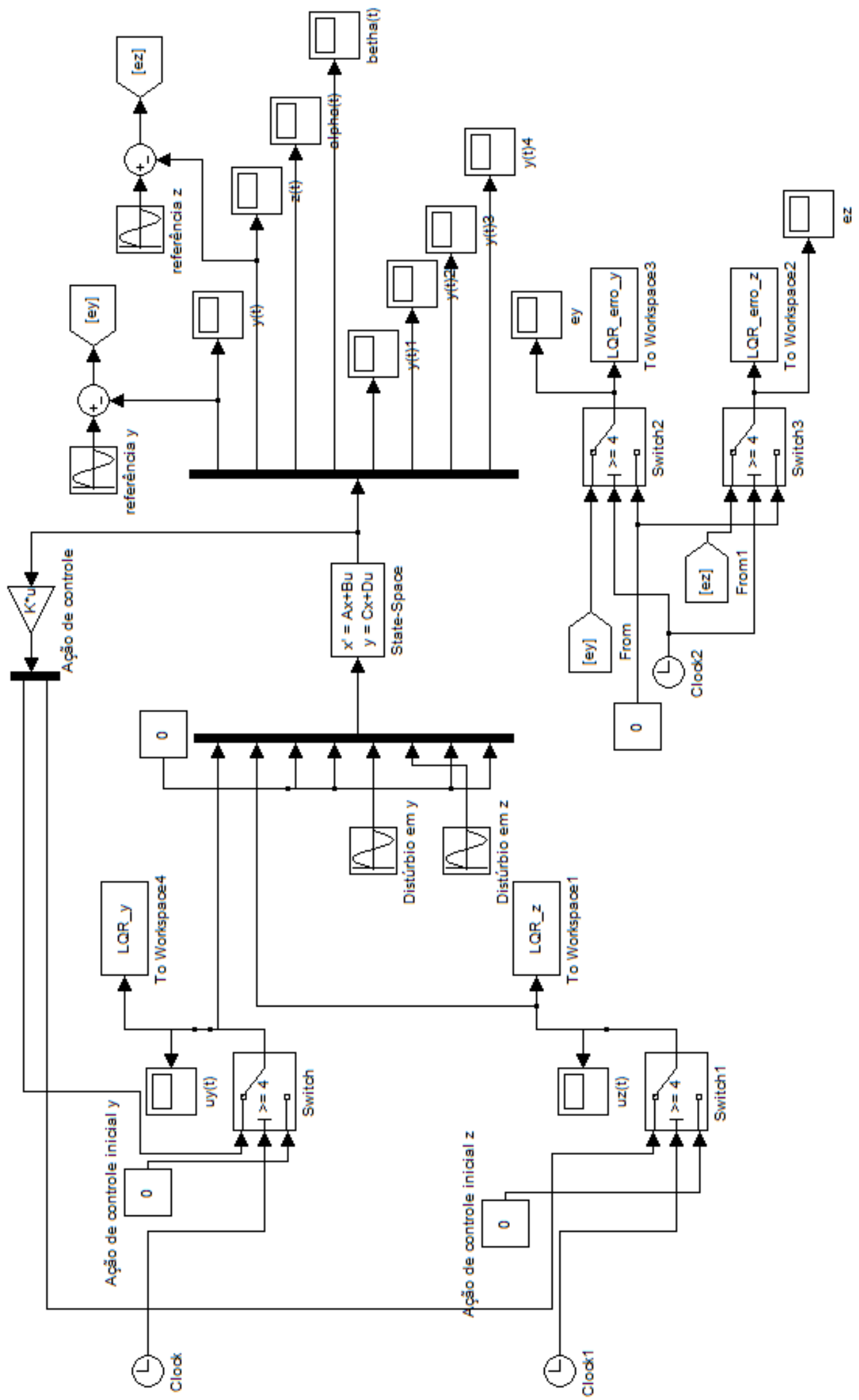

Figura 12 - Diagrama de blocos do controlador LQR. 
A matriz de ganho $\mathrm{K}$ utilizada na realimentação de estados foi obtida através da função lqr do Matlab®. Para utilizar esta função foi necessário definir duas matrizes, Q e R, que penalizam os estados e as entradas, respectivamente. As matrizes de ganho $\mathrm{K}$ foram obtidas utilizando uma matriz Q que penaliza mais os estados y e z, dando menos importância as inclinações do disco, e uma matriz R que penaliza as entradas em y e $\mathrm{z}$, de tal forma que o dispêndio de energia envolvido no controle fosse pequeno. A matriz de ganho K utilizada para o rotor de Laval é exibida na Equação (27) enquanto que a do rotor não simétrico é exibida na Equação (28). O objetivo aqui não é levar os estados do sistema para valores nulos, e sim reduzi-los de tal forma que fiquem similares aos resultados produzidos pelo controlador Udwadia-Kalaba, para efeito de comparação.

$$
\begin{aligned}
& K_{\text {laval }}=\left[\begin{array}{cccccccc}
9,791 & 0 & 0 & 0 & 800,012 & 0 & 0 & 0 \\
0 & 9,791 & 0 & 0 & 0 & 800,012 & 0 & 0
\end{array}\right] \\
& K_{n s}=10^{3} *\left[\begin{array}{rrcccccc}
-2,6566 & -0,0002 & -0,0014 & -0,2662 & 0,9022 & 0 & 0 & 0 \\
0,0002 & -2,6566 & 0,2662 & -0,0014 & 0 & 0,9022 & 0 & 0
\end{array}\right]
\end{aligned}
$$

\subsection{Resultados para o Rotor de Laval}

Nesta seção são apresentados os resultados obtidos com o controlador UdwadiaKalaba, PID e LQR, assim como a comparação entre o desempenho destes para a configuração de rotor de Laval

\subsubsection{Controlador Udwadia-Kalaba}

A primeira avaliação do comportamento do controlador Udwadia-Kalaba se refere à influência dos ganhos $\Sigma$ e K da Equação (25) no desempenho do controlador. 
Tabela 2 - Relação de ganhos avaliada para o rotor de Laval.

\begin{tabular}{ccc}
\hline $\boldsymbol{\Sigma}$ & $\mathbf{K}$ & Status \\
\hline 1 & 1 & $\boldsymbol{x}$ \\
2 & 1 & $\checkmark$ \\
1 & 2 & $\boldsymbol{x}$ \\
5 & 1 & $\checkmark$ \\
1 & 5 & $\mathbf{x}$ \\
10 & 1 & $\checkmark$ \\
1 & 10 & $\boldsymbol{x}$ \\
2 & 2 & $x$ \\
5 & 5 & $\checkmark$ \\
10 & 10 & $\checkmark$ \\
100 & 100 & $\checkmark$ \\
\hline
\end{tabular}

A Tabela 2 apresenta a relação de ganhos avaliada utilizando o modelo do rotor de Laval. O sinal $\times$ representa que a resposta do sistema não convergiu para a restrição desejada, apresentando erro de integração no MATLAB®. O sinal $\checkmark$ significa que o a resposta desejada foi atingida. Por esta tabela nota-se que aumentar somente o ganho $\mathrm{K}$, que pondera a restrição de trajetória original representada pela Equação (22), implica em erro de integração do modelo, entretanto o aumento de $\Sigma$ não acarreta em problemas para a resolução do problema. Nota-se também que o aumento simultâneo dos ganhos não causa problemas de integração, com exceção à situação $\Sigma=2 \mathrm{e} \mathrm{K}=2$. Resta agora avaliar como a variação dos ganhos impacta na resposta do sistema para os valores de ganho que permitem a resolução do problema.

A Figura 13 apresenta a resposta do sistema em três situações de ganho diferentes, as três primeiras com indicador $\checkmark$ na Tabela 2. Constata-se que o aumento do ganho $\Sigma$, ponderador da derivada da restrição original, definida pela Equação (23), acarreta em um aumento no tempo para que o sistema atinja a resposta desejada, tendo em vista que o acionamento do controlador se dá aos dois segundos. 

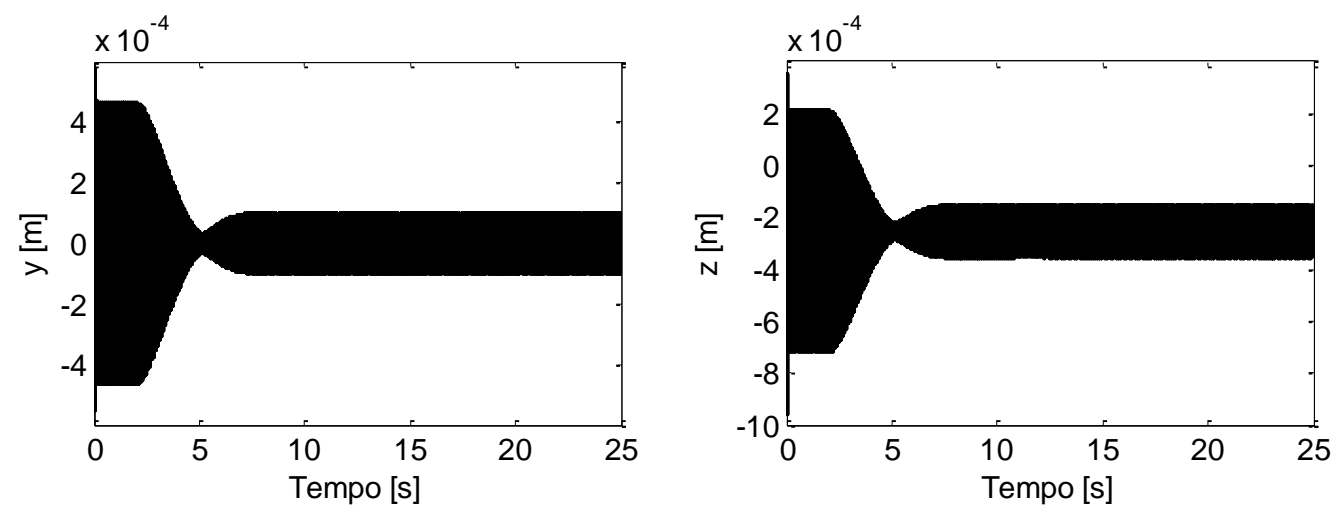

(a) $\Sigma=2, K=1$
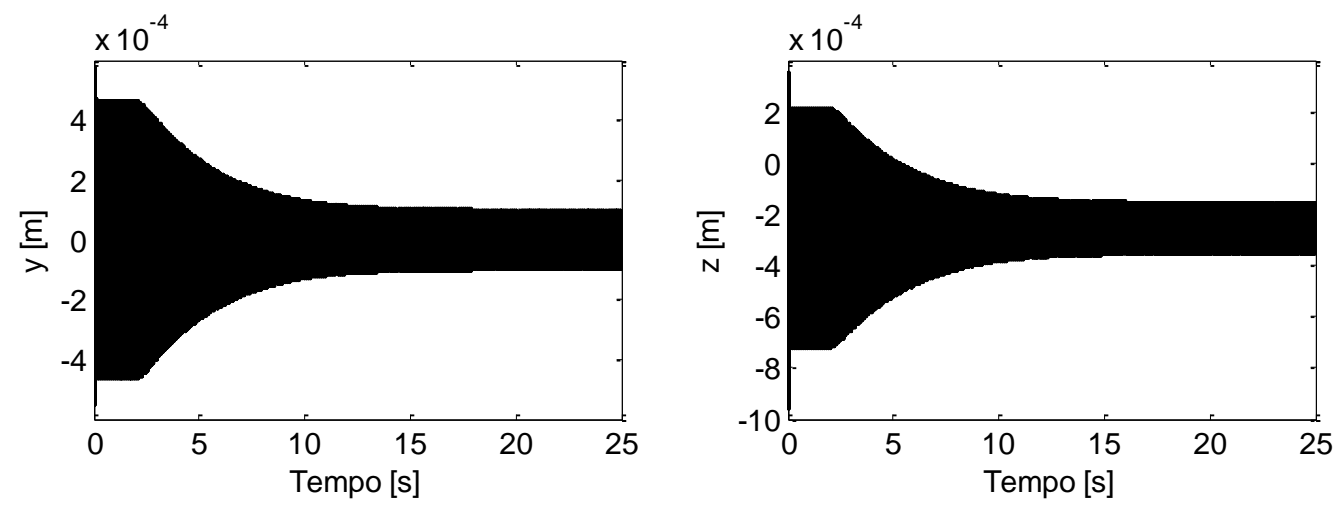

(b) $\Sigma=5, \mathrm{~K}=1$
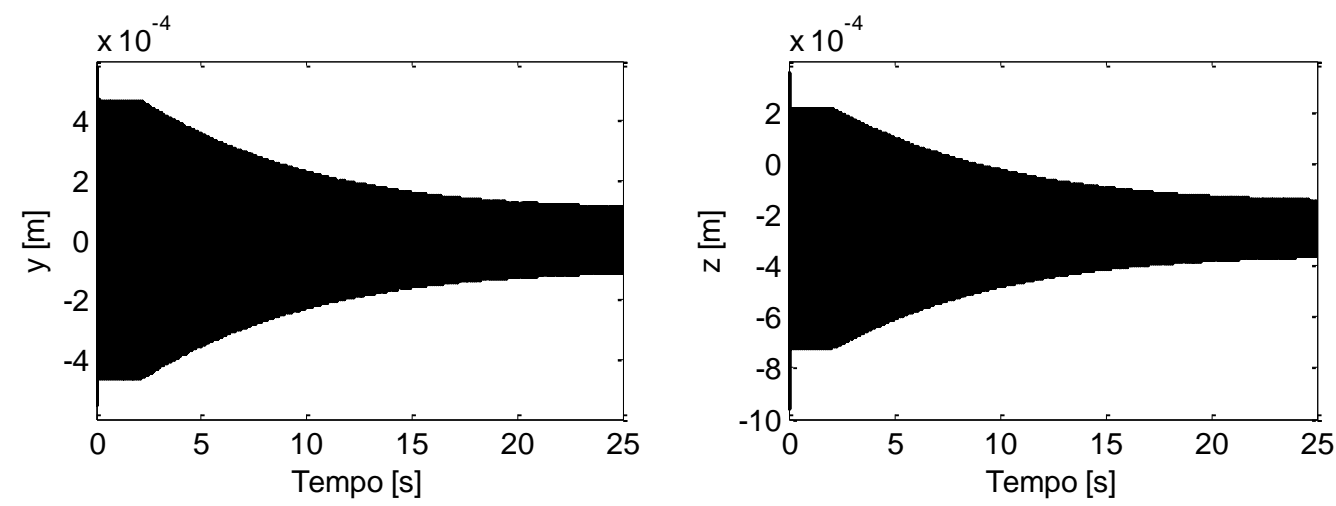

(c) $\Sigma=10, \mathrm{~K}=1$

Figura 13 - Resposta do rotor de Laval em 3 situações de ganhos com $\Sigma>\mathrm{K}$, nas direções y e $\mathrm{Z}$.

Avaliando agora as três últimas condições de ganhos da Tabela 2, nota-se, na Figura 14 que as condições de ganho exibidas apresentam resultados similares, com uma diminuição no tempo para atingir a resposta em regime permanente.

A condição $\Sigma=10, K=10$ foi escolhida como a melhor resposta encontrada para $o$ controlador, isto porque a resposta chega rapidamente à desejada, sem restringir o raio da 
trajetória em valores menores do que o desejado antes de atingir a resposta definitiva, como os caso das situações em que $\Sigma=2$ e $\mathrm{K}=1$ e a situação $\Sigma=5$ e $\mathrm{K}=5$.
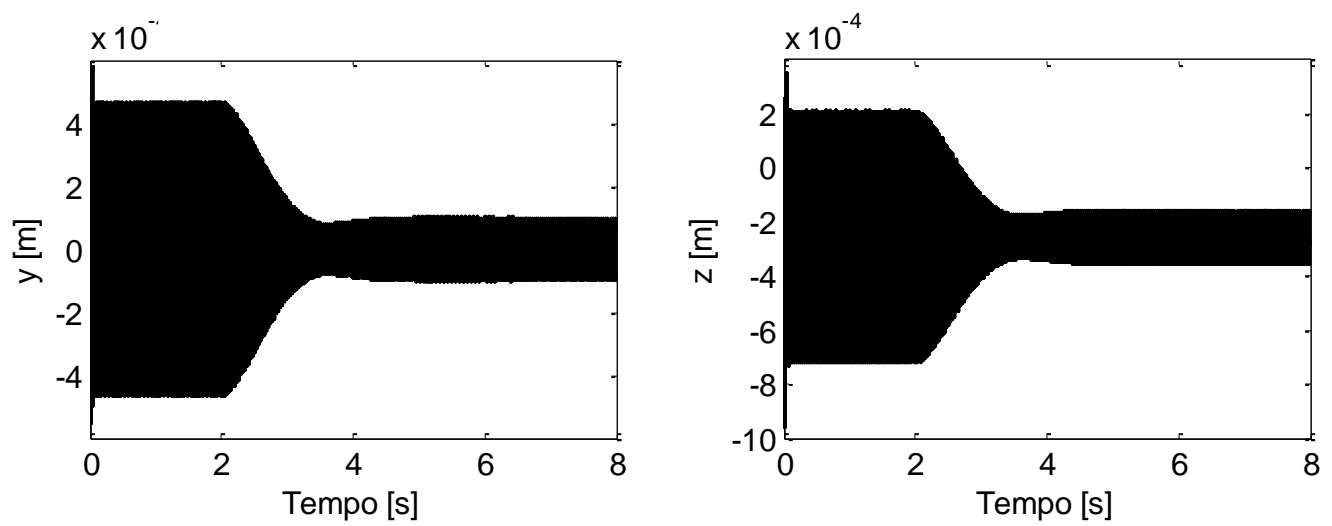

(a) $\Sigma=5, \mathrm{~K}=5$
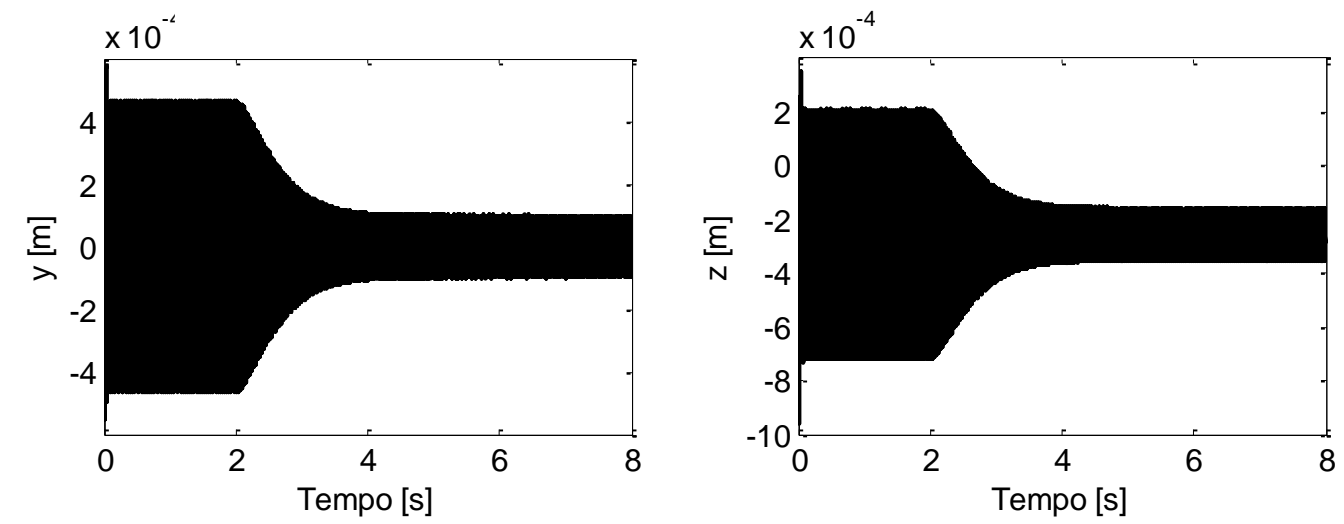

(b) $\Sigma=10, \mathrm{~K}=10$
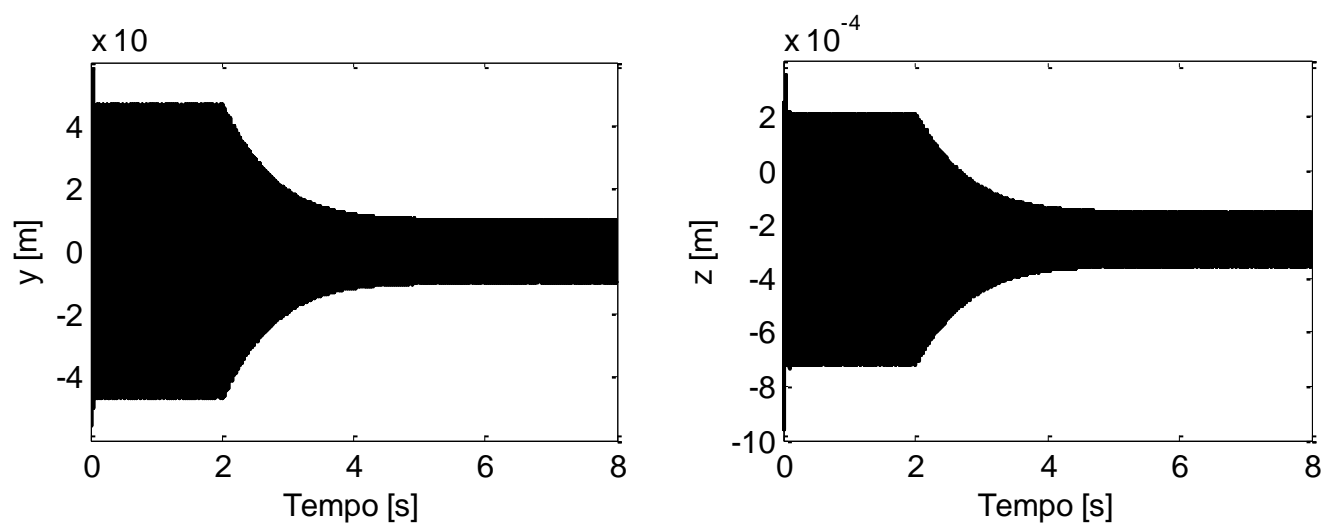

(c) $\Sigma=100, \mathrm{~K}=100$

Figura 14 - Resposta do rotor de Laval em 3 situações de ganhos com $\Sigma=\mathrm{K}$, nas direções y e $\mathrm{Z}$.

A Figura 15 apresenta em destaque a resposta do rotor de Laval para a situação em que o controlador Udwadia-Kalaba apresenta $\Sigma=10$ e $\mathrm{K}=10$. Nota-se que a partir dos 2 
segundos, quando o controlador é ativado, a amplitude de vibração começa a reduzir até atingir valores que correspondem à trajetória desejada, uma órbita circular de raio $\mathrm{R}_{\max }=1 \times 10^{-}$ ${ }^{4}$. Nesta configuração foi possível gerar uma resposta com vibração cinco vezes menor do que se teria sem este controlador, aproximadamente. É interessante verificar que o controle leva em consideração o deslocamento estático do sistema, a posição de equilíbrio em repouso, como se pode notar na resposta do deslocamento em $\mathrm{z}$, em que a vibração continua a ocorrer ao redor do ponto de equilíbrio estático. Pode-se constatar, também, que o controlador não gerou distúrbios como inclinações no disco.

Já a Figura 16 apresenta a força de atuação necessária para a realização o controle nas direções y e z, assim como sinal de erro de trajetória, definido como a diferença entre a resposta real e a desejada. Notam-se sinais de erro bem pequenos, da ordem de $10^{-6} \mathrm{em}$ regime permanente e valores da ação de controle variando de -30 a $30 \mathrm{~N}$ aproximadamente.
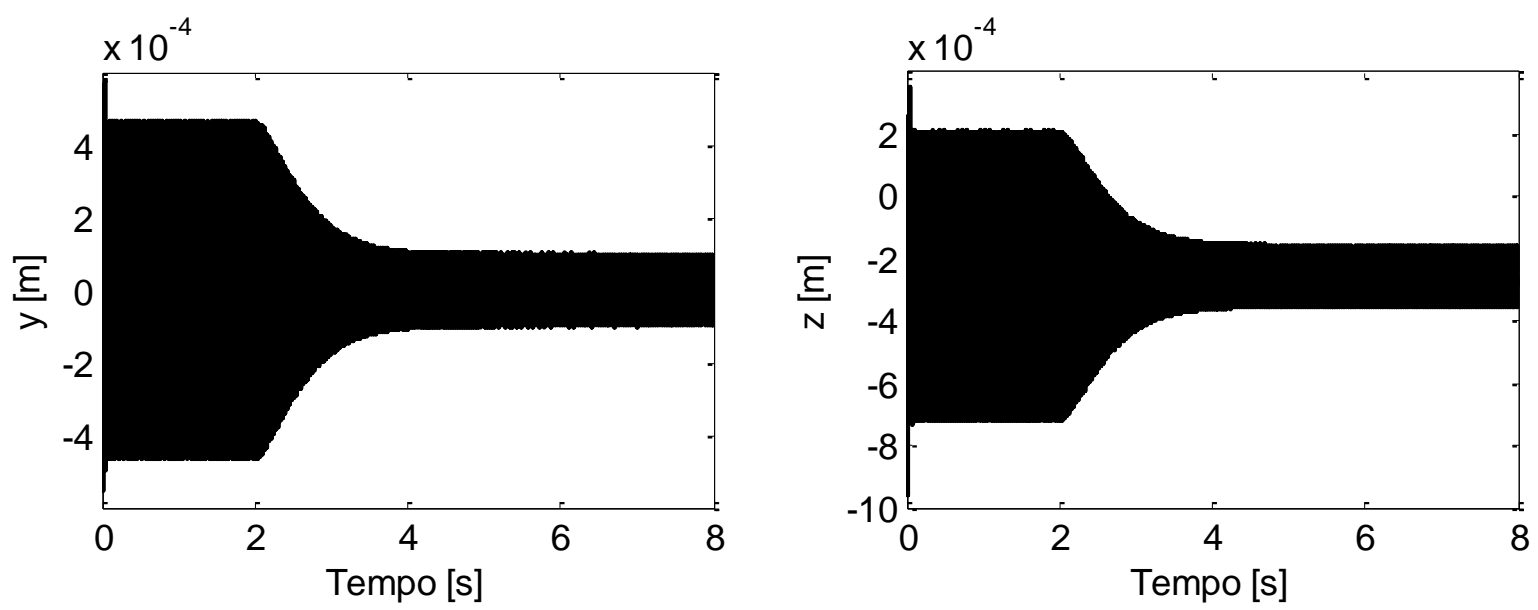

(a) Deslocamento linear
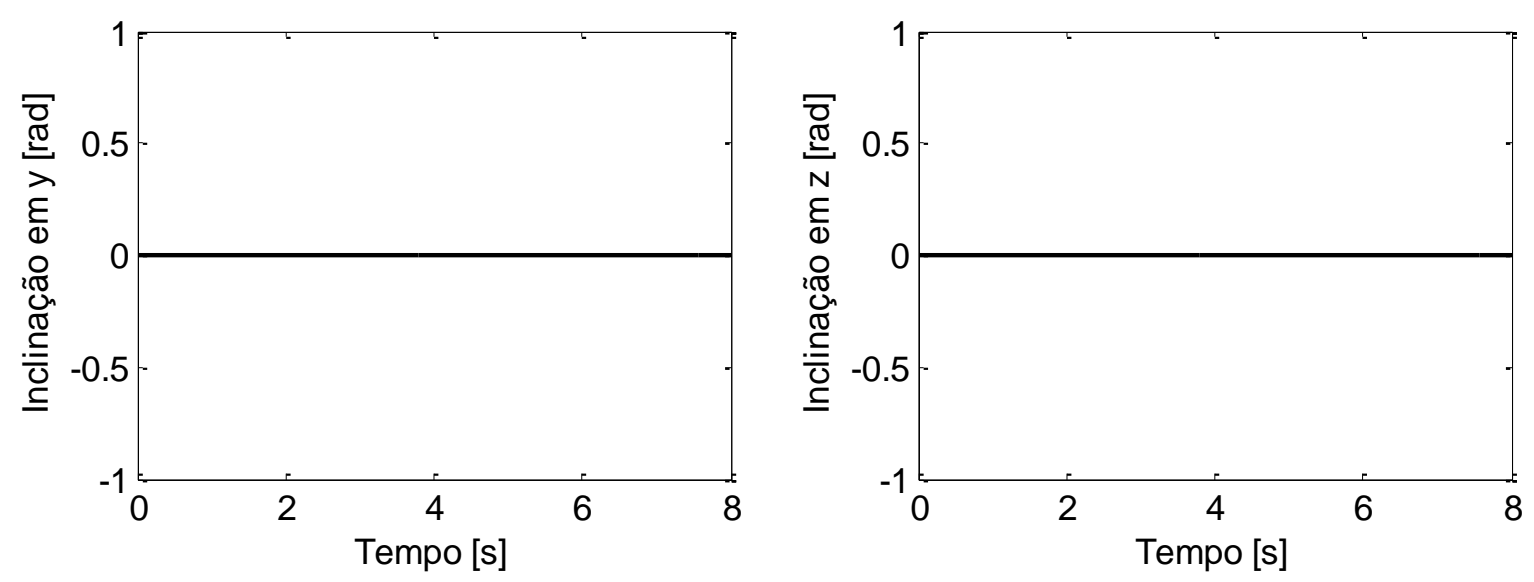

(b) Deslocamento angular

Figura 15 - Resposta do rotor de Laval nos 4 graus de liberdade utilizando o controlador Udwadia-Kalaba. 

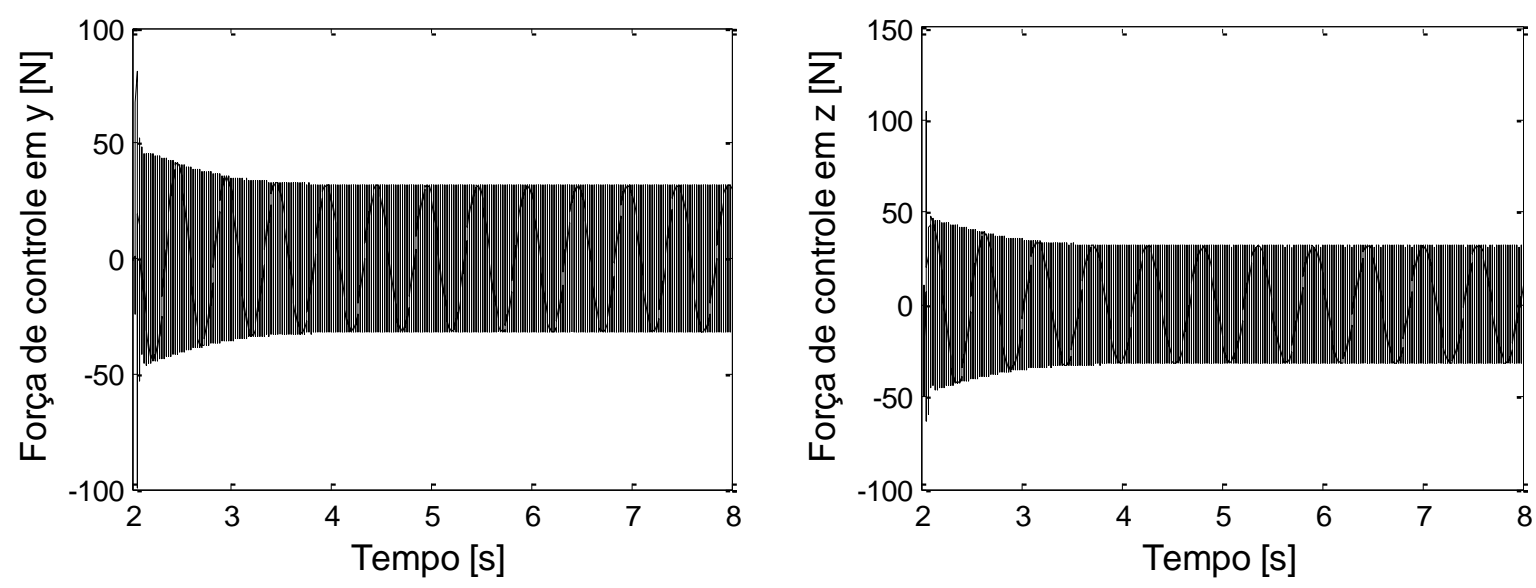

(a) Força de controle
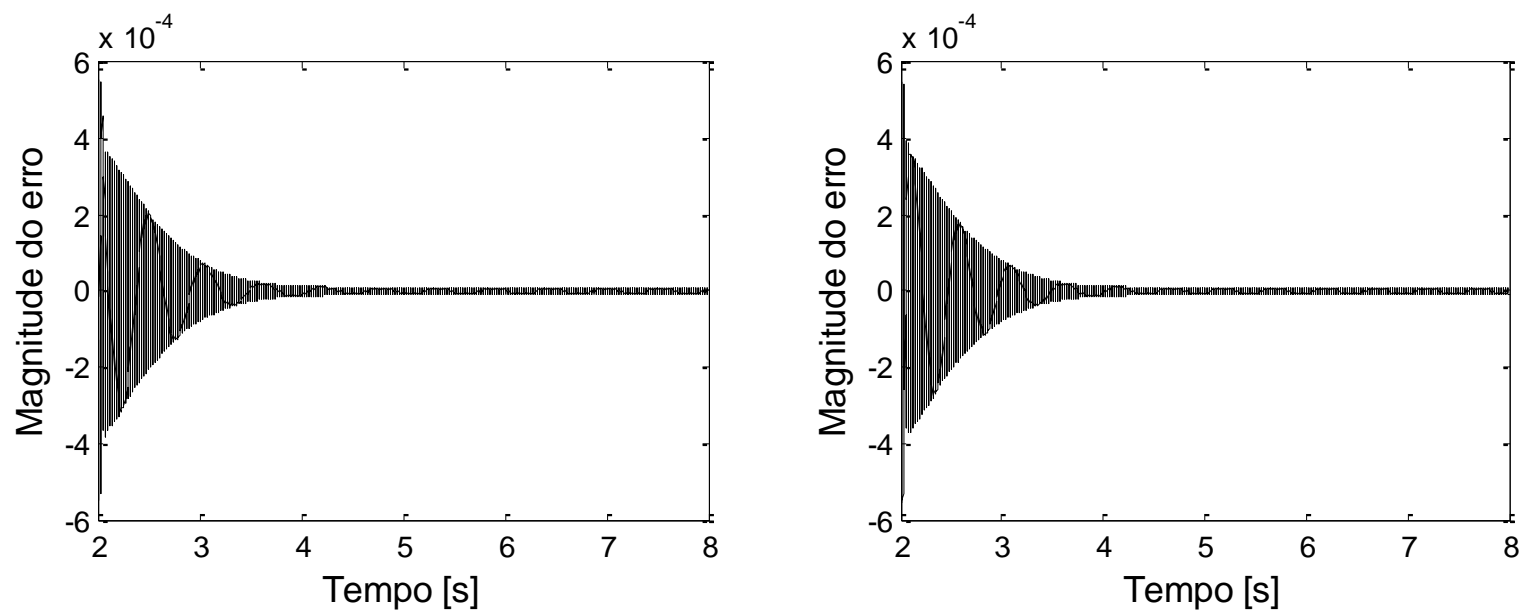

(b) Erro de posicionamento

Figura 16 - Ação de controle e sinal de erro para o rotor de Laval utilizando o controlador Udwadia-Kalaba.

Como os testes realizados até agora consideraram o modelo com rotação constante (2.800 rpm), um teste em run-up (rotor acelerando) é realizado para a verificação do emprego do controlador Udwadia-Kalaba considerando uma amplitude $\mathrm{R}_{\max }$ de $3 \times 10^{-5}$, 10 vezes menor do que o desbalanço residual. A Figura 17 apresenta a resposta do sistema não controlado sobreposta pela resposta controlada e a ação de controle em função da rotação do sistema, necessária para realizar o controle proposto. Nota-se que o controlador atua de forma efetiva por toda faixa de frequência de rotação avaliada, mantendo uma amplitude de vibração constante, inclusive quando o sistema passa pela sua rotação crítica, próxima a $2.000 \mathrm{rpm}$. Avaliando agora a ação de controle, percebe-se que esta cresce gradativamente, diferente do comportamento esperado, no qual a força de controle seria máxima nas proximidades da rotação crítica, uma vez que nesta situação as amplitudes de vibração são máximas. 

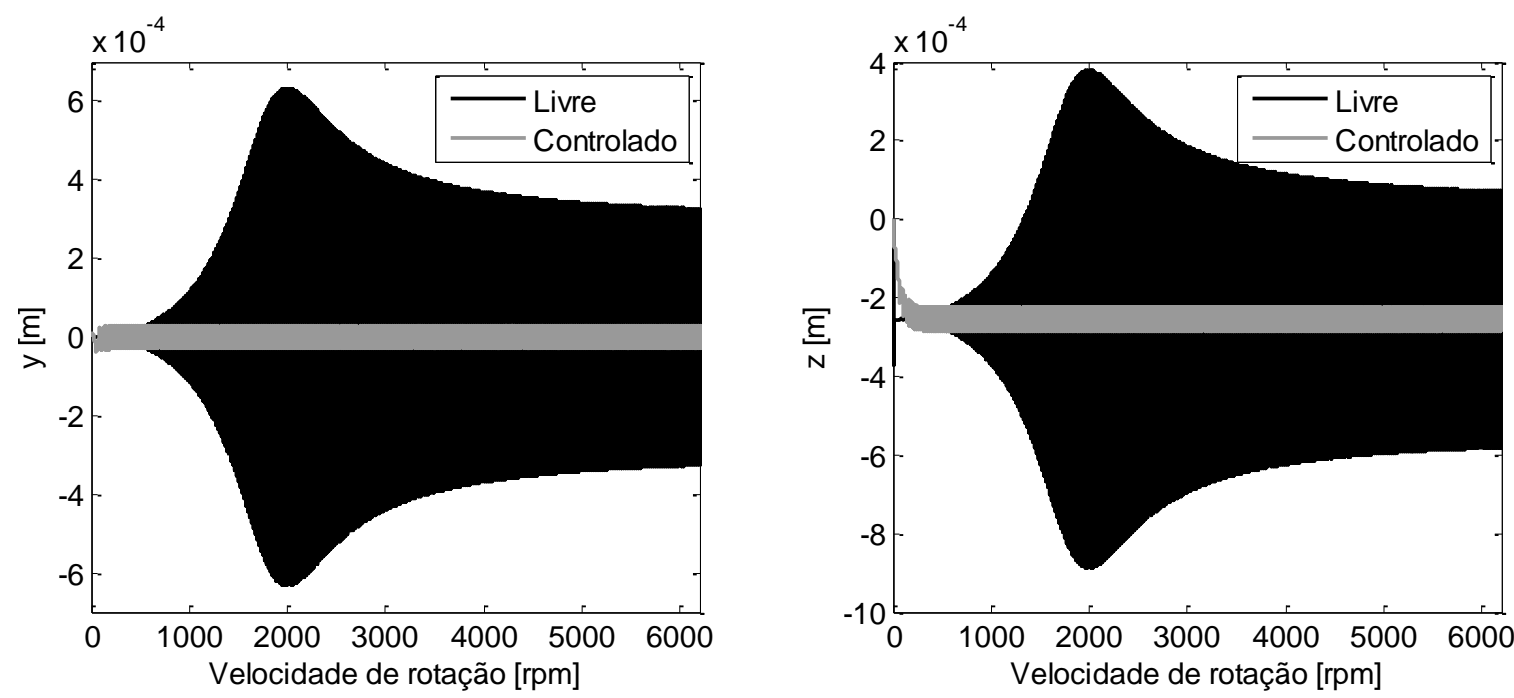

(a) Deslocamento linear
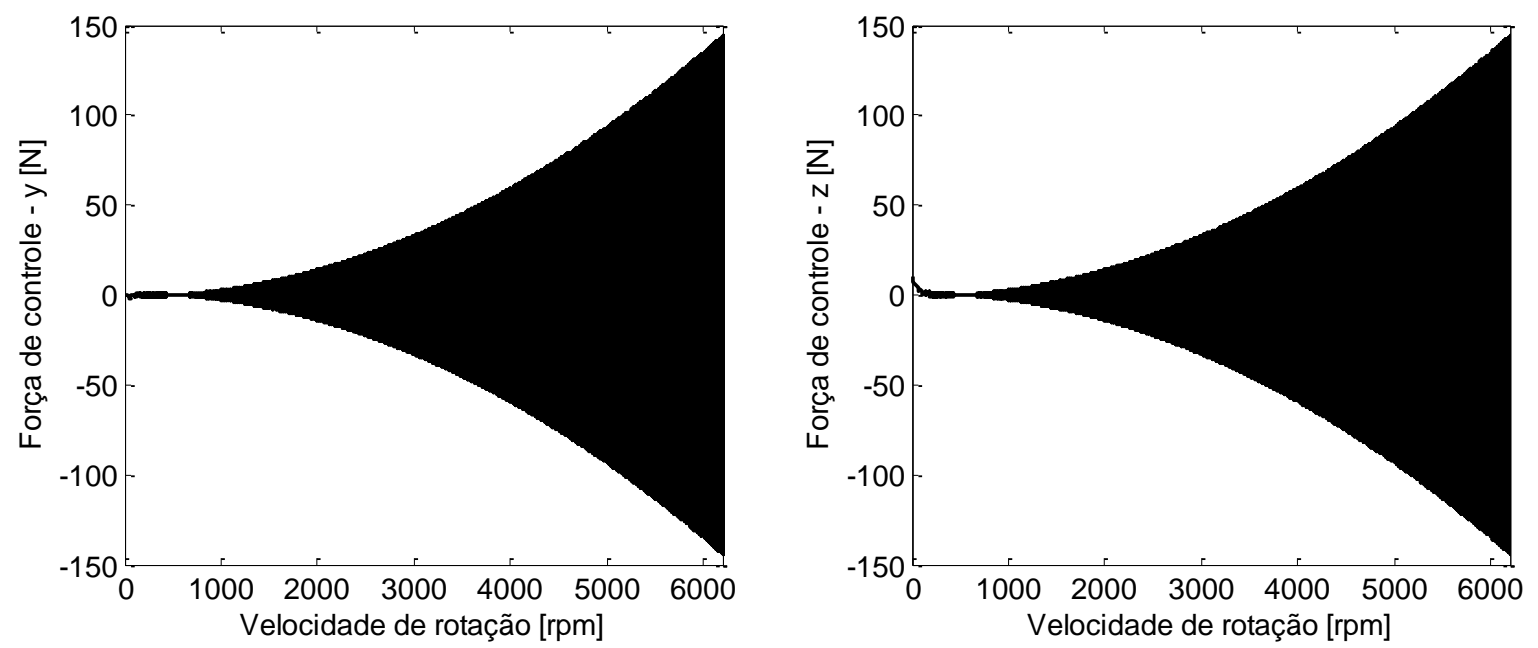

(b) Força de controle

Figura 17 - Run-up do rotor de Laval.

\subsubsection{Controlador PID}

A Figura 18 apresenta os resultados para o controlador PID em relação às amplitudes de vibração e inclinações do disco. Por ela constatam-se resultados similares aos apresentados pelo controlador Udwadia-Kalaba, como a redução da amplitude de vibração para valores próximos do desejado e para direção $\mathrm{z}$ verifica-se que as vibrações também ocorrem em torno do equilíbrio estático do sistema. 

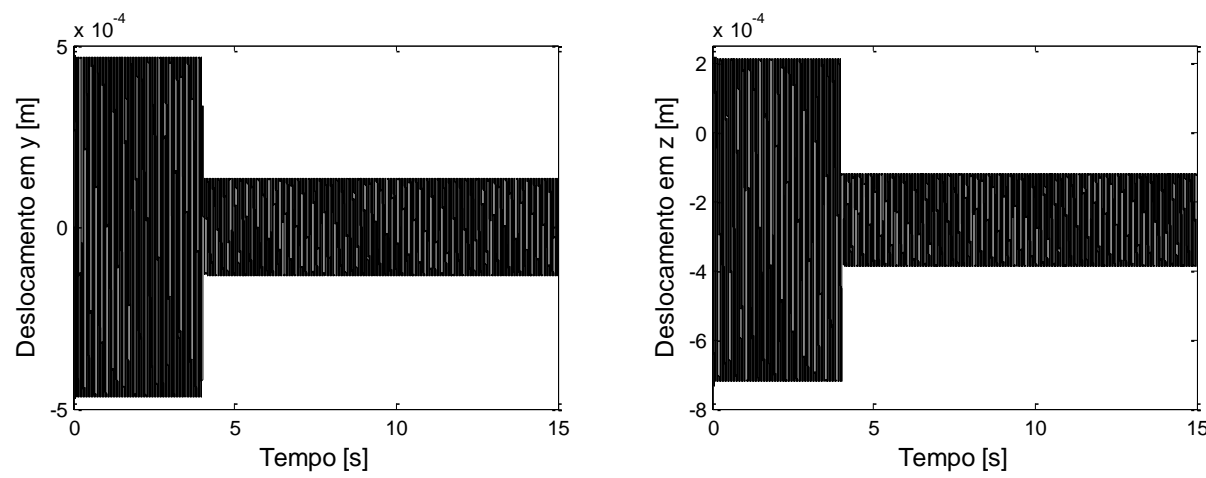

(a) Deslocamento linear
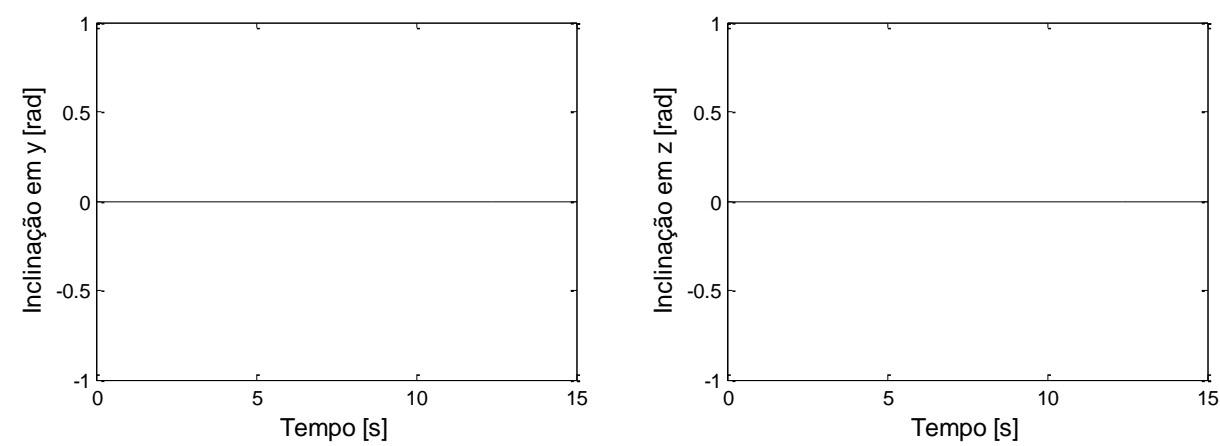

(b) Deslocamento angular

Figura 18 - Resposta do rotor de Laval nos 4 graus de liberdade utilizando o controlador PID.
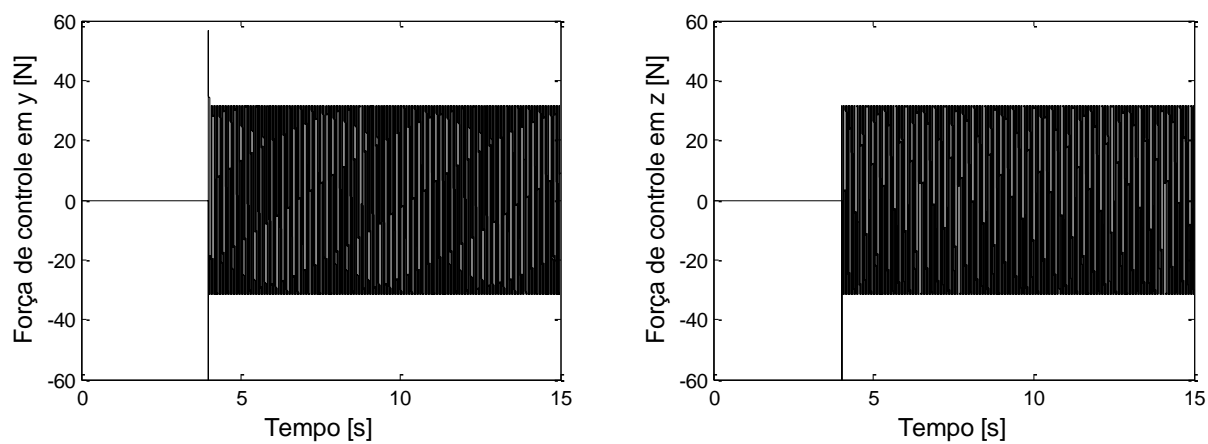

(a) Força de controle
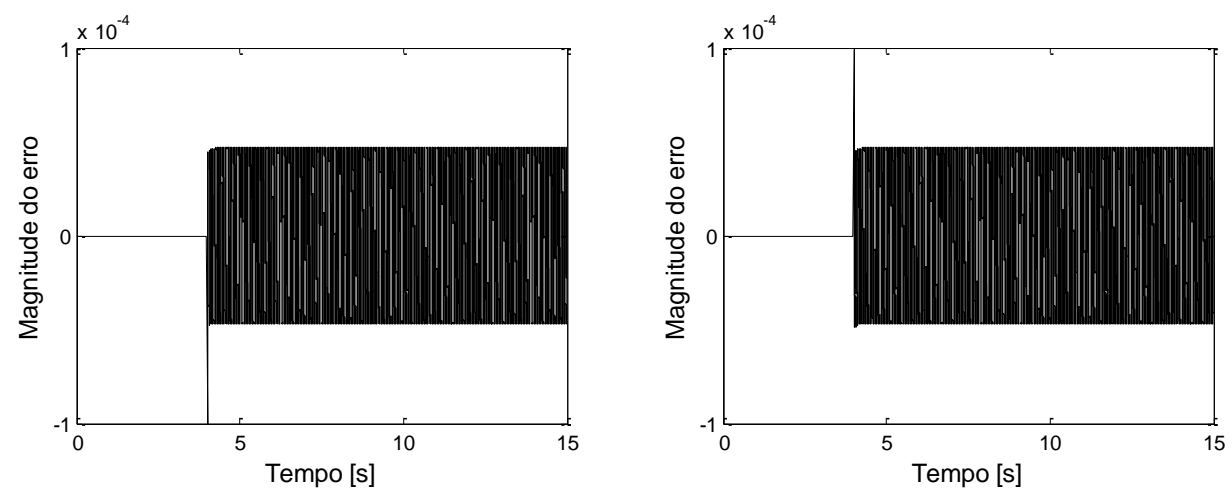

(b) Erro de posicionamento

Figura 19 - Ação de controle e sinal de erro para o rotor de Laval utilizando o controlador PID. 
Já a Figura 19 exibe as ações de controle aplicadas nas direções y e z em conjunto com os sinais de erro nas mesmas direções. Repara-se que a ação de controle varia na mesma faixa apresentada pelo controlador de Udwadia-Kalaba, entre -30 e $30 \mathrm{~N}$, na condição de rotação constante, porém os sinais de erro são significativamente maiores.

\subsubsection{Controlador LQR}

Pela Figura 20 é possível observar resultados para o controlador LQR semelhantes àqueles obtidos com o controlador PID, em termos de redução na amplitude de vibração. Entretanto, analisando-se a Figura 21 nota-se que a ação de controle envolvida foi significativamente menor, variando entre -25 e $25 \mathrm{~N}$.
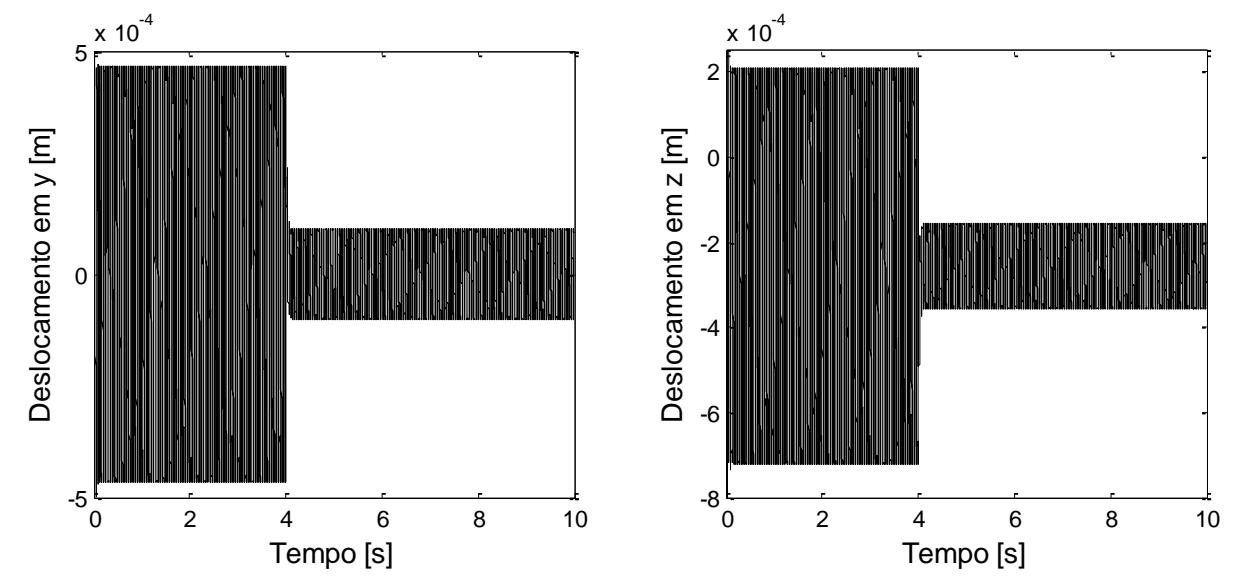

(a) Deslocamento linear
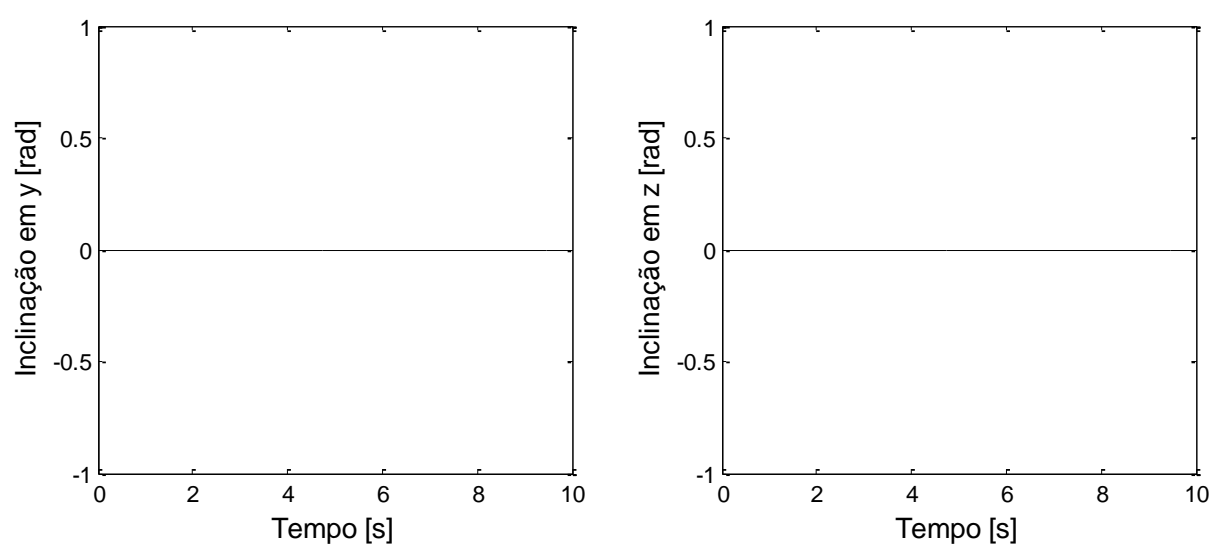

(b) Deslocamento angular

Figura 20 - Resposta do rotor de Laval nos 4 graus de liberdade utilizando o controlador LQR. 
Na Figura 21, percebem-se sinais de erro mais acentuados. Isto se dá em virtude do método de comparação adotado, pois, o controlador LQR não possui uma referência, o seu intuito é levar os estados do sistema para um valor nulo, distinguindo-se do controlador Udwadia-Kalaba e PID. Assim, quando se compara a resposta do sistema com as mesmas referências utilizadas pelos outros controladores, a diferença de fase entre resposta e referência impacta de forma mais acentuada neste controlador, porém quando se avalia a amplitude de resposta, o controlador LQR apresenta comportamento similar aos anteriores.
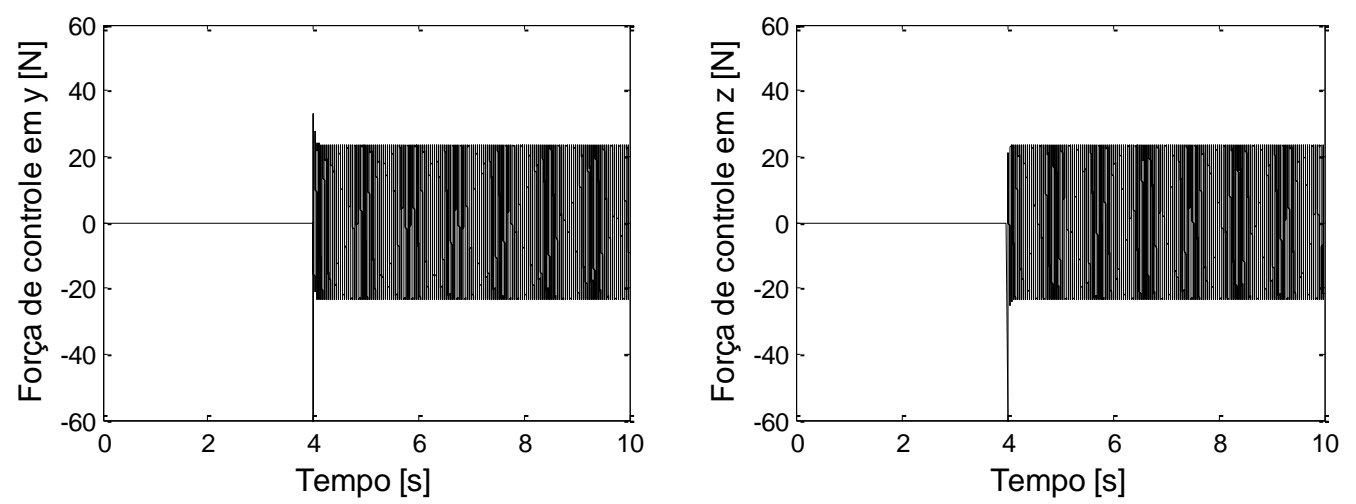

(a) Força de controle
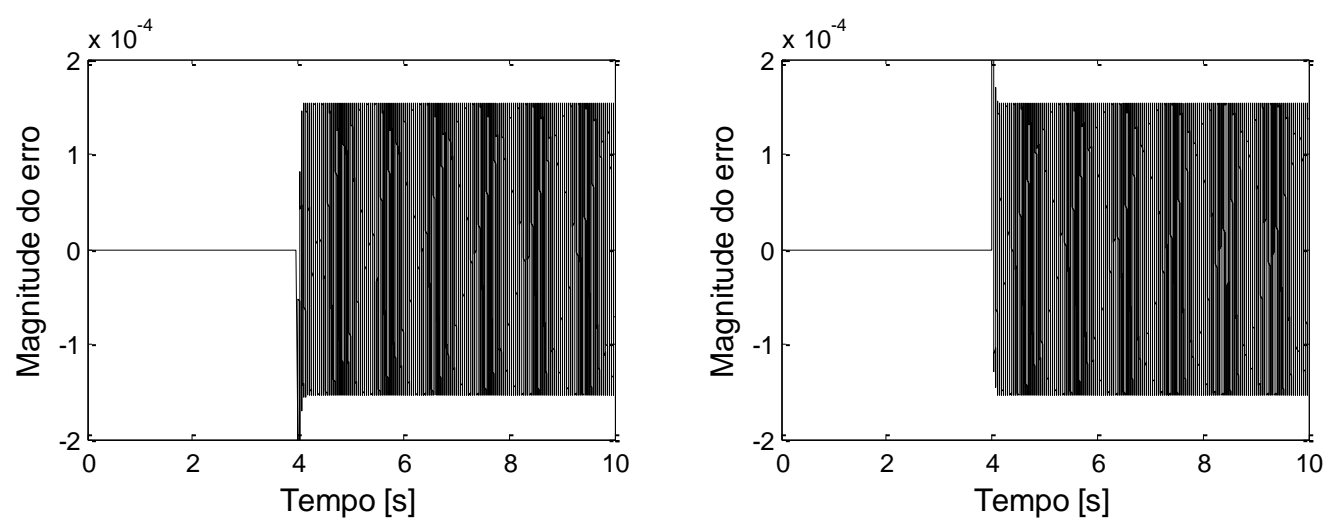

(b) Erro de posicionamento

Figura 21 - Ação de controle e sinal de erro para o rotor de Laval utilizando o controlador LQR.

\subsection{Resultados para o Rotor não Simétrico}

São apresentados aqui os resultados obtidos com os controladores utilizando o modelo do rotor não simétrico. 


\subsubsection{Controlador Udwadia-Kalaba}

Como realizado para o modelo de rotor de Laval, a primeira avaliação deste controlador se dá pela influência dos ganhos $\Sigma$ e K da Equação (25) no desempenho do controlador.

Tabela 3 - Relação de ganhos avaliada para o rotor não simétrico

\begin{tabular}{ccc}
\hline $\boldsymbol{\Sigma}$ & $\mathbf{K}$ & Status \\
\hline 1 & 1 & $\mathbf{x}$ \\
2 & 1 & $\mathbf{x}$ \\
1 & 2 & $\mathbf{x}$ \\
5 & 1 & $\mathbf{x}$ \\
1 & 5 & $\mathbf{x}$ \\
10 & 1 & $\checkmark$ \\
1 & 10 & $\mathbf{x}$ \\
2 & 2 & $\mathbf{x}$ \\
5 & 5 & $\mathbf{x}$ \\
10 & 10 & $\checkmark$ \\
100 & 100 & $\checkmark$ \\
\hline
\end{tabular}

Utilizando a mesma estrutura da Tabela 2 a Tabela 3 apresenta as condições testadas e os resultados referentes a problemas com integração numérica. Percebe-se que com o incremento da complexidade do sistema avaliado, uma vez que o disco não está mais centrado entre os mancais e o efeito giroscópico surge, o controlador apresentou maiores problemas para a realização do controle, já que na grande maioria das condições de ganho avaliadas surgiram problemas de integração numérica. Pela Figura 22, tem-se como conclusão, novamente, que a condição $\Sigma=10$ e K $=10$ apresenta o melhor resultado. 

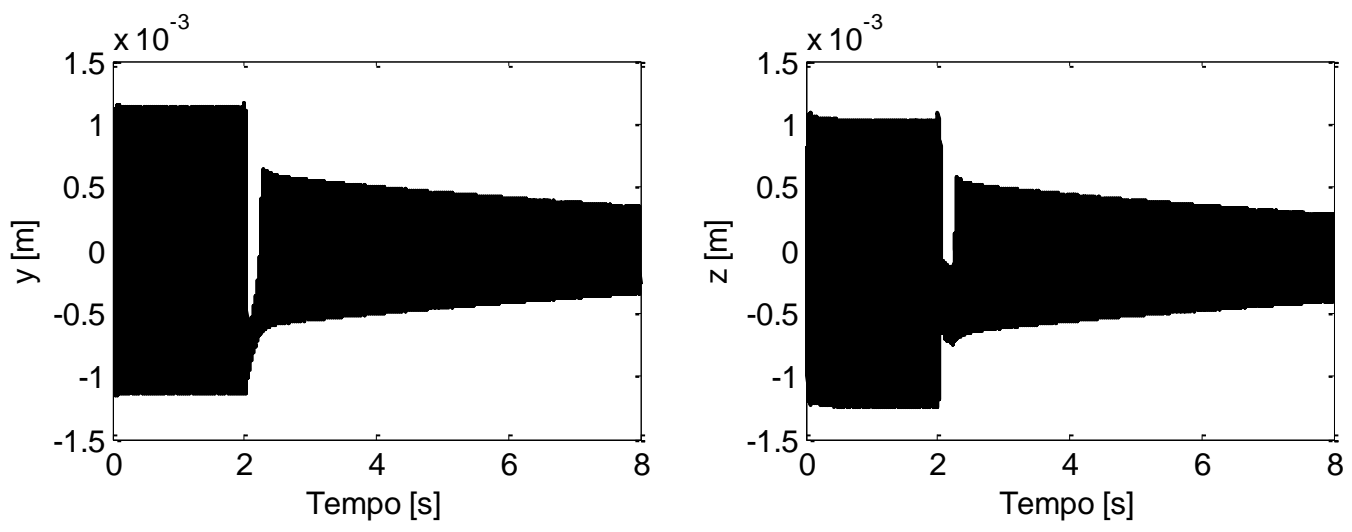

(a) $\Sigma=10, K=1$
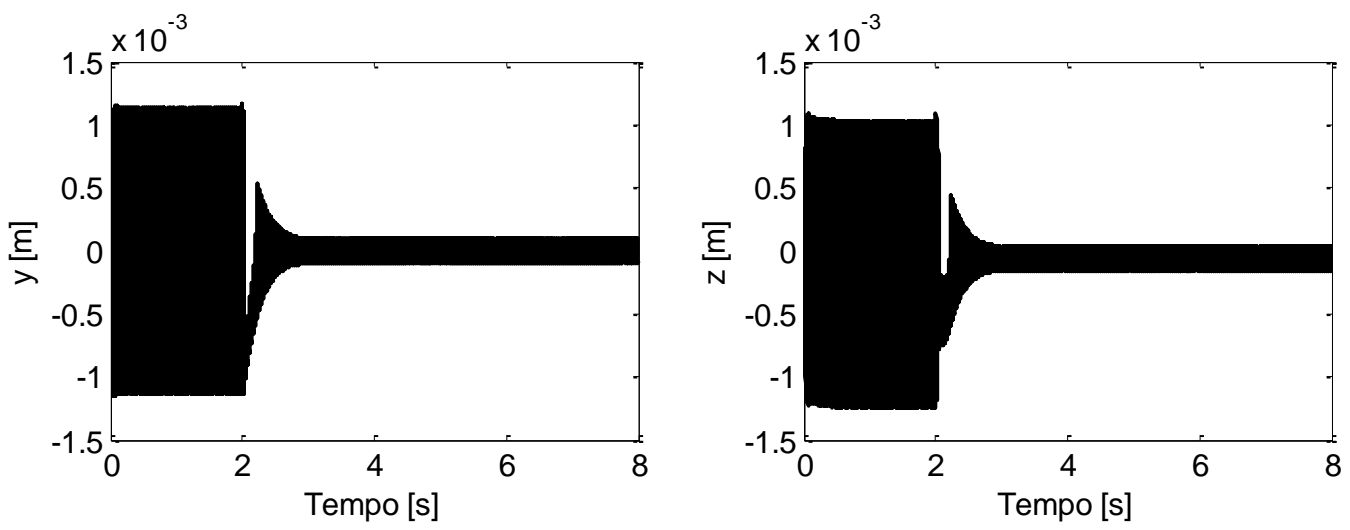

(b) $\Sigma=10, \mathrm{~K}=10$
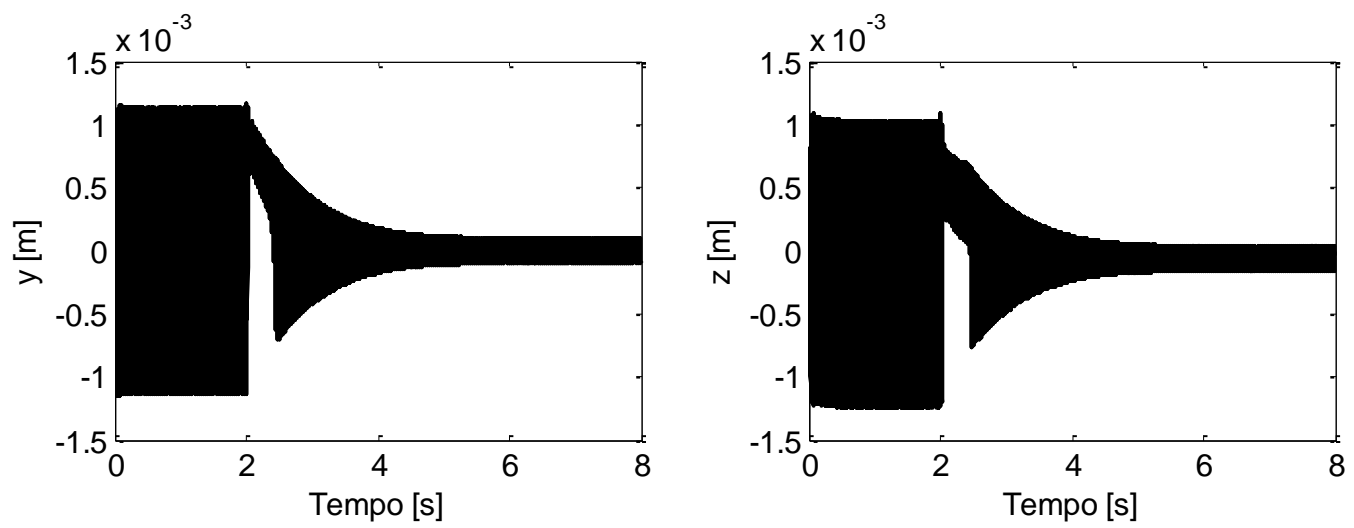

(c) $\Sigma=100, \mathrm{~K}=100$

Figura 22 - Resposta do rotor não simétrico nas condições de ganho avaliadas, para as direções y e z.

A Figura 23 apresenta em destaque a resposta dos 4 graus de liberdade do sistema na condição do rotor não simétrico. Nota-se que o sistema tende rapidamente à resposta desejada e que no momento em que o controlador é acionado, a partir dos 2 segundos, ocorre uma brusca inclinação do disco em ambas as direções. Vale notar que a amplitude de vibração para o sistema não controlado era muito alta, da ordem de $10^{-3} \mathrm{~m}$ em função da velocidade de 
rotação escolhida (4.835 rpm) e que o controlador atuou efetivamente na redução para valores em torno de $1 \times 10^{-4} \mathrm{~m}$, uma redução de 10 vezes na amplitude.
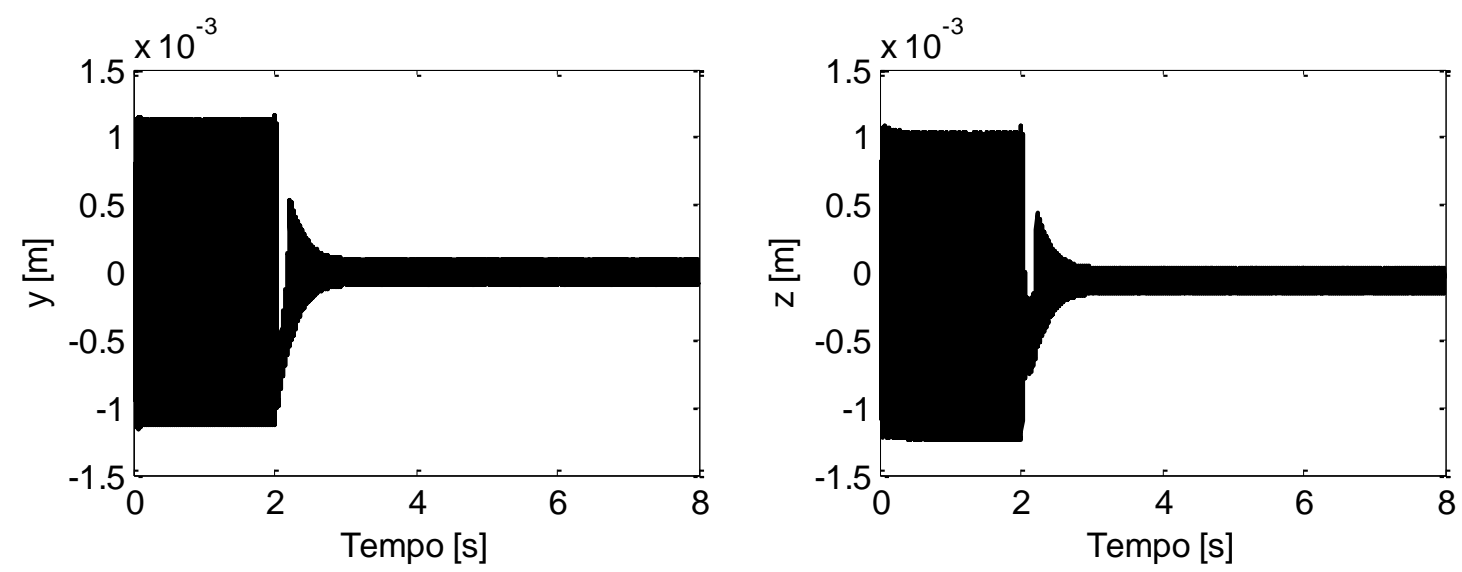

(a) Deslocamento linear
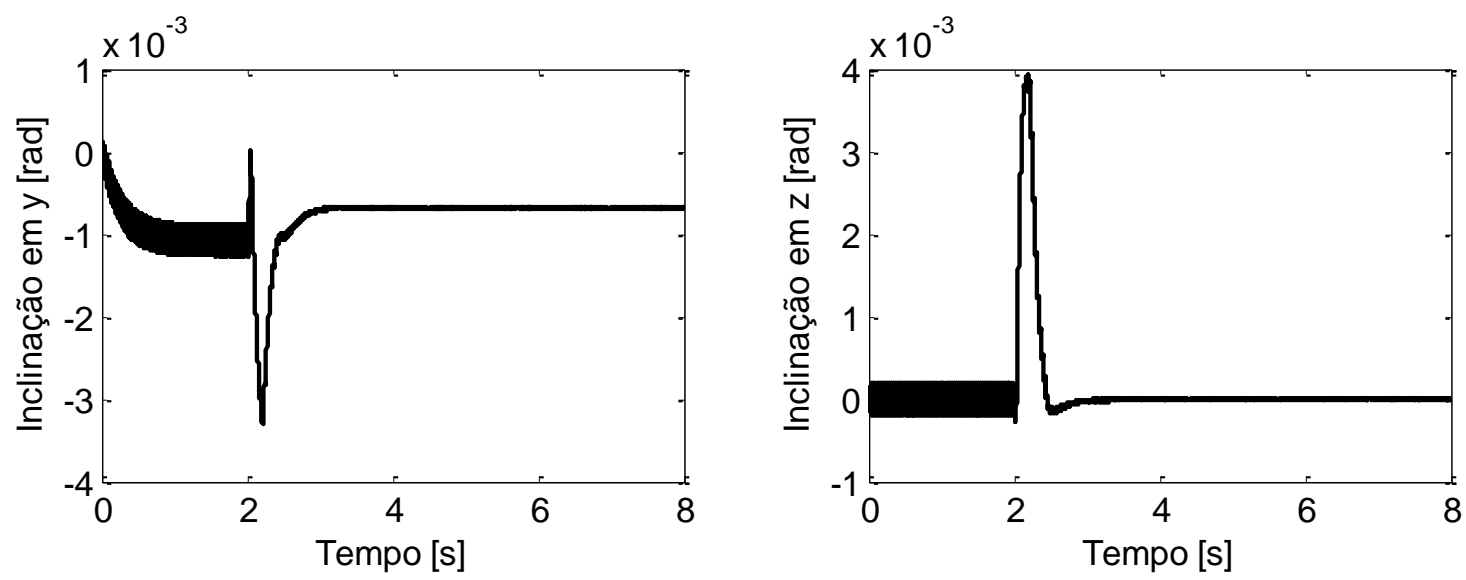

(b) Deslocamento angular

Figura 23 - Resposta do rotor não simétrico nos 4 Graus de liberdade, utilizando o controlador Udwadia-Kalaba.

Observando a Figura 24, que apresenta a ação de controle nas direções y e z e sinais de erro nas mesmas direções, notam-se picos elevados de força de atuação nos instantes próximos ao acionamento do controlador aos 2 segundos e posteriormente uma ação de controle em regime permanente variando entre -60 e $60 \mathrm{~N}$.

Por fim, avalia-se o comportamento do controlador para o caso do rotor não simétrico em run-up pela Figura 25, na qual se constata, novamente, que o controlador atua de forma efetiva por toda faixa de frequência de rotação avaliada, mantendo uma amplitude de vibração constante, inclusive quando o sistema passa pela sua rotação crítica, próxima a $4.000 \mathrm{rpm}$. Observam-se também as inclinações no disco que são indiretamente controladas pela redução das vibrações em y e $z$. 

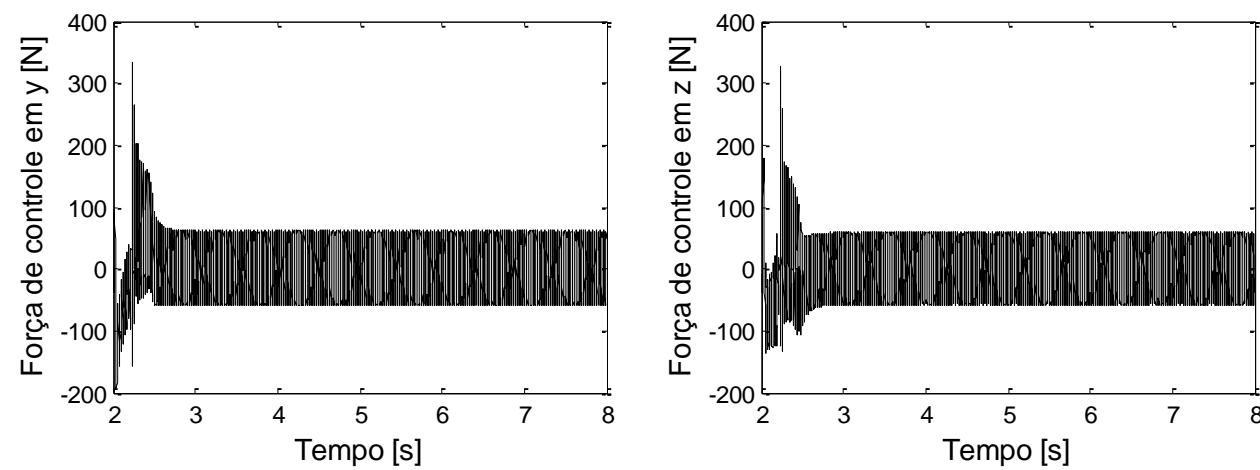

(a) Força de controle
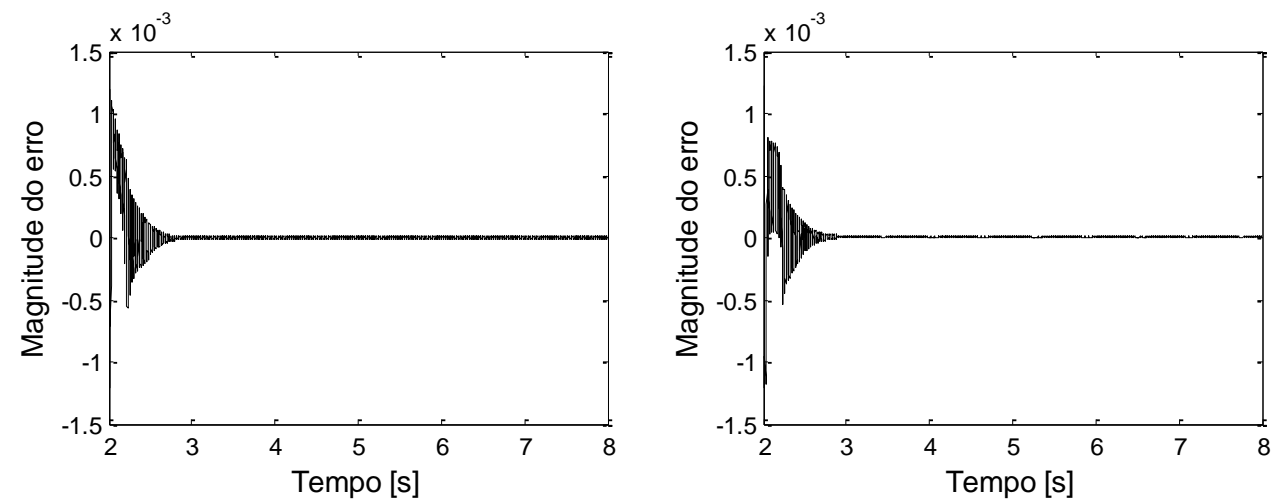

(b) Erro de posicionamento

Figura 24 - Ação de controle e sinal de erro para o rotor não simétrico, utilizando o controlador Udwadia-Kalaba.
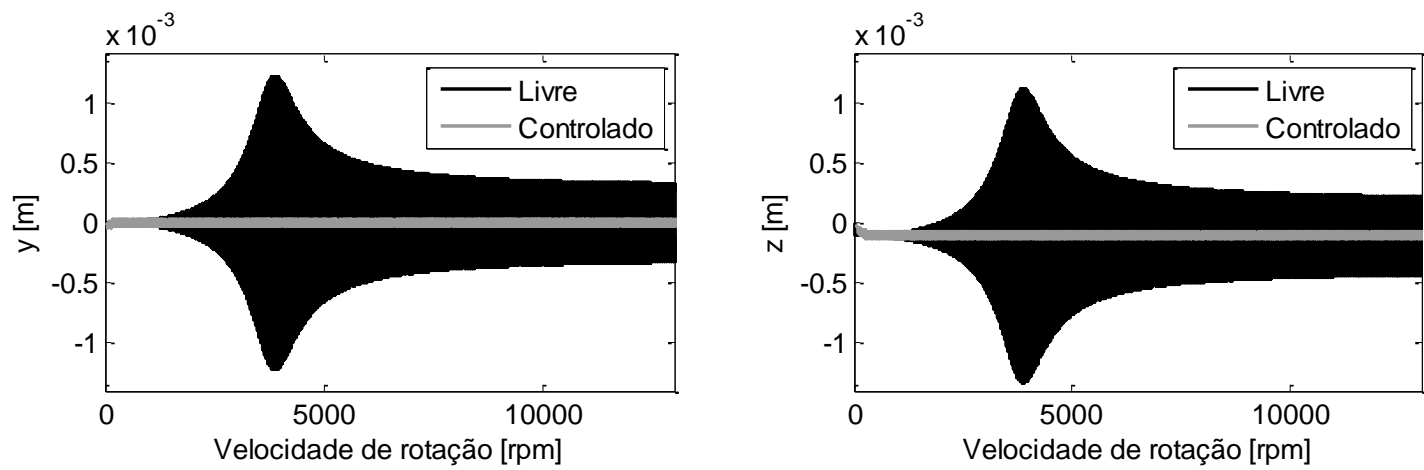

(a) Deslocamento linear
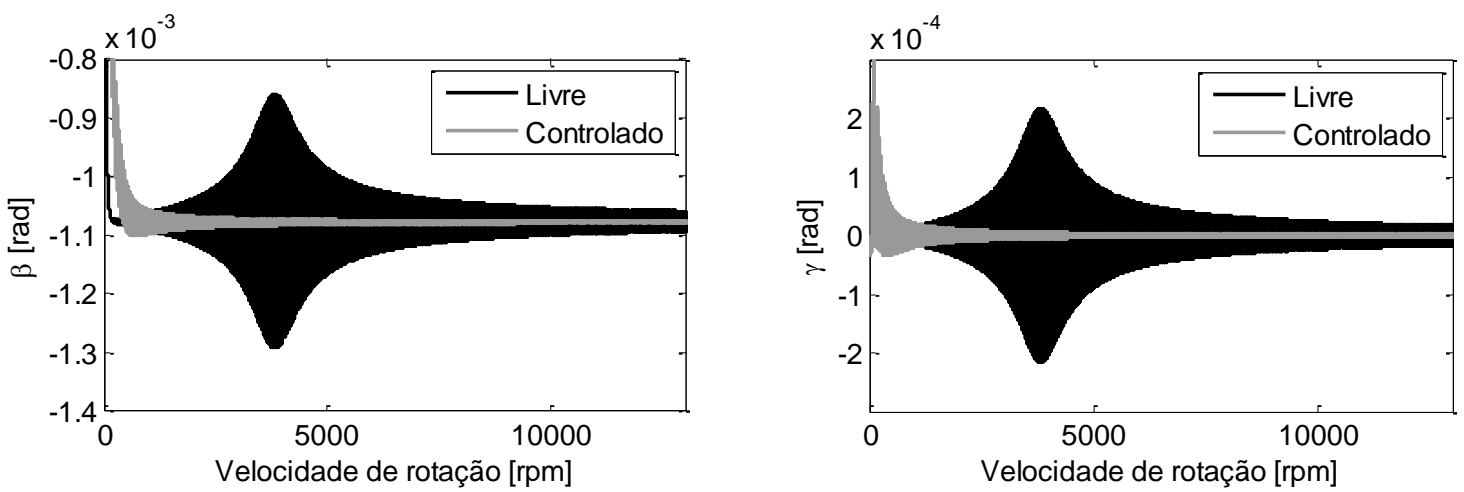

(b) Deslocamento angular

Figura 25 - Run-up do rotor não simétrico. 
Avaliando a ação de controle envolvida no processo, pela Figura 26, percebe-se que ao realizar o controle em run-up do sistema até que se chegue à velocidade de trabalho, o controlador é beneficiado em termos de intensidade de força de atuação, pois se eliminam os picos da ação de controle que foram observados, para o caso de acionamento do controlador com a máquina já em velocidade de trabalho, na Figura 24.
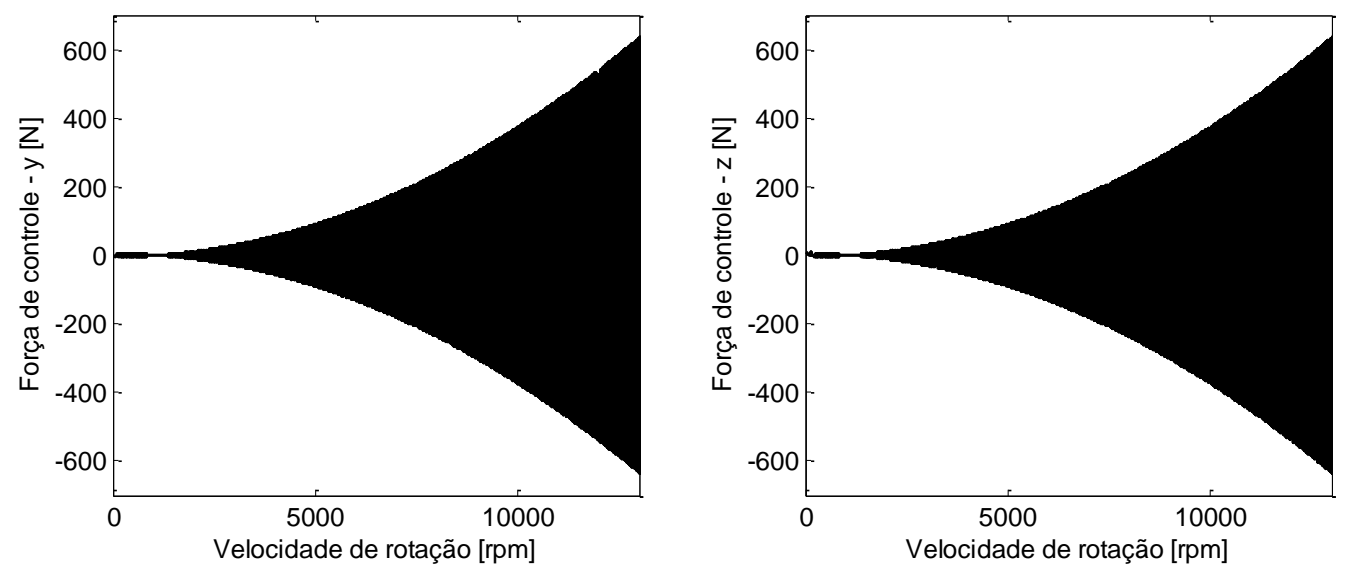

Figura 26 - Ação de controle em run-up do controlador Udwadia-Kalaba para o rotor não simétrico.

\subsubsection{Controlador PID}

A Figura 27 apresenta as amplitudes de vibração do sistema para o controlador PID e a Figura 28 exibe ação de controle aplicada assim como o erro nas direções horizontal e vertical. Os resultados são semelhantes aos obtidos com o controlador Udwadia-Kalaba, o controlador também apresenta picos quando é acionado, porém o mesmo consegue atuar no sistema de forma que em regime permanente o comportamento dos controladores é semelhante. 

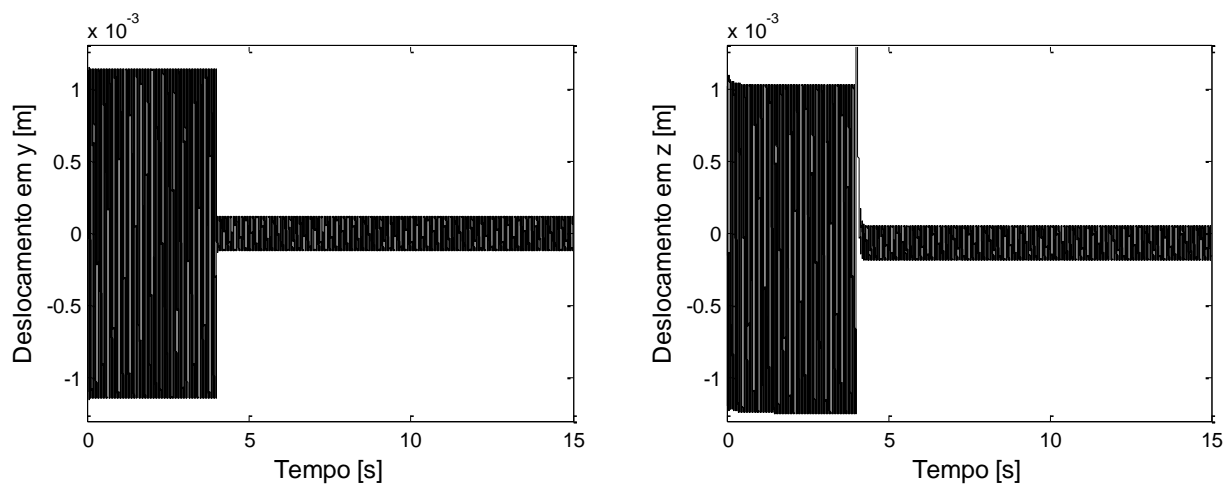

(a) Deslocamento linear
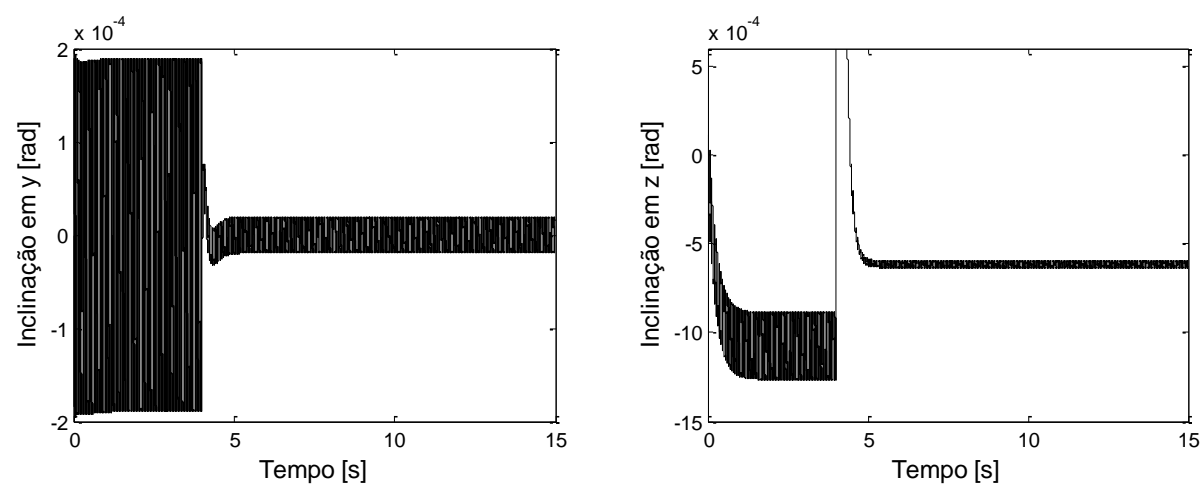

(b) Deslocamento angular

Figura 27 - Resposta do rotor não simétrico nos 4 Graus de liberdade, utilizando o controlador PID.
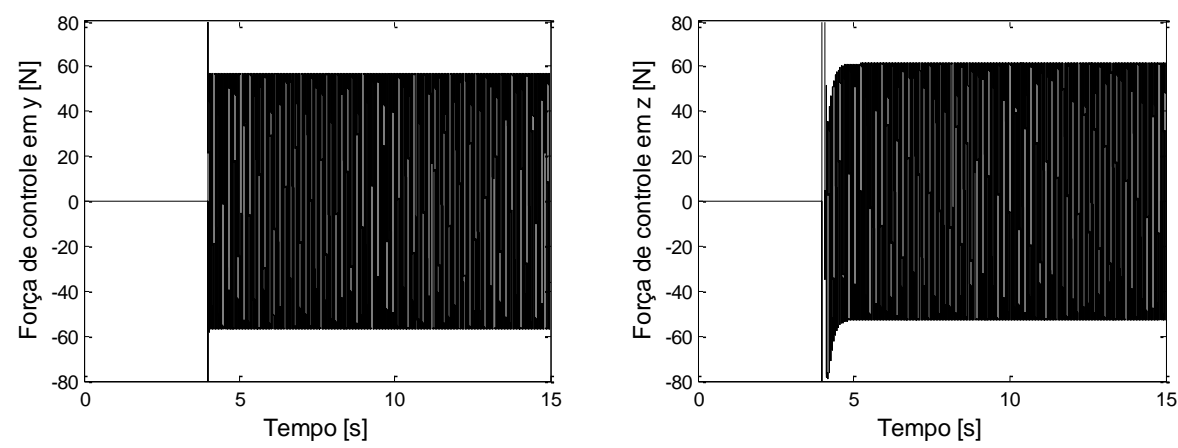

(a) Força de controle
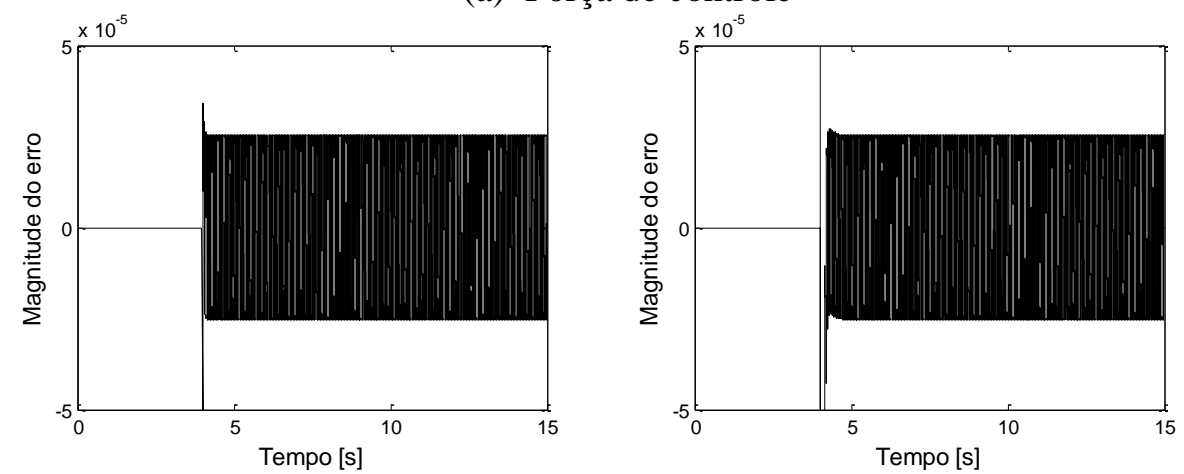

(b) Erro de posicionamento

Figura 28 - Ação de controle e sinal de erro para o rotor não simétrico, utilizando o controlador PID. 


\subsubsection{Controlador LQR}

O controlador LQR também apresentou resultados similares aos outros dois controladores avaliados anteriormente, em termos de redução da amplitude de vibração, entretanto pela Figura 30 verifica-se novamente uma redução na ação de controle, em regime permanente, por parte do controlador LQR. Enquanto os outros controladores apresentaram uma ação de controle entre -60 e $60 \mathrm{~N}$ para reduzir a amplitude de vibração do sistema da casa de $10^{-3}$ para $10^{-4} \mathrm{~m}$, o controlador LQR necessitou somente de valores entre -50 e $50 \mathrm{~N}$, em regime permanente.
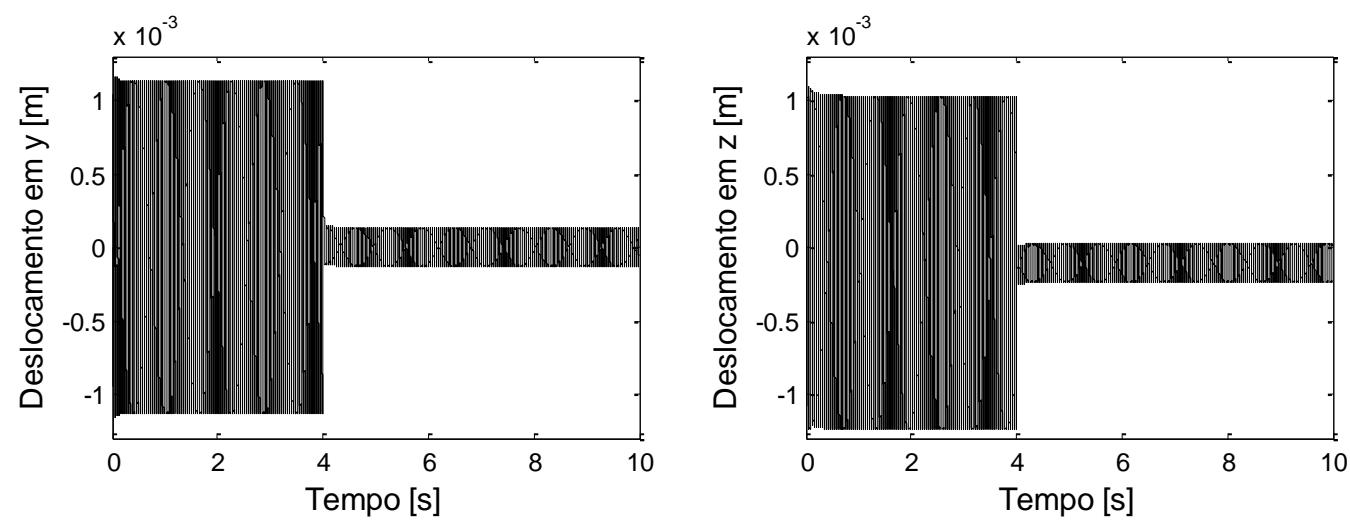

(a) Deslocamento linear
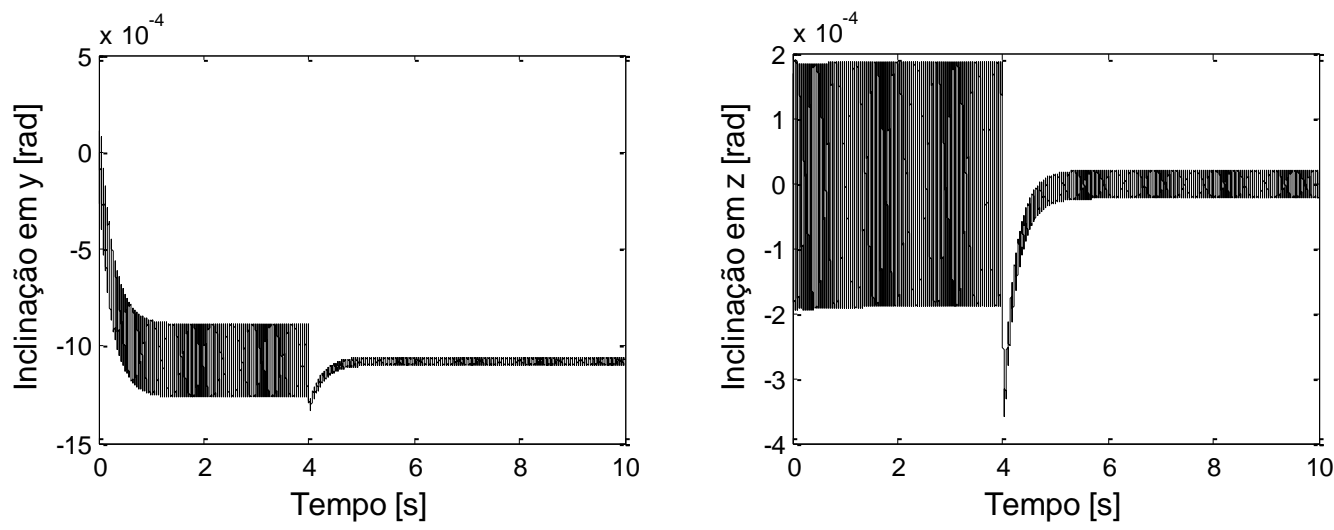

(b) Deslocamento angular

Figura 29 - Resposta do rotor não simétrico nos 4 graus de liberdade, utilizando o controlador LQR. 

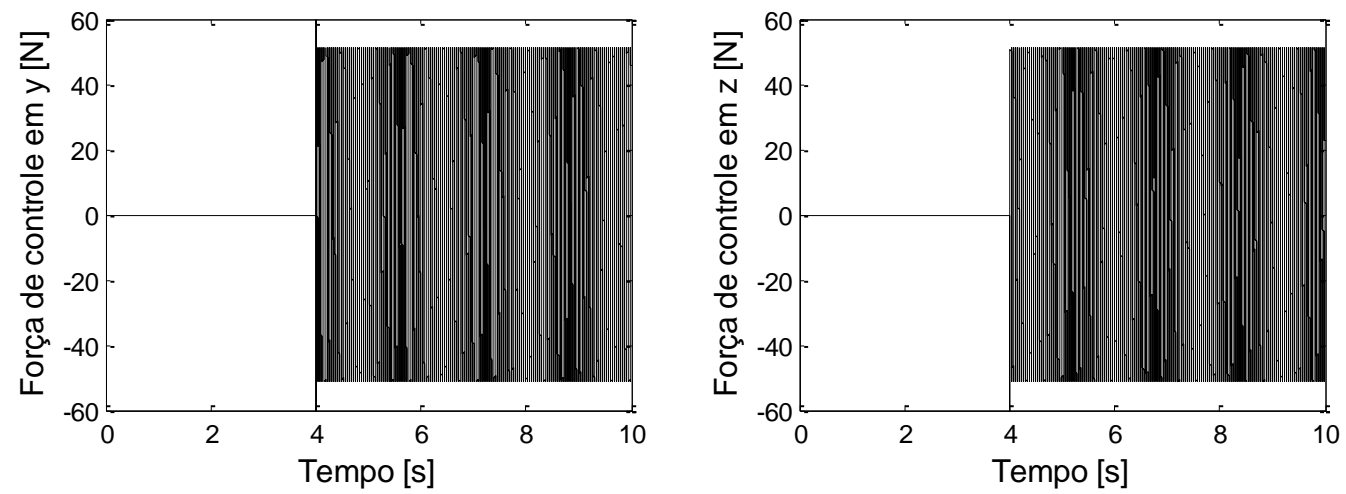

(a) Força de controle
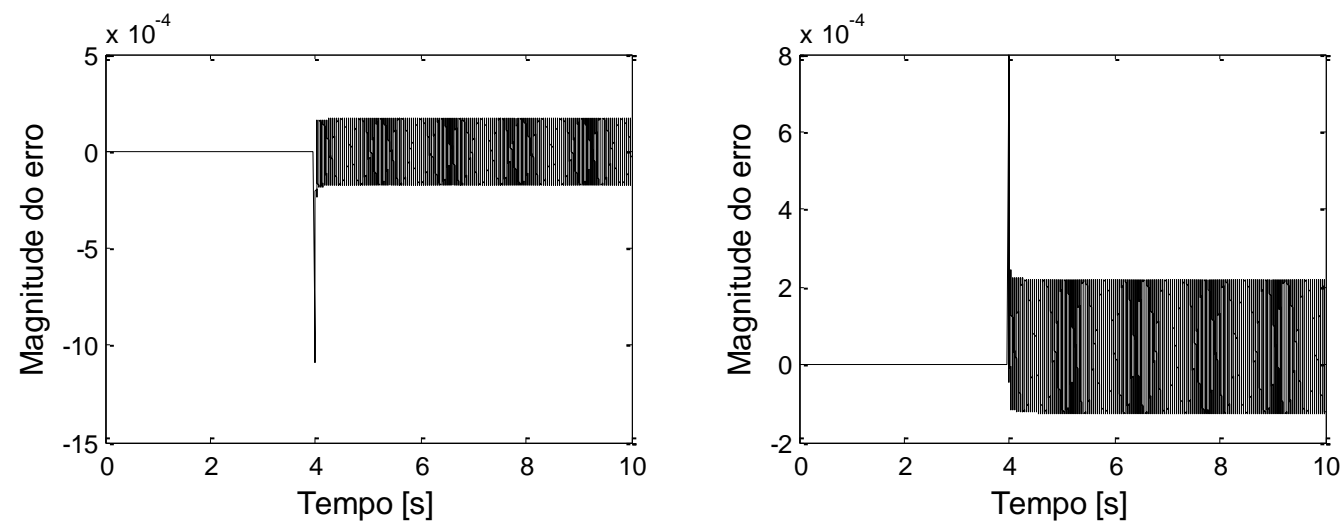

(b) Erro de posicionamento

Figura 30 - Ação de controle e sinal de erro para o rotor não simétrico, utilizando o controlador LQR.

\subsection{Comparação do Valor RMS da Ação de Controle e Sinal de Erro}

A partir dos resultados mostrados anteriormente é possível fazer uma comparação mais justa através da avaliação do valor RMS da ação de controle e do sinal de erro para cada controlador em cada tipo de rotor. Vale destacar que a comparação é realizada avaliando os valores em regime permanente, o que representaria uma condição de trabalho do sistema. A Figura 31 apresenta o comparativo realizado. 


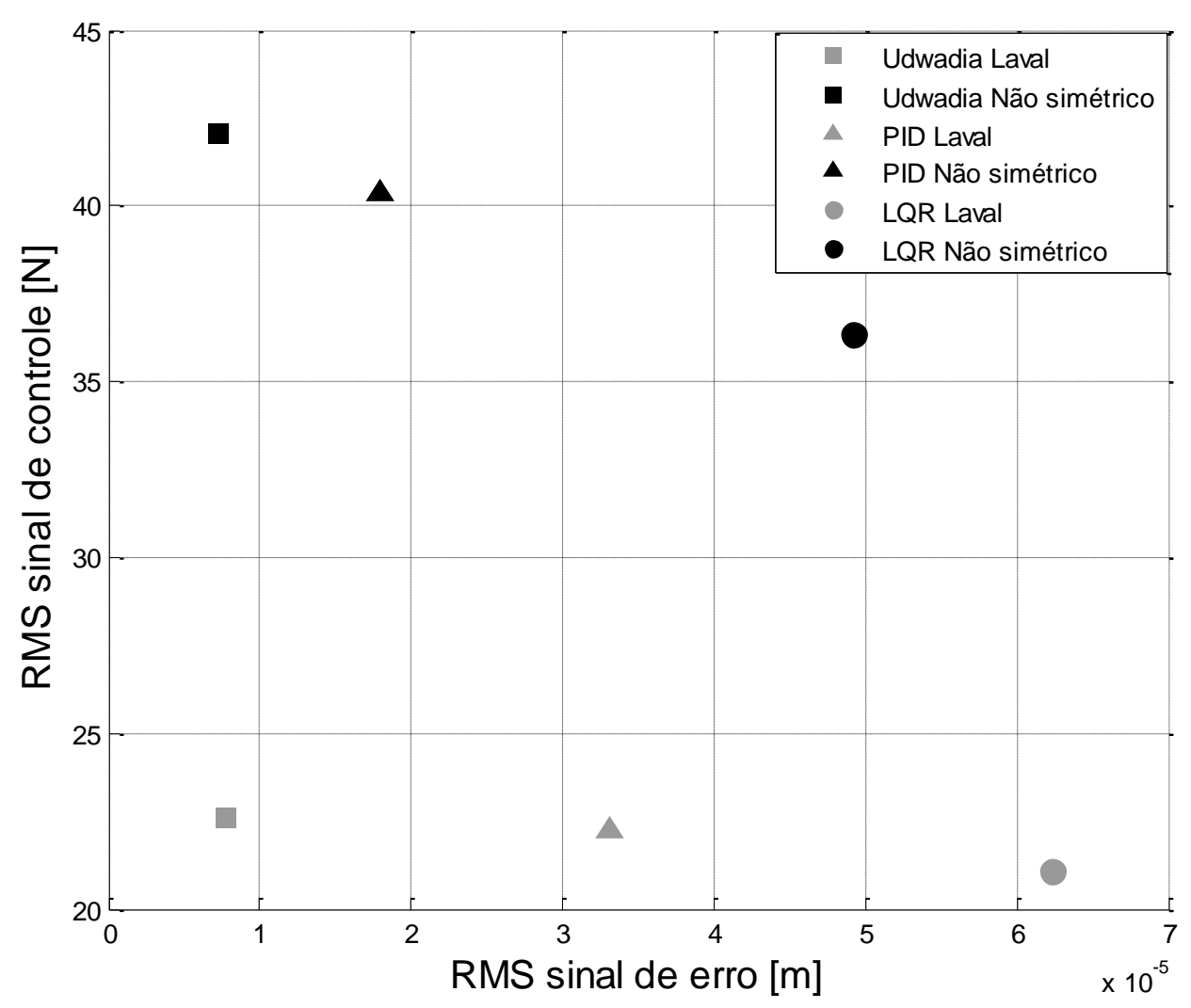

Figura 31 - Comparativo do RMS da ação de controle e sinal erro para todas as configurações de rotores e controladores.

Nota-se que o valor RMS da ação de controle tanto para o rotor de Laval como para o não simétrico é muito similar quando se compara o controlador Udwadia-Kalaba e o controlador PID, já para os valores de erro, o controlador Udwadia-Kalaba é bem mais eficiente, pois para uma ação de controle muito similar o sinal de erro foi significativamente menor.

Já o controlador LQR apresentou os maiores valores de erro, justificados anteriormente pela metodologia de comparação, uma vez que este controlador não possui um sinal de referência, tornando-se difícil avaliar o erro. Porém as ações de controle foram significativamente menores, de tal forma que podemos afirmar que, em regime permanente, o controlador LQR apresenta uma melhor relação custo energético versus redução da amplitude de vibração do que o controlador Udwadia-Kalaba. 


\section{Capítulo 5}

\section{Avaliação do Controlador em Sistema Rotativo Modelado pelo Método dos Elementos Finitos}

No modelo adotado anteriormente, os 4 graus de liberdade eram referentes a movimentação do disco, assim, a ação de controle aplicada no sistema se localizava no próprio disco. Do ponto de vista prático, os atuadores responsáveis por realizar a atuação de controle se encontram usualmente na posição dos mancais. Para realizar a avaliação do controlador considerando uma ação de controle aplicada nos mancais do sistema é necessário modelar o sistema pelo Método dos Elementos Finitos (MEF), permitindo assim a introdução de mais graus de liberdade no sistema.

Neste capítulo são apresentados o modelo em MEF utilizado e a avaliação do comportamento e desempenho do controlador Udwadia-Kalaba para uma aplicação de controle ativo de vibrações.

\subsection{Modelo}

A Figura 32 apresenta o modelo esquemático do sistema adotado, utilizando o método de elementos finitos considerando viga Timoshenko (NELSON, 1980) e os parâmetros da Tabela 4.

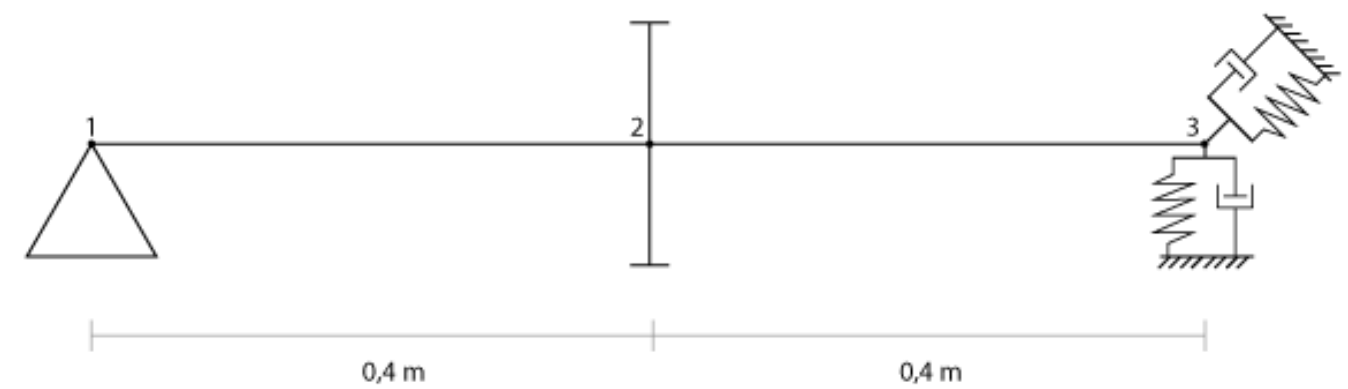

Figura 32 - Desenho esquemático do modelo em elementos finitos. 
O modelo adotado na Figura 32 apresenta uma restrição de translação lateral e vertical no primeiro nó, com o disco desbalanceado no segundo nó, equidistante dos nós 1 e 3. No nó 3 se encontra o mancal, no qual a ação de controle será aplicada. No total, o sistema em questão apresenta 10 graus de liberdade, sendo duas rotações no primeiro nó, duas rotações e duas translações para os nós 2 e 3.

Tabela 4 - Parâmetros do modelo.

\begin{tabular}{llll}
\hline Parâmetro & Valor & Parâmetro & Valor \\
\hline Rotor & & Mancal & \\
\hline Diâmetro do eixo $(\mathrm{m})$ & 0,029 & $\mathrm{~K}_{\mathrm{y} 1}(\mathrm{~N} / \mathrm{m})$ & $7,73 \times 10^{5}$ \\
Massa do disco $(\mathrm{kg})$ & 2.7744 & $\mathrm{~K}_{\mathrm{z} 1}(\mathrm{~N} / \mathrm{m})$ & $1,13 \times 10^{5}$ \\
Diâmetro do disco $(\mathrm{m})$ & 0,15 & $\mathrm{C}_{\mathrm{y} 1}(\mathrm{~N} . \mathrm{s} / \mathrm{m})$ & 25 \\
Espessura do disco $(\mathrm{m})$ & 0,005 & $\mathrm{C}_{\mathrm{z} 1}(\mathrm{~N} . \mathrm{s} / \mathrm{m})$ & 25 \\
Módulo de elasticidade $\left(\mathrm{GN} / \mathrm{m}^{2}\right)$ & 205 & & \\
Densidade $\left(\mathrm{Kg} / \mathrm{m}^{3}\right)$ & 7850 & & \\
Coeficiente de Poisson & 0,3 & & \\
Comprimento dos elementos de eixo $(\mathrm{m})$ & 0,4 & & \\
\hline
\end{tabular}

Montadas as matrizes globais de inércia, amortecimento e rigidez, a dinâmica do sistema é representada pela Equação (29).

$$
\left[M_{g}\right]\{\ddot{q}\}+\left[D_{g}+\Omega G_{g}\right]\{\dot{q}\}+\left[K_{g}\right]\{q\}=\{F\}
$$

O diagrama de Campbell da Figura 33 apresenta a evolução das frequências naturais do sistema. Esta avaliação é feita desde uma rotação nula até o valor de $20.000 \mathrm{rpm}$. Pelo diagrama, constata-se que, nesta faixa de rotação, o sistema passa por 5 rotações críticas, ou seja, teremos passagem por 5 modos naturais de vibrar do sistema. Pelo diagrama de Campbell retiram-se as frequências críticas correlacionadas aos modos de vibrar, de acordo com a Tabela 5.

Tabela 5 - Frequências críticas do modelo.

\begin{tabular}{cc}
\hline Modo & Rotação (rpm) \\
\hline $1^{\circ}$ & 2.050 \\
$2^{\circ}$ & 3.260 \\
$3^{\circ}$ & 7.350 \\
$4^{\text {o }}$ & 11.100 \\
$5^{\circ}$ & 17.100 \\
\hline
\end{tabular}




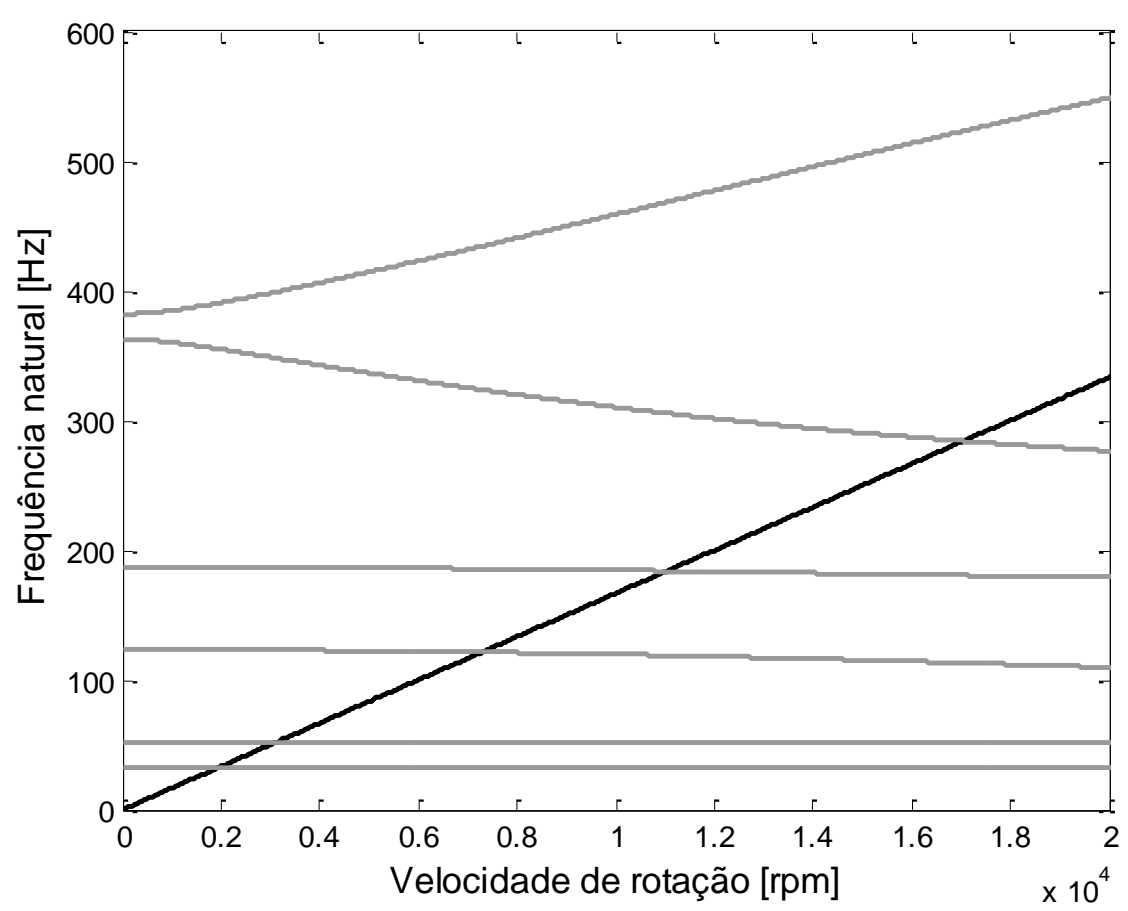

Figura 33 - Diagrama de Campbell do modelo em MEF.

\subsection{Controlador Udwadia-Kalaba}

A aplicação do controlador da mesma forma como foi apresentada anteriormente apresentou problemas na integração numérica. Acredita-se que a causa seja o aumento do número de graus de liberdade em conjunto ao fato da força de atuação obtida com esta metodologia ser não linear, forçando o software MATLAB® a reduzir drasticamente o passo de tempo, de tal maneira que a integração fica-se inviável, mesmo utilizando um solver do tipo stiff, como o ode15s.

Para contornar o problema de integração, foi definida uma nova restrição cinemática, equivalente à definida no capítulo anterior, porém escrita de forma alternativa. Vale destacar o fato de que para se obter uma força de atuação nos mancais, como desejado, é necessário definir as restrições cinemáticas no mesmo local, ou seja, para realizar o controle de vibrações do sistema através de atuação no mancal, deve-se definir a restrição cinemática no mesmo. Assim, a restrição aplicada no mancal é apresentada na Equação (30), que é equivalente a restrição imposta na Equação (22), agora com um $R_{\max }=10^{-5} \mathrm{~m}$.

$$
\varphi=\left\{\begin{array}{c}
y-R_{\max } \cos (\omega t) \\
z-R_{\max } \operatorname{sen}(\omega t)+\delta_{\text {est }}
\end{array}\right\}=0
$$


A partir desta restrição, realiza-se o mesmo procedimento definido anteriormente, diferenciando a restrição com relação ao tempo até se obter uma equação diferencial da mesma ordem do sistema, no caso um sistema de segunda ordem. Assim, a Equação (31) apresenta a primeira derivada, e a Equação (32) a segunda. Como o controlador será avaliado em run-up, a rotação varia no tempo, por isso também deve ser diferenciada, considerando $\dot{\omega}=$ cte e $\ddot{\omega}=0$.

$$
\begin{gathered}
\dot{\varphi}=\left\{\begin{array}{c}
\dot{y}+R_{\text {max }} \operatorname{sen}(\omega t)(\omega+\dot{\omega} t) \\
\dot{z}-R_{\max } \cos (\omega t)(\omega+\dot{\omega} t)
\end{array}\right\}=0 \\
\ddot{\varphi}=\left\{\begin{array}{c}
\ddot{y}+2 \dot{\omega} R_{\text {max }} \operatorname{sen}(\omega t)+R_{\text {max }} \cos (\omega t)(\omega+\dot{\omega} t)^{2} \\
\ddot{z}-2 \dot{\omega} R_{\text {max }} \cos (\omega t)+R_{\text {max }} \operatorname{sen}(\omega t)(\omega+\dot{\omega} t)^{2}
\end{array}\right\}=0
\end{gathered}
$$

Como explicado anteriormente, a Equação (32) equivale à Equação (30) somente para certas condições iniciais. Assim, a combinação proposta na Equação (5) deve ser realizada. Entretanto, esta maneira alternativa de impor a restrição cinemática só foi possível com ganhos elevados $(\Sigma=1000$ e $\mathrm{K}=1000)$.

O sistema deve atender as restrições impostas pela combinação das Equações (30), (31) e (32) e ao mesmo tempo é necessário restringir a aplicação da ação de controle somente nas direções y e z na posição do mancal (nó 3 do modelo), desta forma tem-se a Equação (33).

$$
[A]\{\ddot{q}\}=\{b\}
$$

Onde:

$$
\begin{gathered}
{[A]\{\ddot{q}\}=\left[\begin{array}{lll}
0_{2 x 6} & I_{2 x 2} & 0_{2 x 2}
\end{array}\right]\left\{\begin{array}{l}
\ddot{\beta}_{1} \\
\ddot{\gamma}_{1} \\
\ddot{y}_{2} \\
\ddot{z}_{2} \\
\ddot{\beta}_{2} \\
\ddot{\gamma}_{2} \\
\ddot{y}_{3} \\
\ddot{z}_{3} \\
\ddot{\beta}_{3} \\
\ddot{\gamma}_{3}
\end{array}\right\}} \\
\{b\}=\left\{\begin{array}{l}
\left.-2 \dot{\omega} R_{\max } \operatorname{sen}(\omega t)-R_{\max } \cos (\omega t)(\omega+\dot{\omega} t)^{2}-\Sigma \dot{\varphi}-K \varphi\right\} \\
2 \dot{\omega} R_{\max } \cos (\omega t)-R_{\max } \operatorname{sen}(\omega t)(\omega+\dot{\omega} t)^{2}-
\end{array}\right.
\end{gathered}
$$


A Equação (36) apresenta o rearranjo da Equação (29) que representa a dinâmica do sistema. Em conjunto à Equação (33) têm-se todas as informações para aplicação da Equação (8) que gera a ação de controle do controlador Udwadia-Kalaba.

$$
\left[M_{g}\right]\{\ddot{q}\}=\{F\}-\left[D_{g}+\Omega G_{g}\right]\{\dot{q}\}-\left[K_{g}\right]\{q\}=\{Q\}
$$

\subsection{Resultados}

A Figura 34 apresenta a resposta no mancal a um run-up de 0 a $20.000 \mathrm{rpm}$ em 40 segundos sobreposta pela resposta controlada. Percebe-se que no mancal o controlador aplicou exatamente a restrição imposta por toda a faixa do run-up em ambas as direções y e z.
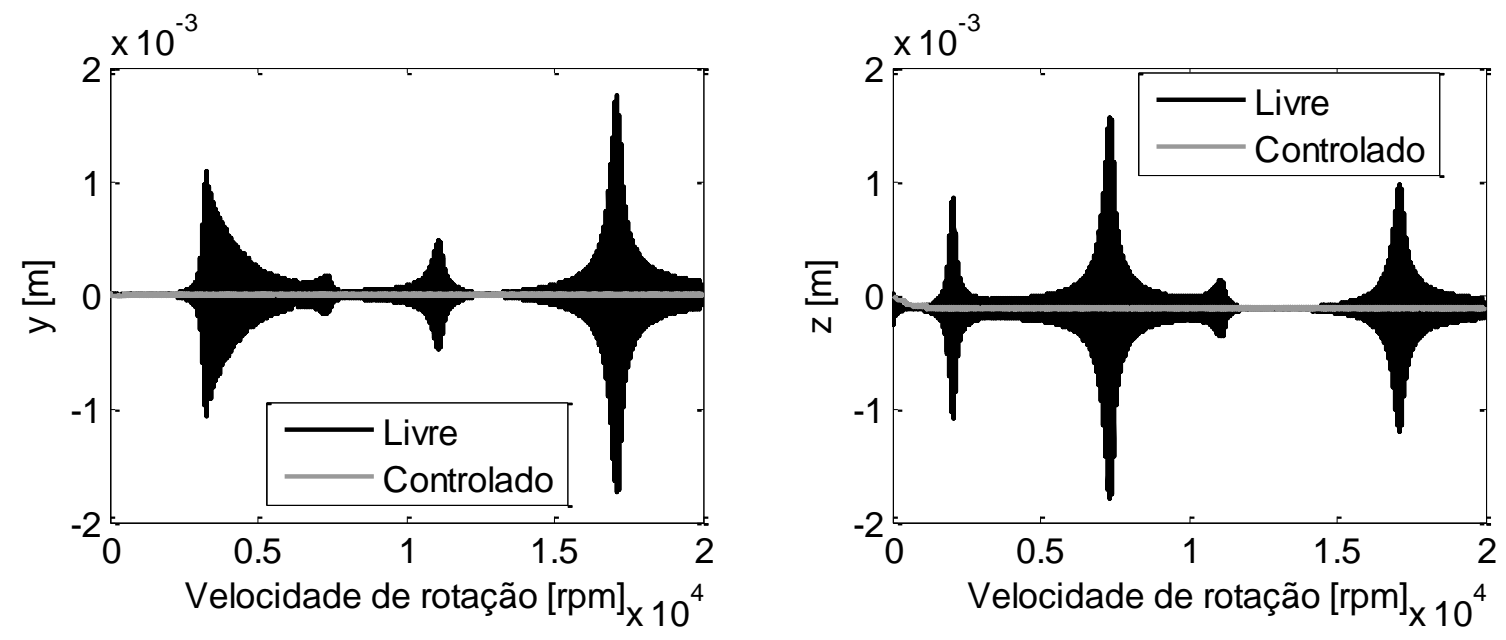

Figura 34 - Resposta vibratória do mancal nas direções y e z.
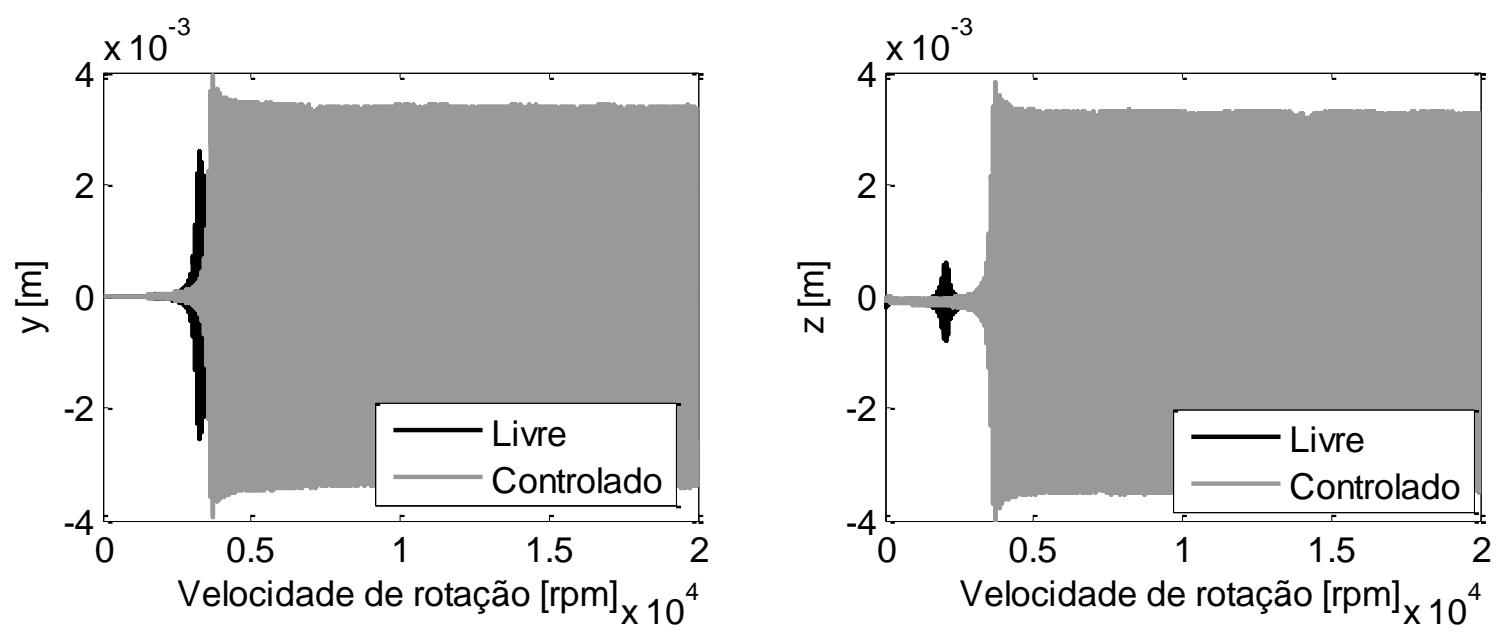

Figura 35 - Resposta vibratória do disco nas direções y e z.

Já na Figura 35 apresenta-se a resposta em y e z para o disco sobreposta pela resposta controlada. Por ela, percebe-se que atuação no mancal foi suficiente para atenuar as vibrações 
no disco até o início do segundo modo de vibrar, aos $3.260 \mathrm{rpm}$, entretanto elevou os níveis de vibração para rotações superiores.

Uma segunda tentativa para aumentar a faixa de rotação em que a resposta no disco é atenuada foi a de adicionar uma ação de torque no mancal, da mesma maneira como foram adotadas as restrições nas direções y e z, de tal forma que as restrições atuem em 4 direções no mancal. A resposta nestas 4 direções para o mancal é exibida na Figura 36, e por ela se o controlador funciona adequadamente em toda faixa de operação. Pela Figura 37 percebe-se que com a adição de uma atuação de torque no mancal aumentou de 3.260 para 5.000 rpm o limite em que o controlador consegue atenuar as vibrações no disco através das restrições aplicadas no mancal.
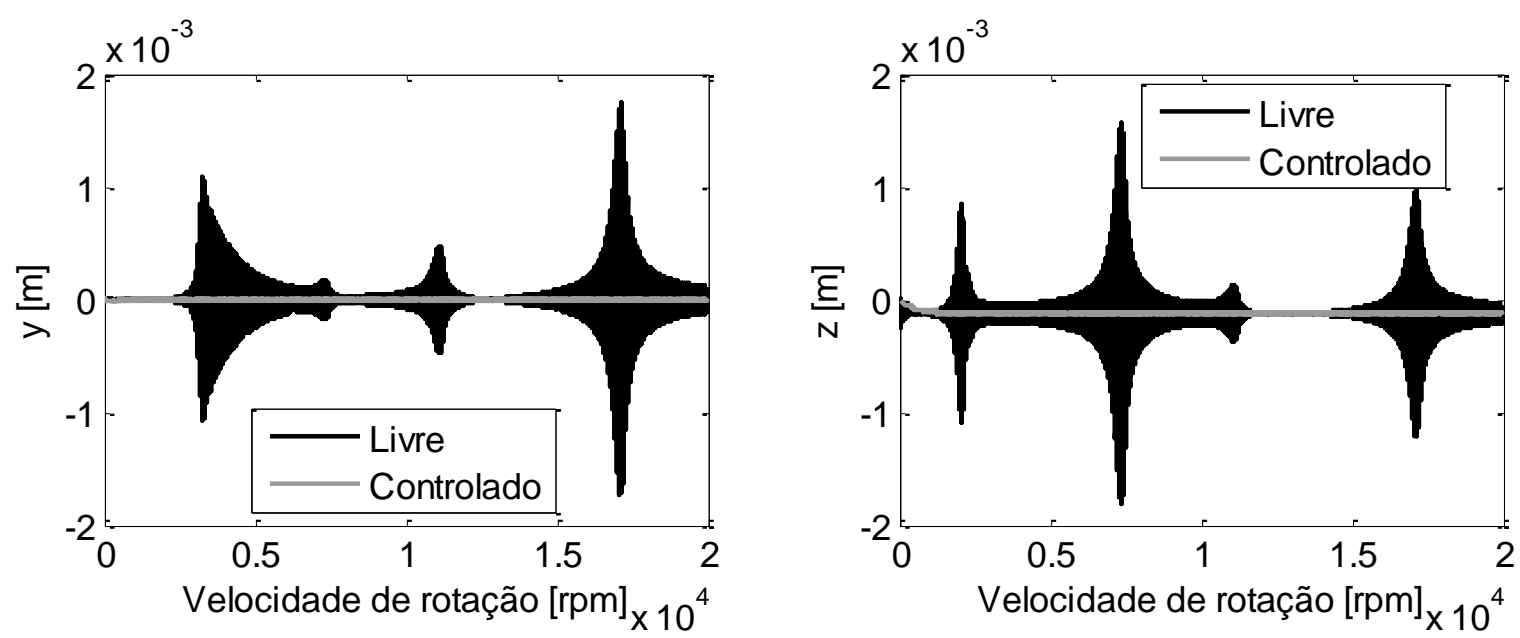

(a) Deslocamento linear
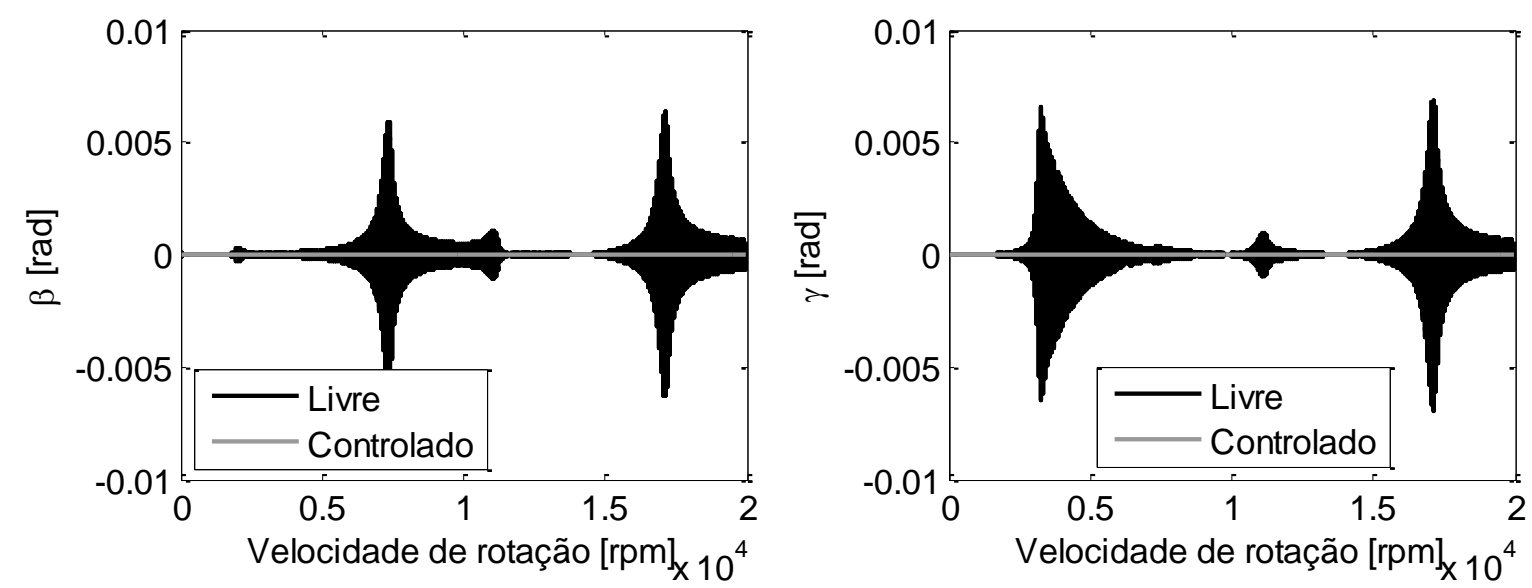

(b) Deslocamento angular

Figura 36 - Resposta vibratória no mancal aplicando atuação nas 4 direções. 

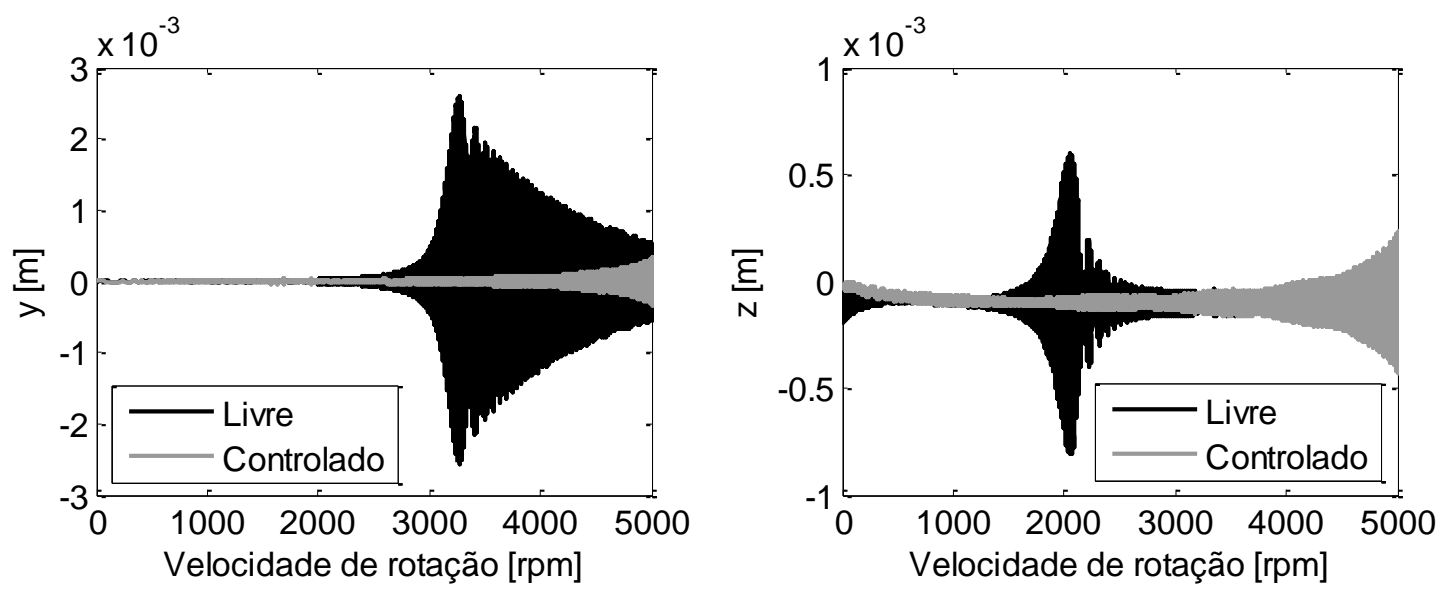

Figura 37 - Resposta vibratória do disco para as direções y e z até 5.000 rpm.

Para realizar o controle as forças e torques de atuação aplicados no mancal são apresentados na Figura 38 até a rotação de $5.000 \mathrm{rpm}$. Percebe-se que ao se aproximar da rotação que apresenta o limite da atenuação pelo controlador, as forças e torques envolvidos aumentam significativamente e estas atuações elevadas, que são exigidas para manter as restrições aplicadas no mancal, acabam produzindo o aumento das vibrações no disco.
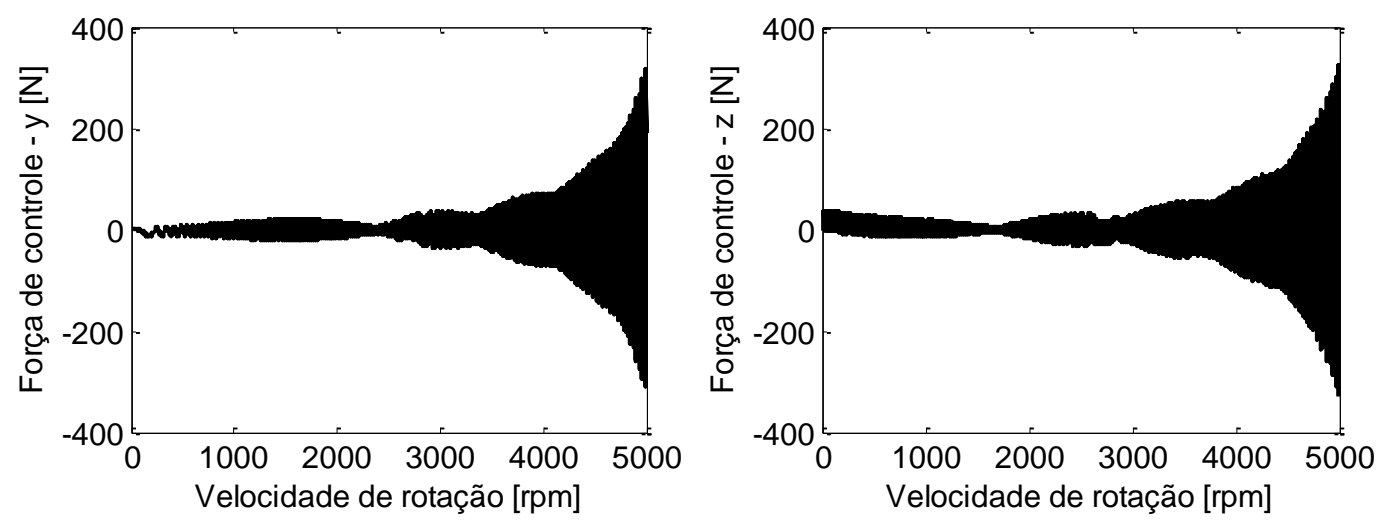

(c) Força de controle
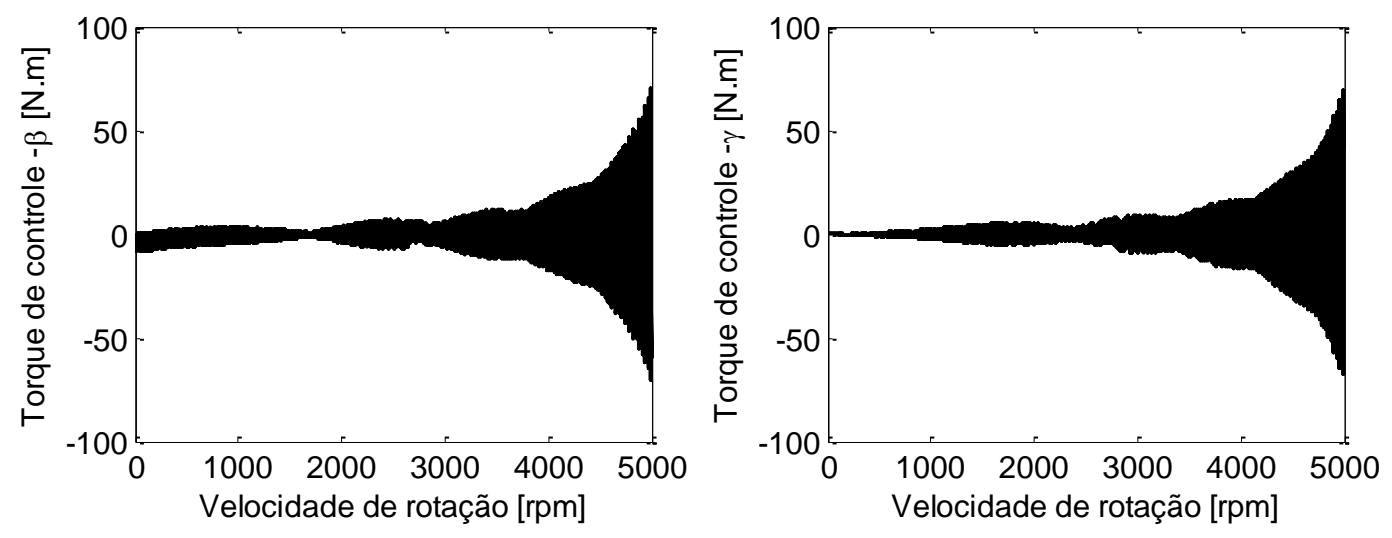

(d) Torque de controle

Figura 38 - Ação de controle nas 4 direções no mancal. 
Uma alternativa para entender o motivo de o controlador apresentar tal comportamento pode ser feita através de comparação dos modos de vibrar livres e controlados do sistema. A Figura 39 apresenta o $1^{\circ}$ modo de vibrar. Na posição $L=0 \mathrm{~m}$ encontra-se o primeiro nó do sistema, que apresenta restrição de translação nas direções y e z. A posição $L=0,4 \mathrm{~m}$ corresponde à posição do disco que pode se movimentar livremente e a posição $L=0,8 \mathrm{~m}$ se refere ao mancal, no qual a restrição é aplicada. Para o primeiro modo, percebese que o controlador realiza atenuação das vibrações sem alterar significativamente o modo de vibrar, principalmente na direção z.

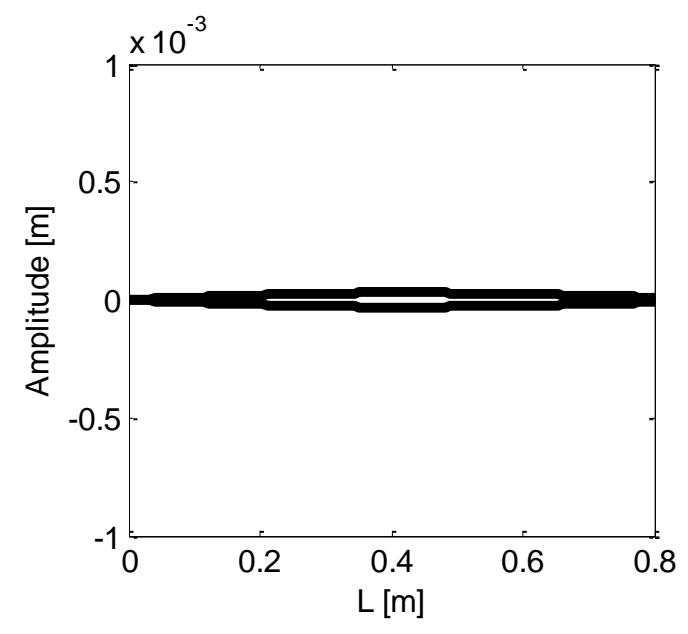

(a) $1^{\circ}$ Modo - Y

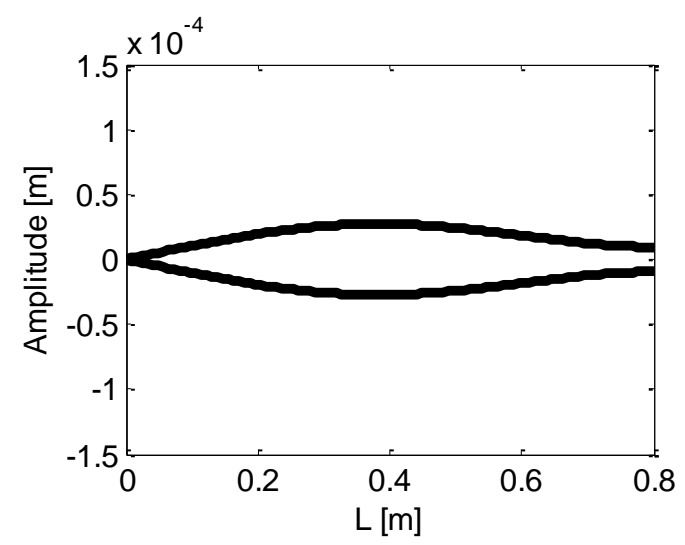

(c) $1^{\circ}$ Modo controlado $-\mathrm{Y}$

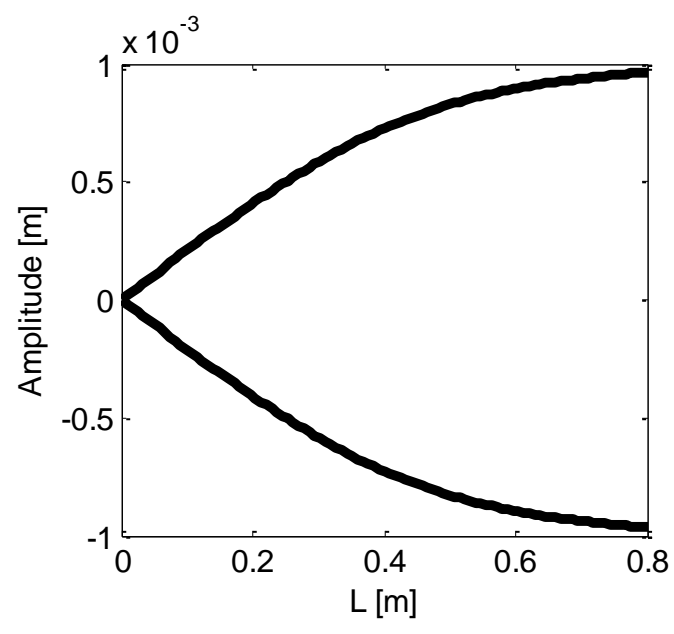

(b) $1^{\circ}$ Modo $-\mathrm{Z}$

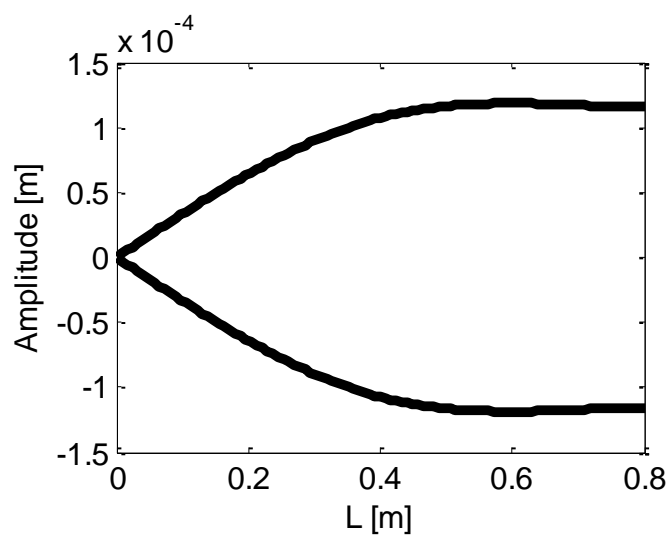

(d) $1^{\circ}$ Modo controlado $-\mathrm{Z}$

Figura $39-1^{\circ}$ modo de vibrar nas direções y e z nas condições livre e controlado. 


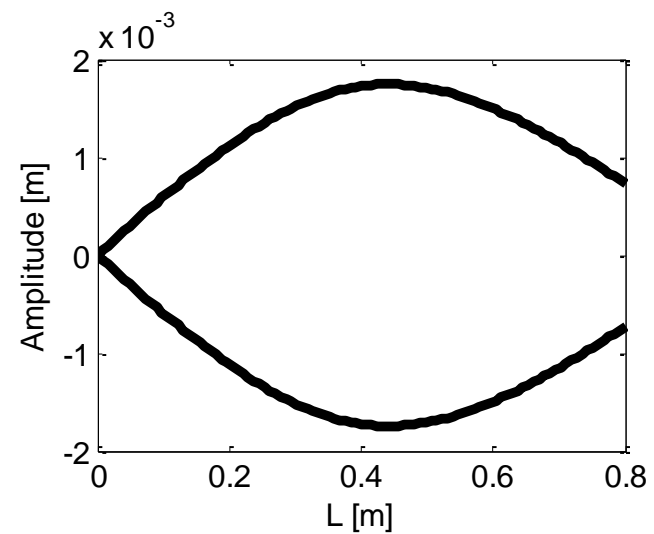

(a) $2^{\circ}$ Modo - Y

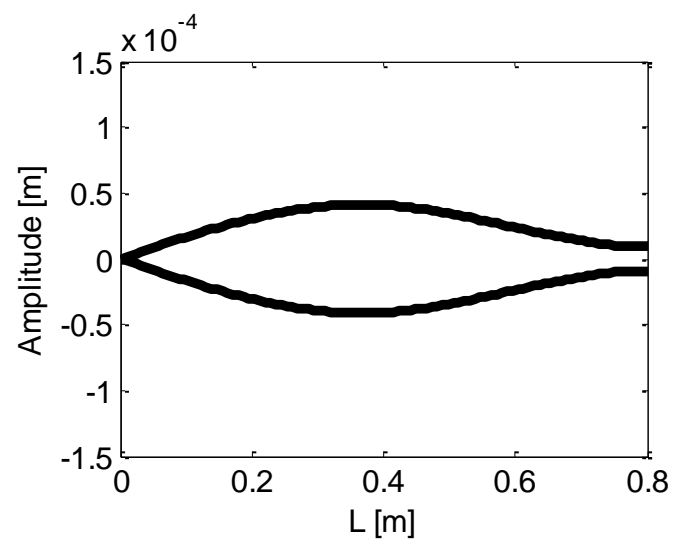

(c) $2^{\circ}$ Modo controlado $-\mathrm{Y}$

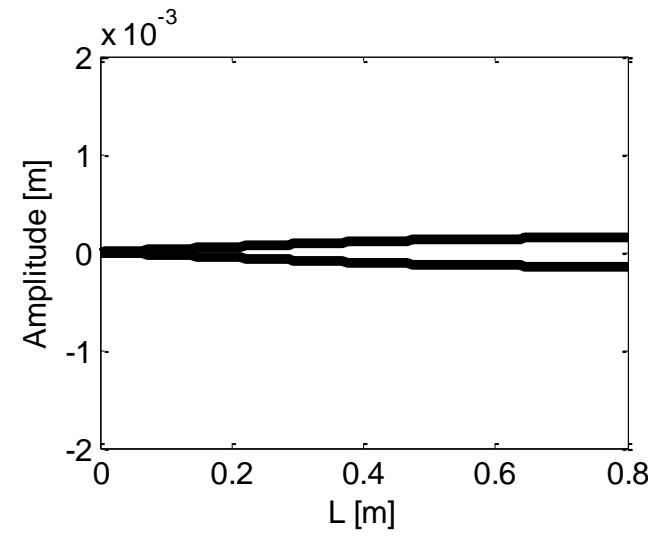

(b) $2^{\circ}$ Modo $-\mathrm{Z}$

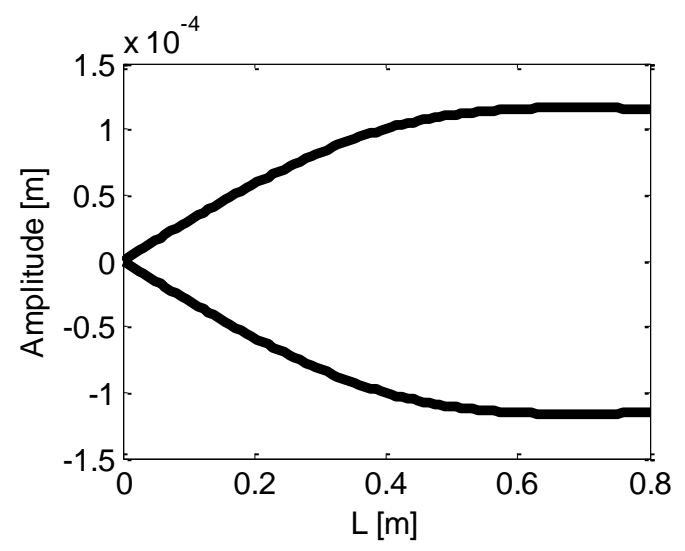

(d) $2^{\circ}$ Modo controlado $-\mathrm{Z}$

Figura 40 - $2^{\circ}$ modo de vibrar nas direções y e z nas condições livre e controlado.

No segundo modo, Figura 40, é possível observar uma redução acentuada na amplitude de vibração na direção y, enquanto z se mantem em níveis similares. No entanto, é interessante observar a condição de engaste sendo aplicada em $L=0,8 \mathrm{~m}$, posição do mancal. 


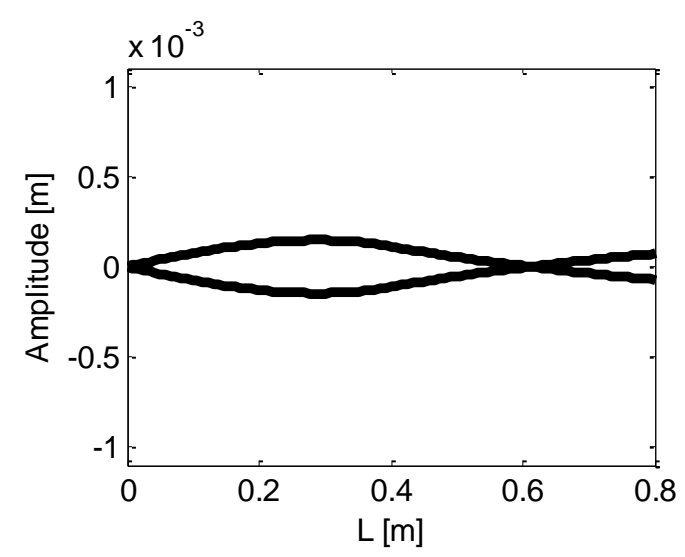

(a) $3^{\circ}$ Modo - Y

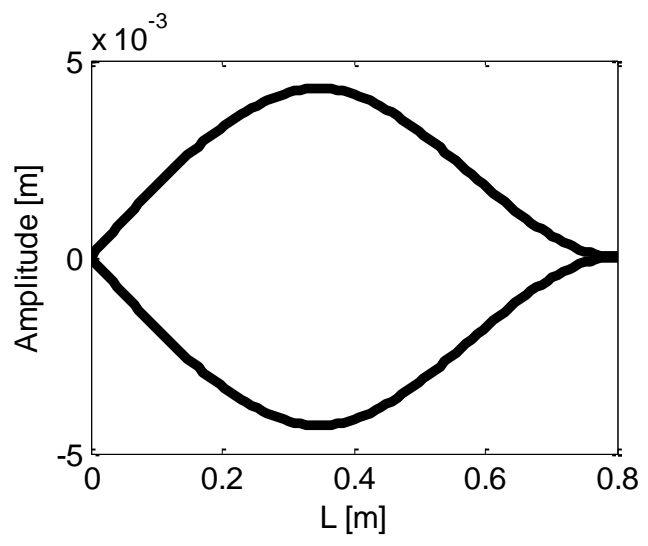

(c) $3^{\circ}$ Modo controlado - Y

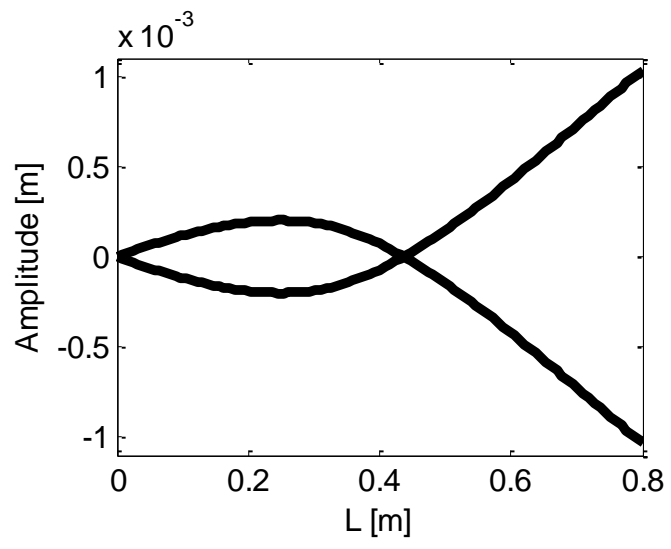

(b) $3^{\circ}$ Modo $-\mathrm{Z}$

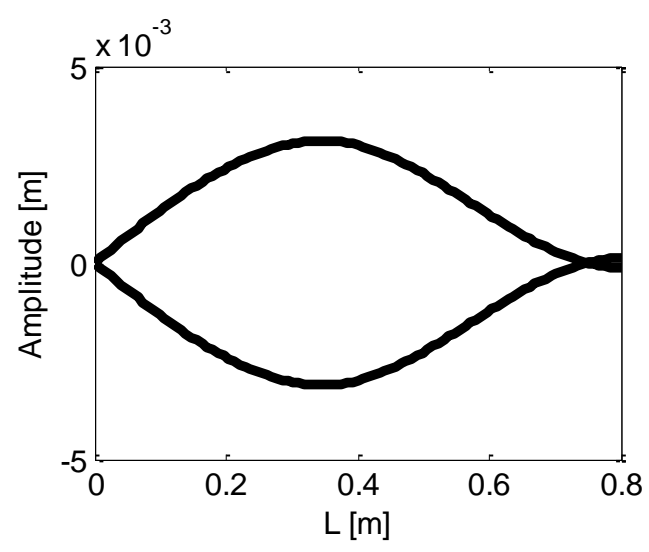

(d) $3^{\circ}$ Modo controlado $-\mathrm{Z}$

Figura $41-3^{\circ}$ modo de vibrar nas direções y e z nas condições livre e controlado.

Pelo terceiro modo de vibrar, Figura 41, nota-se uma diferença drástica entre os modos de vibrar da estrutura sem controle e com controle. Na situação controlada, as amplitudes de vibração são significativamente maiores.

A partir desta avaliação, pode-se afirmar que o controlador Udwadia-Kalaba não está de fato aplicando um controle, mas sim alterando a condição de contorno do sistema, provocando uma condição de engaste no mancal, aumentando a rigidez equivalente do sistema e consequentemente afastando frequências críticas. Isto pode ser visto pelo fato da estrutura livre já estar em um $3^{\circ}$ modo de vibrar, enquanto que na situação controlada, para a mesma rotação, o sistema aparenta continuar no mesmo modo apresentado por rotações inferiores.

Este efeito também pode ser observado em modos de vibrar superiores, conforme mostrado na Figura 42 e Figura 43. 


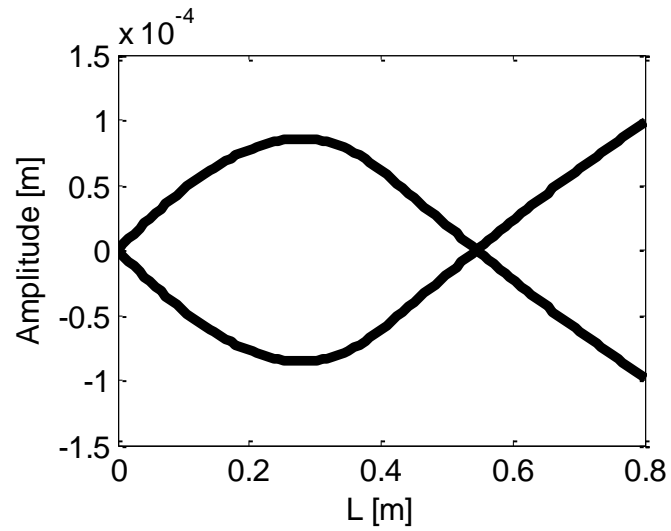

(a) $4^{\circ}$ Modo $-\mathrm{Y}$

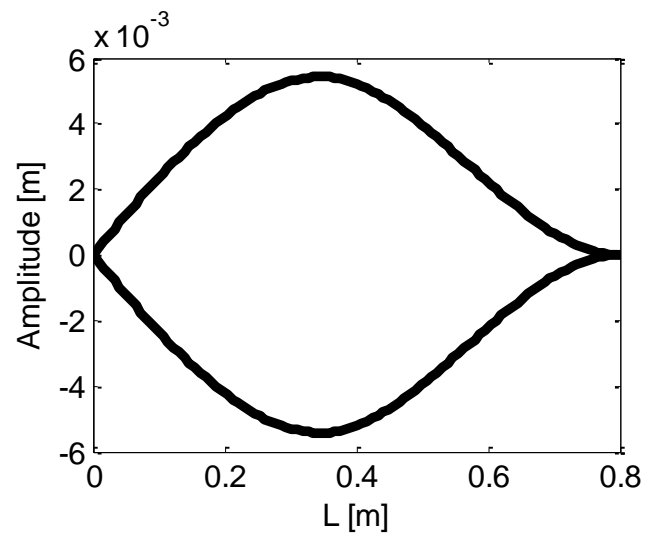

(c) $4^{\circ}$ Modo controlado - Y

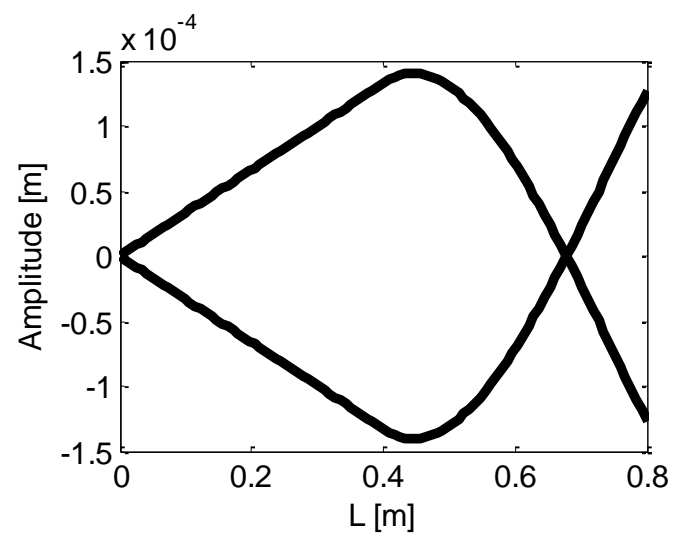

(b) $4^{\circ}$ Modo $-\mathrm{Z}$

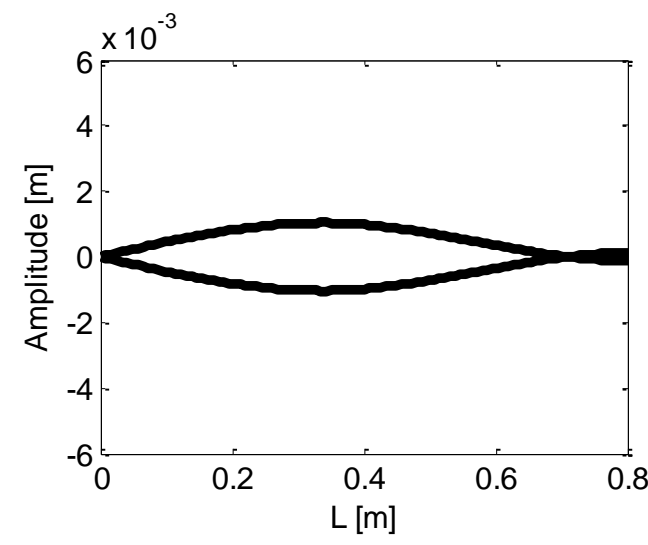

(d) $4^{\circ}$ Modo controlado $-\mathrm{Z}$

Figura $42-4^{\circ}$ modo de vibrar nas direções y e z nas condições livre e controlado.

Do ponto de vista prático, em que a atuação de controle é feita nos mancais, a técnica aqui avaliada não apresenta a melhor solução para um problema que envolve mais graus de liberdade. Isto porque o controle de vibração, nos graus de liberdade desejados, deve ser realizado de forma indireta, através do controle dos graus de liberdade do mancal, o que consequentemente acarreta na alteração das condições de contorno no mancal. Em outras palavras, o controlador Udwadia-Kalaba impõe no sistema uma condição de contorno no ponto de aplicação das forças de controle. Assim, a alteração das condições de contorno somente trará benefício para determinados pontos da estrutura em determinadas faixas de operação. 


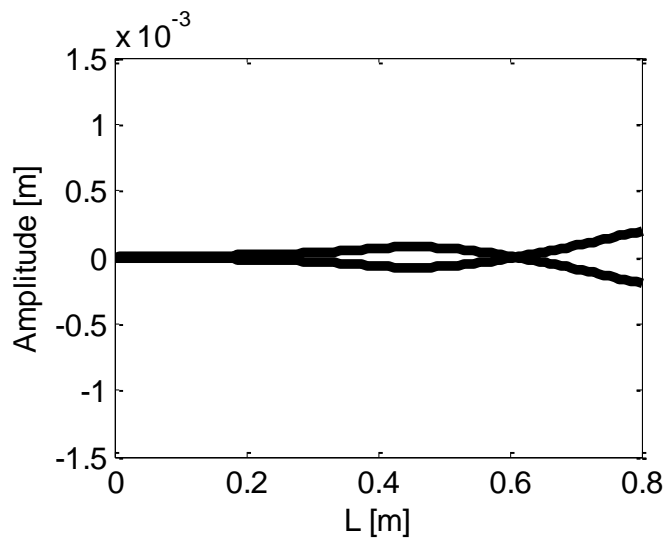

(a) $5^{\circ}$ Modo $-\mathrm{Y}$

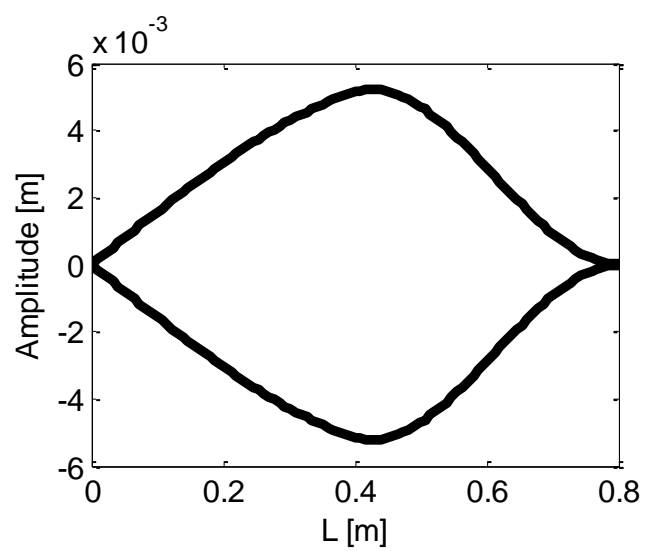

(c) $5^{\circ}$ Modo controlado - Y

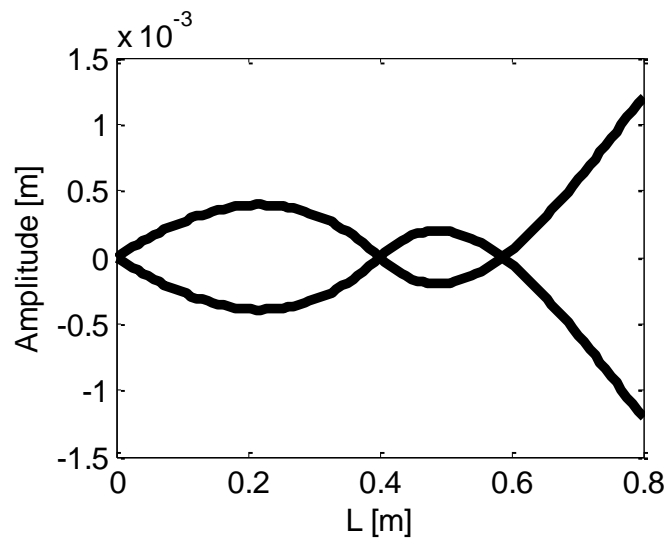

(b) $5^{\circ}$ Modo $-\mathrm{Z}$

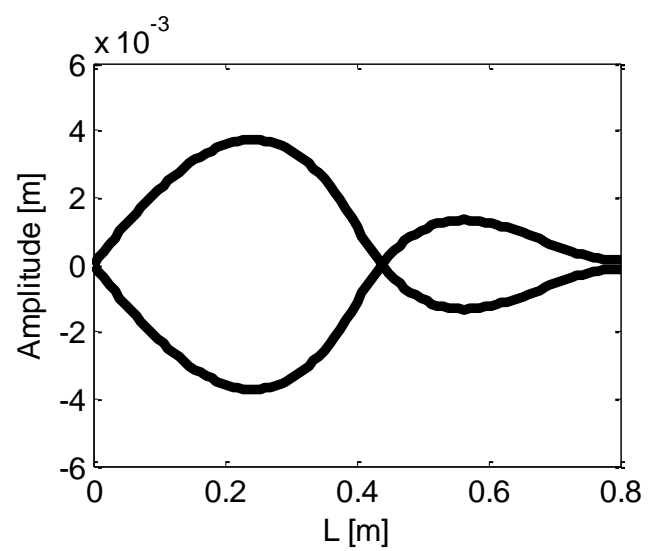

(d) $5^{\circ}$ Modo controlado $-\mathrm{Z}$

Figura $43-5^{\circ}$ modo de vibrar nas direções y e z nas condições livre e controlado. 


\section{Capítulo 6}

\section{Exemplo de Aplicação}

No capítulo 4 o comportamento e desempenho do controlador Udwadia-Kalaba foi avaliado para sistemas rotativos com poucos graus de liberdade e tendo em vista as conclusões retiradas do capítulo 5, a aplicação da técnica obteve melhores resultados em sistemas mais simples.

Neste capítulo um exemplo de aplicação da técnica é apresentado para um modelo que considera o eixo rígido, que, como consequência, apresenta a mesma amplitude de vibração por toda sua extensão. Desta maneira, o controlador Udwadia-Kalaba pode ser aplicado no mancal do sistema, pois a amplitude de vibração controlada no mancal será diretamente proporcional à amplitude de vibração na posição do disco, eliminando o problema visto no capítulo anterior.

Primeiramente é realizada a modelagem de um mancal hidrodinâmico ativo realizada no Simulink®, que leva em consideração os 2 graus de liberdade do sistema, os deslocamentos em y e z. Posteriormente é apresentado o modelo dos atuadores eletromagnéticos localizados no mancal e responsáveis pela força de atuação do controlador. Na sequência, são exibidos os resultados obtidos pelo controlador e por fim uma avaliação da sensibilidade do controlador às variações no modelo da planta.

\subsection{Modelo do Mancal Hidrodinâmico}

O modelo de mancal hidrodinâmico utilizado neste trabalho foi realizado no Simulink ${ }^{\circledR}$ através da utilização de look-up tables que associam, primeiramente, a razão de excentricidade ao número de Sommerfeld do mancal. A razão de excentricidade é a razão entre a posição do eixo, em relação ao centro do mancal hidrodinâmico, e a folga do mancal, enquanto que o número de Sommerfeld é um valor adimensional que considera características geométricas e operacionais do mesmo. A partir do número de Sommerfeld, obtêm-se a rigidez e amortecimento equivalentes, novamente através de look-up tables, utilizando método de interpolação-extrapolação dos valores. O modelo de rigidez e amortecimento equivalentes é utilizado neste trabalho para evitar a integração da equação de Reynolds no perfil de óleo de 
do mancal simultaneamente a integração para obtenção da atuação de controle, o que dificultaria a aplicação do controlador em tempo real.

A associação entre excentricidade e número de Sommerfeld utilizada no modelo é apresentada na Figura 45, baseada em valores de um mancal hidrodinâmico real (SOMEYA, 1989), cuja configuração é representada na Figura 44, no qual a carga W é aplicada entre sapatas do mancal segmentado (load between pads). Já a Figura 46 apresenta a relação entre número de Sommerfeld e os coeficientes adimensionalizados de rigidez e amortecimento do mesmo. Para obtenção dos valores de rigidez e amortecimento dimensionais do mancal simulado neste trabalho, foi utilizado um valor de $212,45 \mathrm{~N}$ para a carga no mancal e de 500 $\mu \mathrm{m}$ de folga.

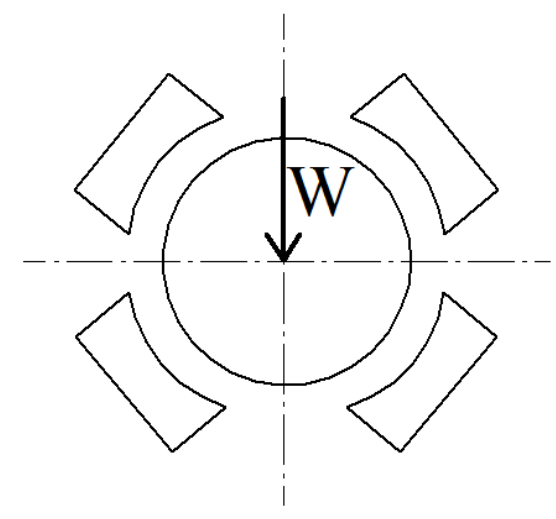

Figura 44 - Desenho esquemático do mancal hidrodinâmico segmentado.

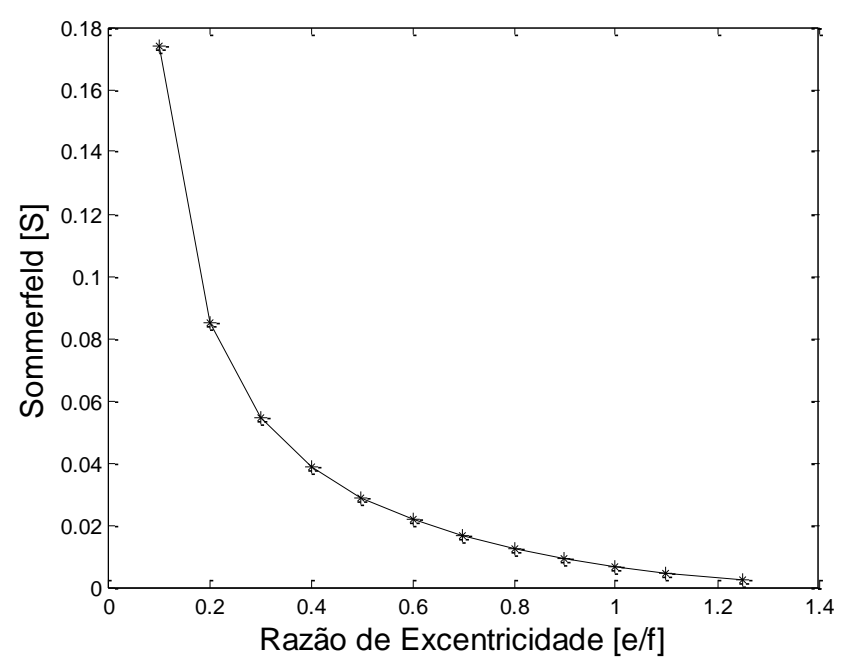

Figura 45 - Relação entre a razão de excentricidade e o número de Sommerfeld do mancal. 

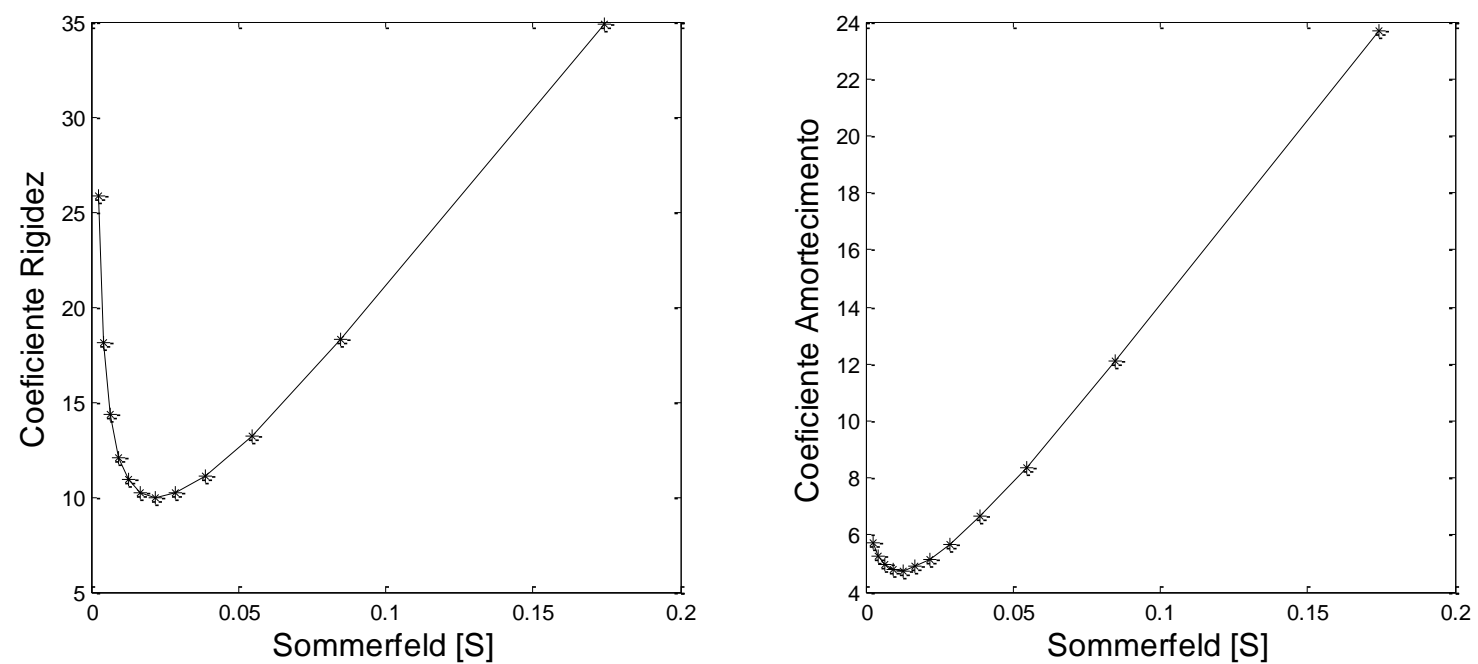

Figura 46 - Relação entre o número de Sommerfeld e rigidez e amortecimento do mancal.

\subsection{Atuador Eletromagnético}

Neste exemplo de aplicação o mancal hidrodinâmico apresenta 4 atuadores eletromagnéticos. A utilização de quatro atuadores é justificada pelo fato dos mesmos somente realizarem força de atração, tornando-se necessária a utilização de um par de atuadores para cada direção a ser controlada. A força eletromagnética em cada atuador é definida como uma função da corrente elétrica que passa pelo enrolamento e da distância entre eixo e atuador:

$$
F=K \frac{i^{2}}{d^{2}}
$$

onde $i$ é a corrente, $d$ a distância e $K$ uma constante de proporcionalidade do atuador.

Considera-se a corrente no enrolamento do atuador como uma função da tensão aplicada em seus terminais, segundo a Equação (38):

$$
i=\left(\frac{j \omega a_{1}+a_{0}}{j \omega b_{1}+b_{0}}\right) v
$$

onde $v$ é a voltagem aplicada no atuador, $b_{0}$ é a resistência elétrica do enrolamento e $b_{1}$ sua indutância. Os termos $a_{0}$ e $a_{1}$ são utilizados para ajustar o modelo, de tal forma que a força eletromagnética seja expressa na maneira da Equação (39). Vale destacar que $s=j \omega$ é a 
variável complexa associada à transformada de Laplace e que neste caso as tensões aplicadas nos enrolamentos devem estar entre -10 e $10 \mathrm{~V}$.

$$
F=\left(\frac{j \omega a_{1}+a_{0}}{j \omega b_{1}+b_{0}}\right)^{2} \frac{v^{2}}{d^{2}}
$$

Adotando os parâmetros da Tabela 6 para os quatro atuadores, a Figura 47 apresenta a magnitude e fase da força produzida pelo atuador para quatro sinais de tensão do tipo chirp de 5 a $50 \mathrm{~Hz}$, com intensidade de 2, 4, 6 e $8 \mathrm{~V}$. É importante ressaltar que esta modelagem é baseada no trabalho de Viveros e Nicoletti (2014), no qual o modelo foi validado experimentalmente com dados reais em bancada de testes.

Tabela 6 - Parâmetros do atuador.

\begin{tabular}{cc}
\hline Parâmetro & Valor \\
\hline$a_{0}$ & $4,91 \times 10^{-5}$ \\
$a_{1}$ & $5,33 \times 10^{-5}$ \\
$b_{0}$ & $2,6 \Omega$ \\
$b_{1}$ & $95 \mathrm{mH}$ \\
\hline
\end{tabular}
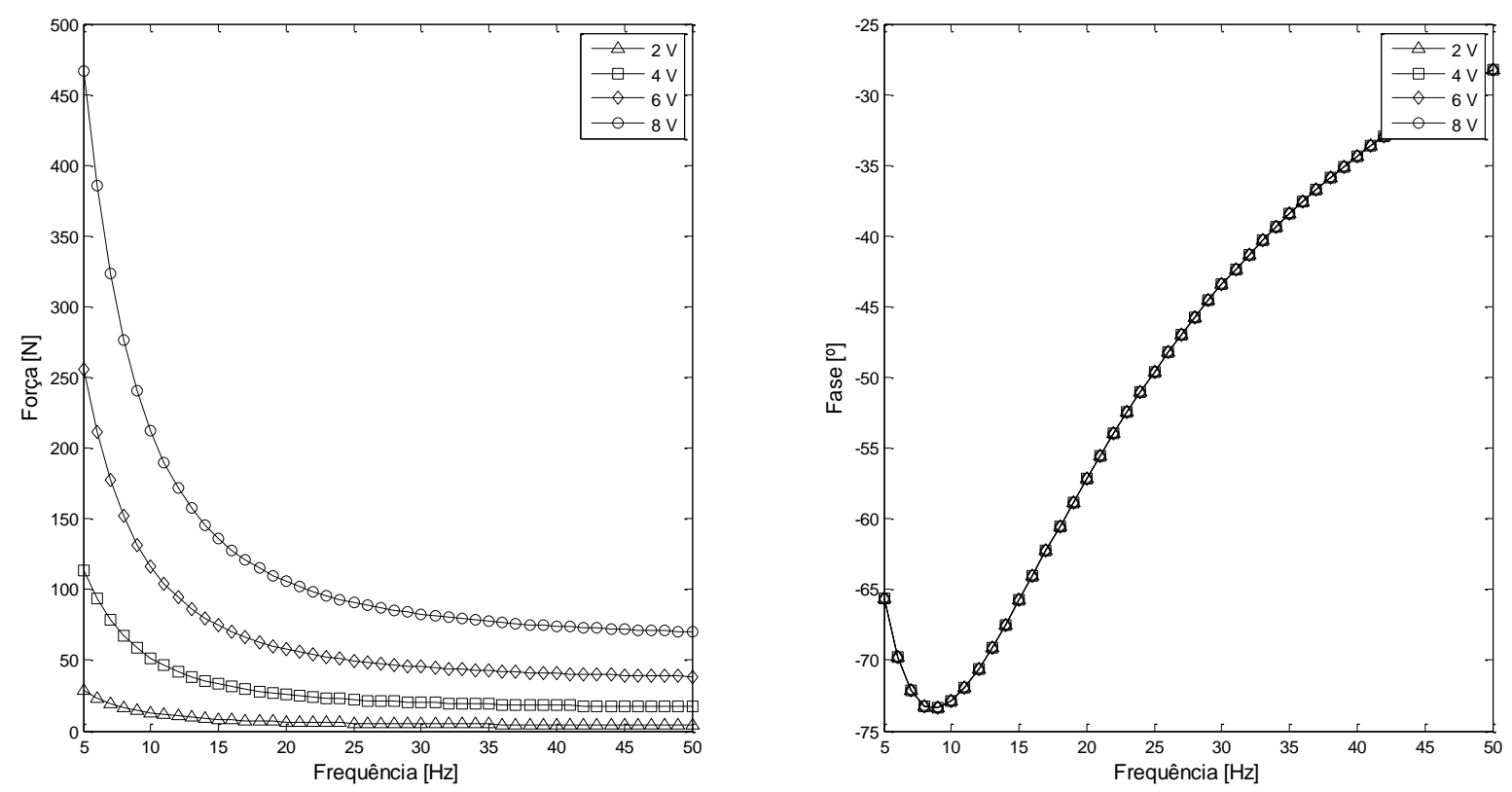

Figura 47 - Magnitude e fase da força eletromagnética do atuador.

Pela Figura 47 se observa uma queda rápida na magnitude da força com o aumento da frequência, até atingir certa estabilização em frequências mais altas. Vale destacar que a queda na magnitude da força é mais acentuada em situações com maior nível de tensão 
aplicada. Verifica-se também que o modelo não apresenta alteração de fase em função de variação na tensão aplicada.

Do ponto de vista do controlador Udwadia-Kalaba, a força de controle produzida, expressa pela Equação (8), não permite a inclusão do modelo do atuador, sendo assim necessária a realização de um modelo inverso do atuador, de tal forma que as entradas correspondam às forças em y e z, determinadas pelo controlador, e as distâncias em y e z do eixo aos atuadores, obtendo como saída os quatro sinais de voltagem a serem aplicados nos atuadores. A Figura 48 apresenta o diagrama de blocos do modelo inverso dos quatro atuadores.

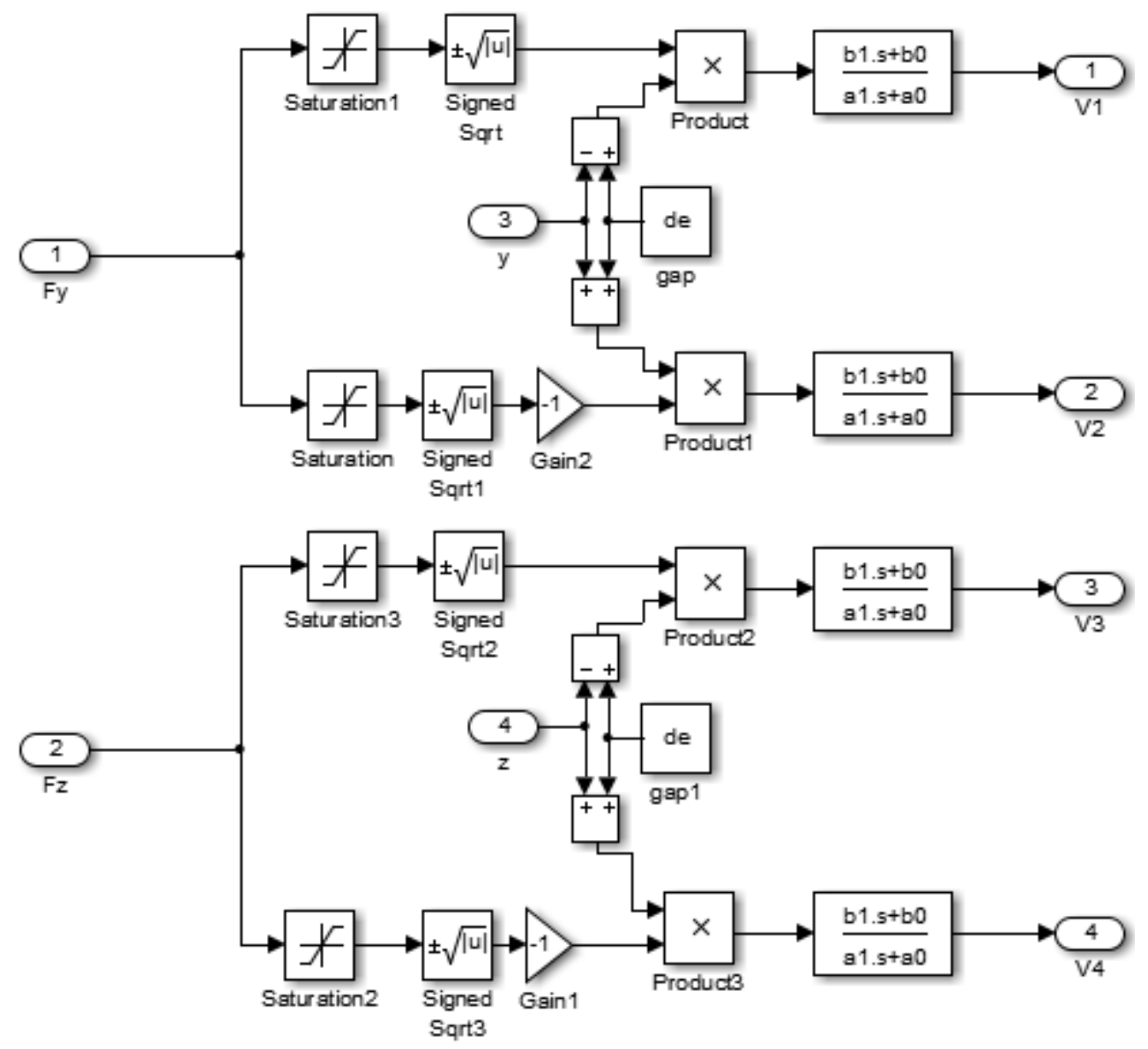

Figura 48 - Diagrama de blocos no Simulink® do atuador inverso.

O diagrama exibido na Figura 48 executa a separação da força de atuação, para ambas as direções, em dois sinais de força, um positivo e um negativo. Cada atuador fica responsável por aplicar um destes sinais de força, de acordo com o seu posicionamento. A Equação (40) representa o funcionamento do diagrama: 


$$
v_{i}= \pm\left(\frac{j \omega b_{1}+b_{0}}{j \omega a_{1}+a_{0}}\right)(d \pm \delta) \sqrt{F_{i}}
$$

onde $d$ representa a distância nominal fixa entre o eixo e o atuador e $\delta$ corresponde ao deslocamento na direção de atuação do atuador. Os sinais de positivo e negativo da equação são referentes ao posicionamento dos atuadores e determinados de acordo a orientação do sistema de coordenadas, de tal maneira que um deslocamento positivo em z, por exemplo, deve resultar em uma diminuição na distância entre eixo e o atuador superior enquanto que a distância entre eixo e atuador inferior seja aumentada.

\subsection{Resultados}

Os resultados apresentados nesta seção foram obtidos seguindo a mesma metodologia do controlador Udwadia-Kalaba apresentada no capítulo 4, definindo agora uma amplitude de vibração desejada em $R_{\max }=10^{-6} \mathrm{~m}$.

Considerando as limitações de aplicação de tensão nos atuadores entre -10 e $10 \mathrm{~V}$, a resposta em y e z é apresentada na Figura 49 para um run-up do sistema até 18.000 rpm, nas situações livre e controlada, levando em consideração um excitação de desbalanço de 300 g.mm em um disco de $2,5 \mathrm{~kg}$.
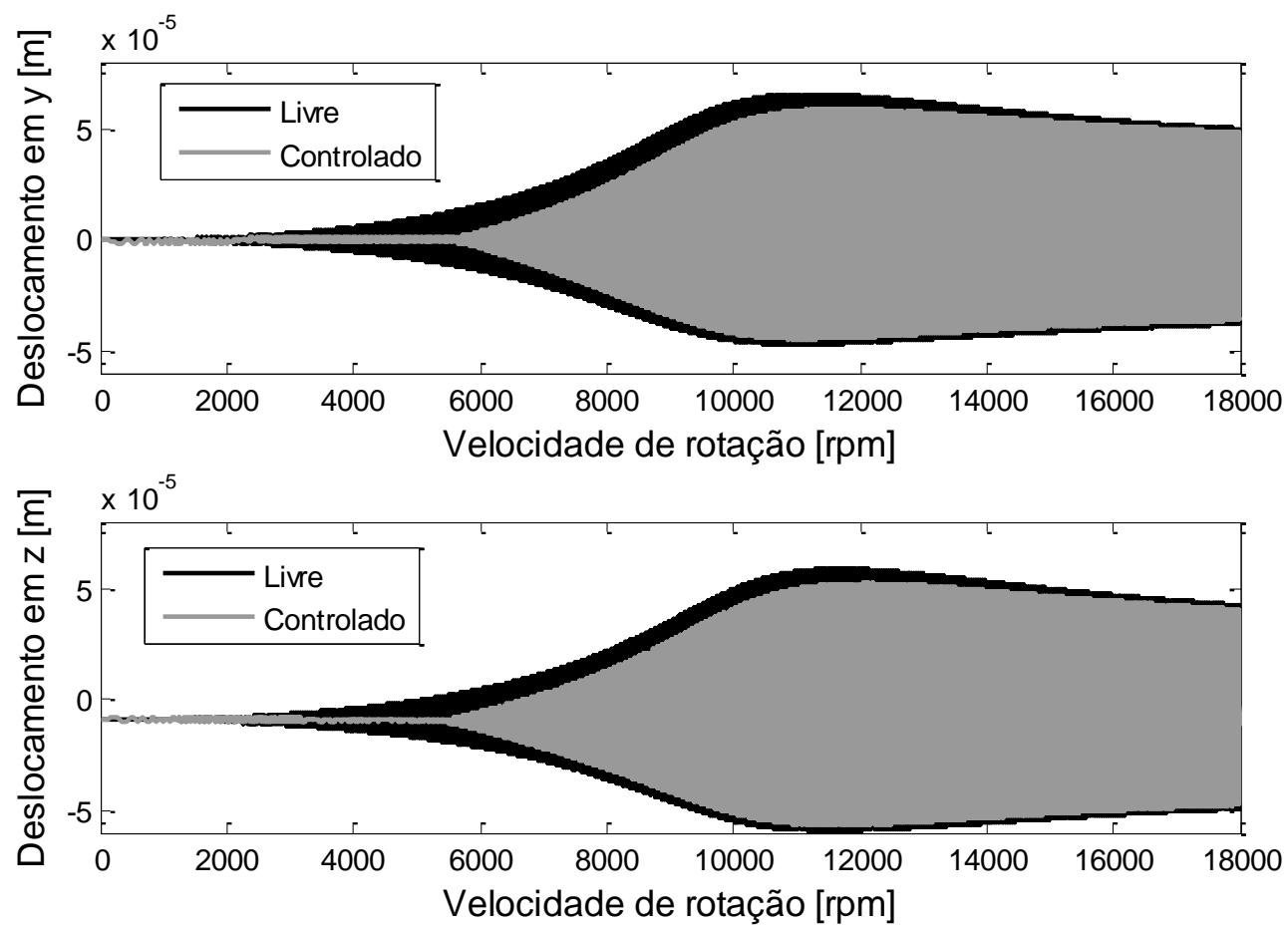

Figura 49 - Resposta do eixo rígido em run-up para ambas as direções, nas condições livre e controlada. 
Pela Figura 49 se observa que o controlador realiza a aplicação da restrição até cerca de $5.500 \mathrm{rpm}$. A partir deste instante, as limitações de tensão nos atuadores começam a comprometer o desempenho do controlador, que apresenta uma redução na amplitude de vibração de somente $11 \%$ na ressonância. A tensão aplicada nos atuadores é exibida na Figura 50, na qual se percebe as limitações de voltagem se iniciando por volta dos $5.000 \mathrm{rpm}$ para valores positivos de tensão nos atuadores e a partir de $10.000 \mathrm{rpm}$ para valores negativos. Já a Figura 51 apresenta a corrente aplicada nos atuadores, obtidas a partir do sinal de tensão.
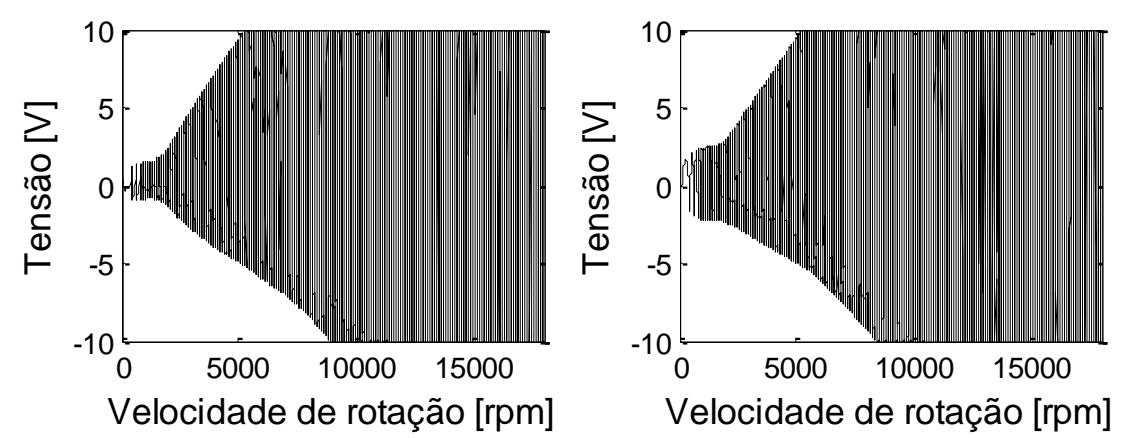

(a) Tensão no atuador $1 \mathrm{em} \mathrm{Y}$

(b) Tensão no atuador 2 em Y
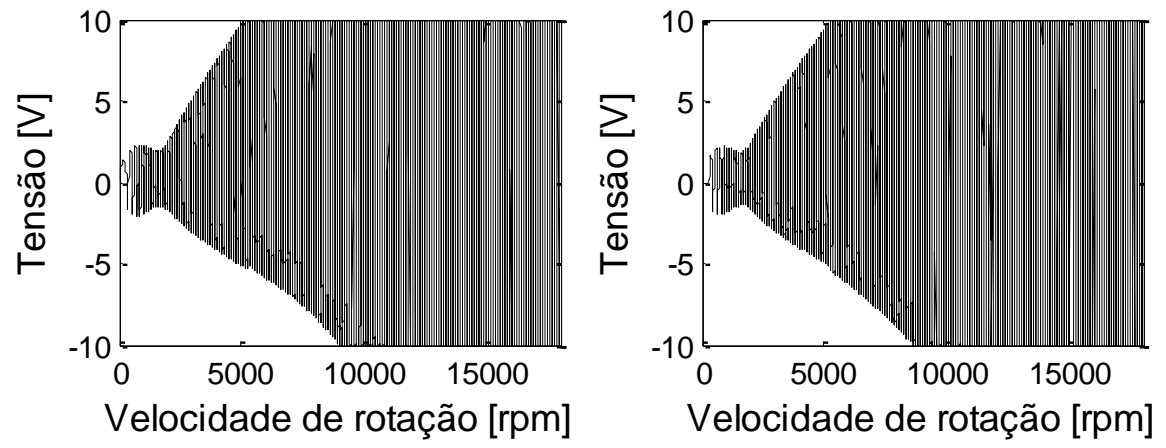

(c) Tensão no atuador $3 \mathrm{em} \mathrm{Z}$

(d) Tensão no atuador $4 \mathrm{em} \mathrm{Z}$

Figura 50 - Tensão elétrica nos quatro atuadores.

Com tensão e corrente é possível obter a potência consumida em cada atuador, exibida na Figura 52. Por ela observa-se o pico de potência ocorrendo em todos os atuadores por volta da rotação em que ocorre saturação do valor de tensão disponível, $5.000 \mathrm{rpm}$. Com a saturação ocorrendo para valores positivos de tensão, a corrente, e consequentemente a potência consumida, diminui, até a velocidade de rotação de $10.000 \mathrm{rpm}$, situação em que os valores negativos de tensão nos atuadores começam a saturar. Vale ressaltar que os baixos valores de potência observados são resultado da baixa corrente associada aos sinais de tensão aplicados nos atuadores. 

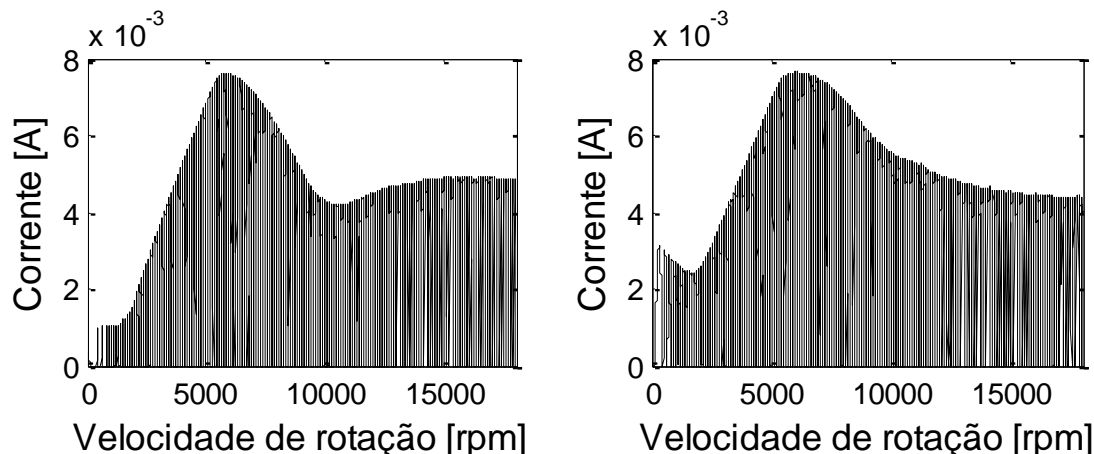

(a) Corrente no atuador $1 \mathrm{em} \mathrm{Y}$

(b) Corrente no atuador $2 \mathrm{em} \mathrm{Y}$

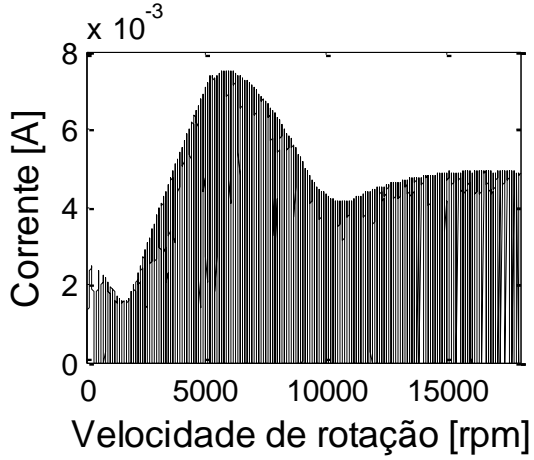

(c) Corrente no atuador $3 \mathrm{em} \mathrm{Z}$

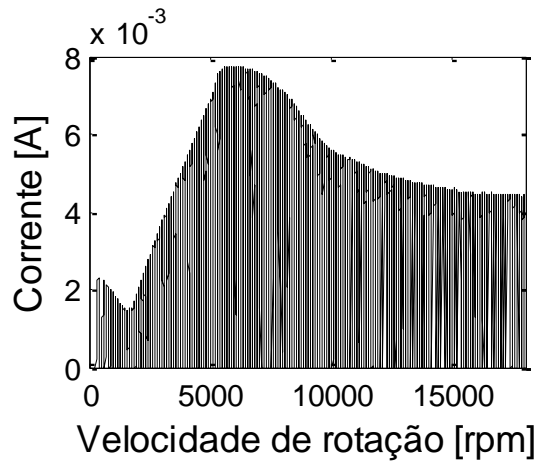

(d) Corrente no atuador $4 \mathrm{em} \mathrm{Z}$

Figura 51 - Corrente aplicada nos quatro atuadores.

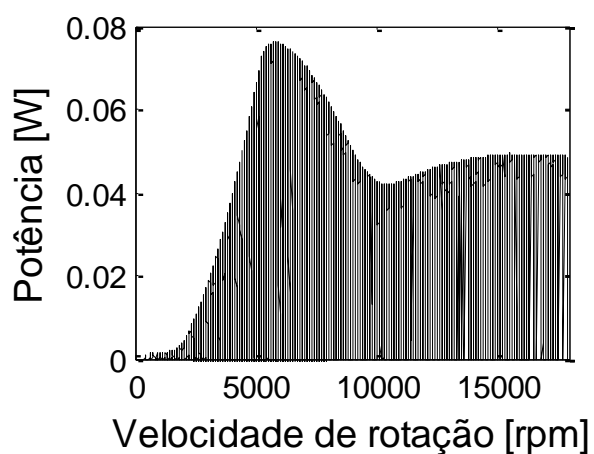

(a) Potência no atuador $1 \mathrm{em} \mathrm{Y}$

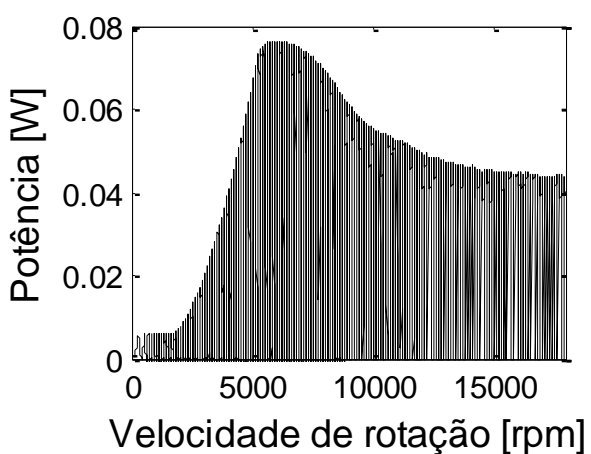

(b) Potência no atuador $2 \mathrm{em} \mathrm{Y}$

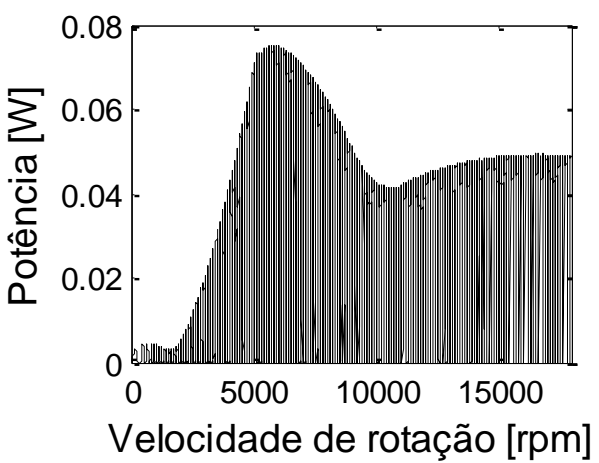

(c) Potência no atuador $3 \mathrm{em} \mathrm{Z}$

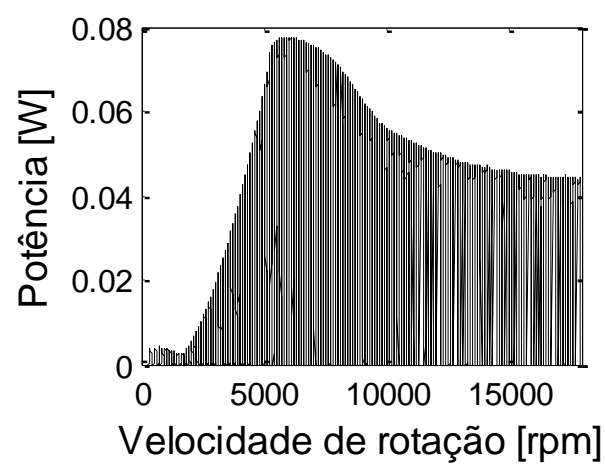

(d) Potência no atuador $4 \mathrm{em} \mathrm{Z}$

Figura 52 - Potência consumida pelos atuadores. 


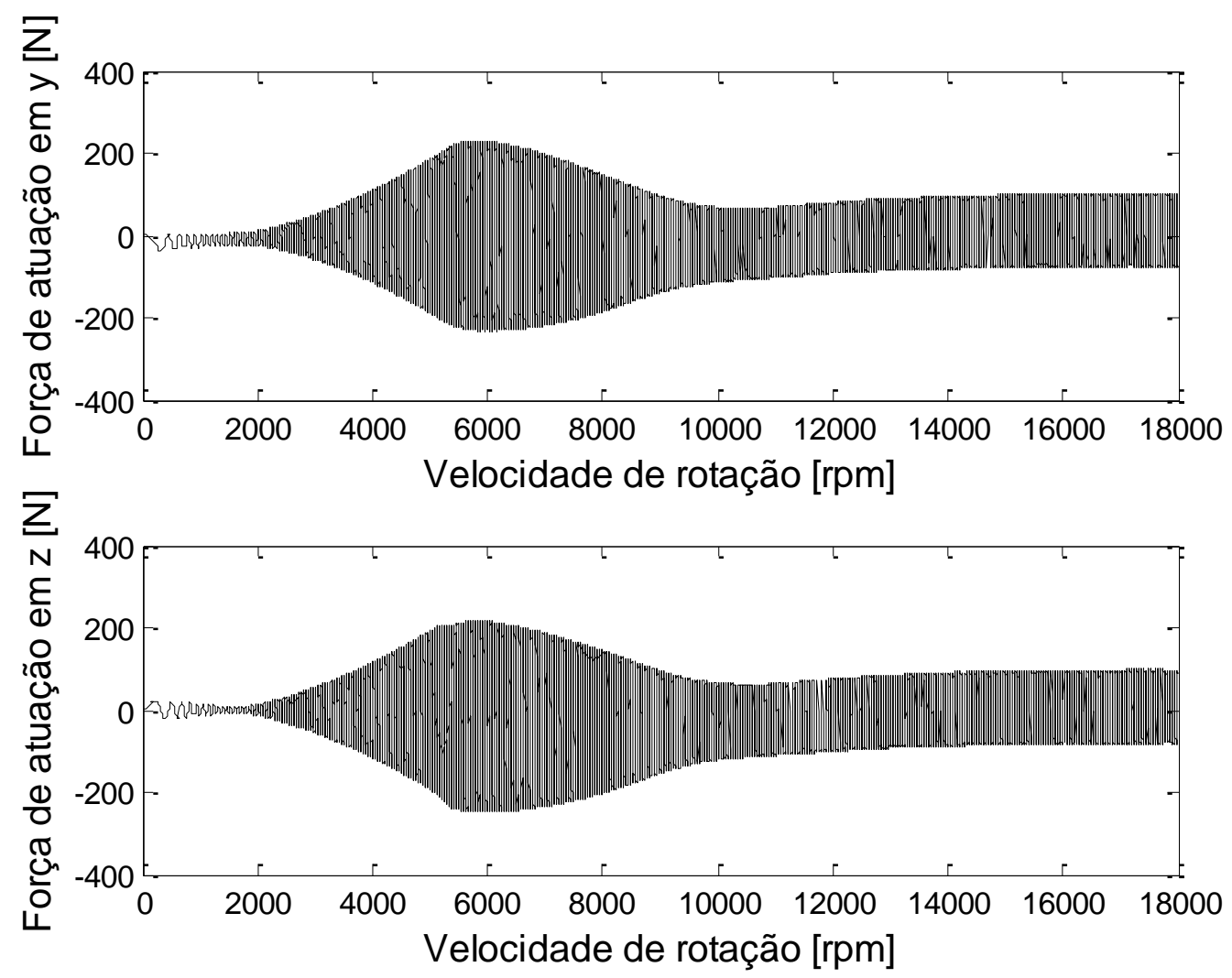

Figura 53 - Força de atuação produzida pelos atuadores eletromagnéticos.

Pela Figura 53 se percebe que a limitação de tensão nos atuadores, que começa a ocorrer por volta dos $5.500 \mathrm{rpm}$, resulta na diminuição da força de atuação produzida para rotações superiores até certo ponto em que ocorre estabilização. Isto se dá pelo comportamento do atuador demonstrado na Figura 47.

Realizando agora um cenário hipotético, em que os atuadores não possuam limitações, o controlador exibe o mesmo comportamento obtido no capítulo 4, como esperado, na Figura 54. Neste caso, entretanto, a tensão elétrica nos atuadores é bastante superior ao limite de $10 \mathrm{~V}$ imposto pelo sistema de medição e controle. 

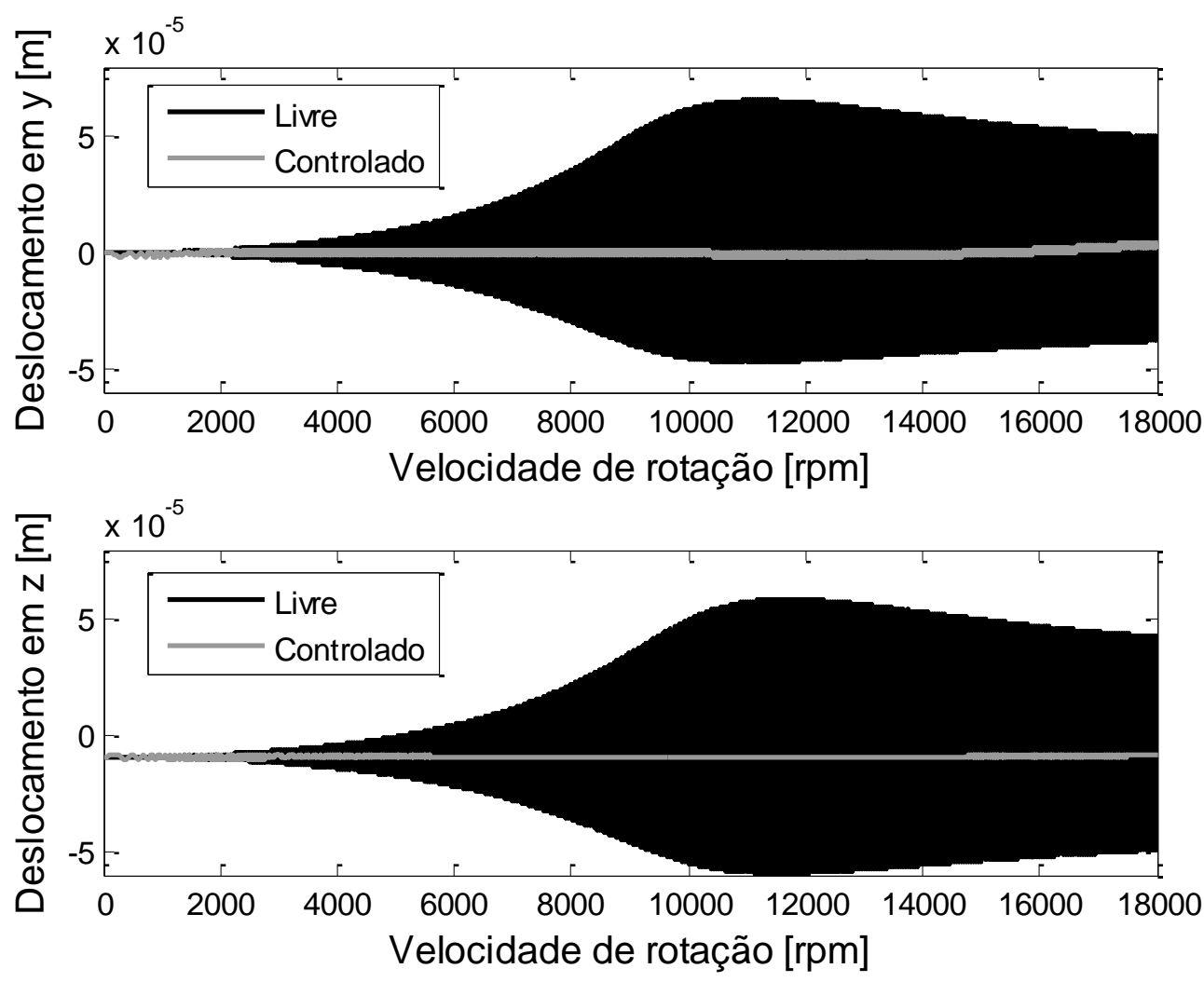

Figura 54 - Resposta do eixo rígido em run-up para ambas as direções, nas condições livre e controlada, sem limitações do atuador. 


\section{Capítulo 7}

\section{Conclusões}

A avaliação do comportamento e desempenho da técnica de controle ativo proposta por Udwadia-Kalaba foi realizada no âmbito da redução de vibrações em sistemas rotativos. Inicialmente as características e metodologia da técnica desenvolvida por Udwadia-Kalaba foi apresentada e mostrou-se ser uma maneira simples e prática de realizar a modelagem de sistemas multicorpos que possuem algum tipo de restrição cinemática, a qual foi estendida para uma aplicação em controle de trajetória de sistemas não lineares.

$\mathrm{Na}$ sequência, em uma primeira abordagem, a técnica foi empregada em sistemas rotativos mais simples, com poucos graus de liberdade, e comparada a técnicas mais usuais, como o controle PID e LQR. Os resultados se mostraram satisfatórios no sentido da redução da amplitude de vibração do modelo por toda a faixa de rotação avaliada. A intensidade de atuação necessária para obtenção desta redução foi muito similar àquela produzida pelo controlador PID, porém quando comparada aos resultados obtidos pelo controlador LQR, este leva vantagem em termos de custo energético. Do ponto de vista da aplicação da restrição cinemática imposta pelo controlador, e consequentemente a adequação a trajetória desejada, o controlador Udwadia-Kalaba apresentou os melhores resultados.

A evolução do trabalho consistiu na investigação da aplicação da técnica em sistemas rotativos mais complexos, com um número maior de graus de liberdade. Nesta situação, a aplicação do controlador foi realizada nos graus de liberdade do mancal do sistema, em uma aplicação em eixo flexível. Para garantir a atuação no mancal do sistema, foi necessário definir as restrições cinemáticas nos próprios graus de liberdade do mancal, o que resultou em um controlador que na realidade está efetuando uma alteração nas condições de contorno do sistema, e não de fato a aplicação de uma abordagem de controle convencional. Como resultado disto, a redução da amplitude de vibração do sistema, na posição do disco, ocorreu pelo fato do aumento da rigidez equivalente na posição do mancal, empurrando assim as frequências críticas para valores mais altos. A partir dos resultados exibidos no capítulo 5, foi possível observar que a aplicação desta metodologia em sistemas flexíveis com um número maior de graus de liberdade não representa a melhor abordagem de controle ativo de vibrações em sistemas rotativos flexíveis. 
Por fim, foi considerada uma aplicação que apresentou mais potencial, pelos resultados obtidos quando considerado sistemas mais simples com menos graus de liberdade. A abordagem consistiu na avaliação do emprego da técnica em questão para um sistema com eixo rígido suportado por um mancal hidrodinâmico que apresentava quatro atuadores eletromagnéticos. Os resultados apresentaram um bom desempenho do controlador, considerando as limitações apresentadas pelos atuadores, de tal forma que o sistema atendeu as imposições das restrições cinemáticas até o momento da ocorrência da saturação dos valores de tensão nos atuadores eletromagnéticos. Quando as limitações foram removidas, observou-se comportamento similar ao apresentado no capítulo 4, que tratava de sistemas com poucos graus de liberdade.

As principais limitações apresentadas no emprego do controlador Udwadia-Kalaba foram:

- a posição da aplicação da atuação de controle é diretamente relacionada às coordenadas que se deseja controlar, assim, para que a atuação seja realizada em um mancal, o controle deve aplicar as restrições cinemáticas no mesmo, dificultando a aplicação em sistemas com eixo flexível;

- o necessário conhecimento das forças externas atuando no sistema.

Como conclusão deste trabalho, é possível afirmar que a metodologia aqui avaliada é eficaz no âmbito de controle ativo de sistemas rotativos que apresentem eixos rígidos, de tal maneira que aplicação da atuação de controle nos mancais do sistema possa ser baseada em uma restrição cinemática imposta em outra posição do eixo, já que o eixo rígido vibra como um todo. Apesar dos resultados serem satisfatórios a aplicação em sistemas com eixo rígido, a sua aplicação em estruturas flexíveis está limitada a uma faixa restrita de operação, abaixo da segunda velocidade crítica do sistema.

\subsection{Trabalhos Futuros}

Algumas abordagens não adotadas neste trabalho ainda podem ser realizadas com intuito de avaliar minuciosamente à aplicação que se apresentou mais problemática, eixos flexíveis: 
- determinar a restrição no tempo que deve ser imposta aos graus de liberdade do mancal para que seja possível atenuar as vibrações em uma posição desejada do eixo. Para isto, é necessário investigar os modos de vibrar da estrutura e avaliar a possibilidade de aplicação de uma restrição cinemática variável no tempo;

- avaliação da robustez do controlador;

- validação experimental. 


\section{Referências Bibliográficas}

ADAMS, M. L., MCCLOSKEY, T. H. A feasibility and technology assesment for the implementation of active rotor vibration control systems in power plant rotating machinery. $3^{\text {rd }}$ Int. Conf. on Rotordynamics, 1990, Lyon. Proceedings... Lyon: Centre National de la Recherche Scientifique, p.327-332, 1990.

BARBARACI, G.; VIRZI' MARIOTTI, G. Performances Comparison for a Rotating Shaft Suspended by 4-Axis Radial Active Magnetic Bearings via $\mu$-Synthesis, Loop-Shaping Design, and $\mathrm{Sub}(\mathrm{H}) \infty$ with Uncertainties. Modelling and Simulation in Engineering, v. 2011, p. 1-10, 2011.

BURROWS, C. R.; KEOGH, P. S.; SAHINKAYA, M. N. Progress towards smart rotating machinery through the use of active bearings. Proceedings of the Institution of Mechanical Engineers, Part C: Journal of Mechanical Engineering Science, v. 223, n. 12, p. 28492859, 2009.

BUTTINI, T. M.; NICOLETTI, R. PD controller synthesis from open-loop response measurements of rotating system. Iet Control Theory and Applications, v. 6, n. 14, p. 22092215, 2012a.

BUTTINI, T. M.; NICOLETTI, R. Self identification algorithm for the autonomous control of rotating systems. 10th International Conference on Vibrations in Rotating Machinery, September 11, 2012 - September 13, 2012, 2012b, London, United kingdom. Woodhead Publishing Limited. p.389-397.

CHEN, X.; JI, L.; LIU, K. A BP neural network controller for Magnetic Suspended Flywheel System. 2010 3rd IEEE International Conference on Computer Science and Information Technology, ICCSIT 2010, July 9, 2010 - July 11, 2010, 2010, Chengdu, China. IEEE Computer Society. p.448-452.

CHILDS, D., Turbomachinery Rotordynamics: Phenomena, Modeling, and Analysis. New York: J. Wiley,1993.

CHO, H.; UDWADIA, F. E. Explicit control force and torque determination for satellite formation-keeping with attitude requirements. Journal of Guidance, Control, and Dynamics, 1801 Alexander Bell Drive, Suite 500, Reston, VA 20191-4344, United States, v. 36, n. 2, p. 589-605, 2013.

DAS, A. S.; DUTT, J. K.; RAY, K. Active control of coupled flexural-torsional vibration in a flexible rotor-bearing system using electromagnetic actuator. International Journal of NonLinear Mechanics, v. 46, n. 9, p. 1093-1109,2011. 
DAS, A. S.; DUTT, J. K.; RAY, K.; IRRETIER, H. Active Vibration Control of a Flexible Rotor Mounted on Journal Bearings. Advances in Vibration Engineering, v. 9, n. 2, 2010.

DEFOY, B.; ALBAN, T.; MAHFOUD, J. Experimental Assessment of a New Fuzzy Controller Applied to a Flexible Rotor Supported by Active Magnetic Bearings. Journal of Vibration and Acoustics, v. 136, n. 5, p. 051006-051006, 2014.

DOUBRAWA FILHO, F. J., Controle de Vibração Flexional em Sistemas Girantes

Utilizando Neutralizadores Dinâmicos Viscoelásticos. 2008. Dissertação de Mestrado, Universidade Tecnológica Federal do Paraná, Curitiba.

HORST, H. G.; WOLFEL, H. P. Active vibration control of a high speed rotor using PZT patches on the shaft surface. Journal of Intelligent Material Systems and Structures, v. 15, n. 9-10, p. 721-728, 2004.

HUANG, J.; CHEN, Y. H.; ZHONG, Z. Udwadia-Kalaba Approach for Parallel Manipulator Dynamics. Journal of Dynamic Systems, Measurement, and Control, v. 135, n. 6, p. 061003-061003, 2013.

JEFFCOTT, H. H. XXVII. The lateral vibration of loaded shafts in the neighbourhood of a whirling speed.-The effect of want of balance. Philosophical Magazine Series 6, v. 37, n. 219, p. 304-314, 1919. Disponível em: < http://dx.doi.org/10.1080/14786440308635889 >. Acesso em: 2013/07/01.

JEON, S.; AHN, H.-J.; HAN, D.-C. Model validation and controller design for vibration suppression of flexible rotor using AMB. KSME International Journal, v. 16, n. 12, p. 1583-1593, 2002.

KASARDA, M. E. F. Overview of active magnetic bearing technology and applications. Shock and Vibration Digest, United States, v. 32, n. 2, p. 91-99, 2000.

KOROISHI, E. H., Controle de Vibrações em Máquinas Rotativas utilizando Atuadores Eletromagnéticos. 2013. Tese de Doutorado, Universidade Federal de Uberlândia, Uberlândia, 2013.

KOROISHI, E. H.; BORGES, A. S.; CAVALINI, A. A.; STEFFEN, V. Numerical and Experimental Modal Control of Flexible Rotor Using Electromagnetic Actuator. Mathematical Problems in Engineering, v. 2014, p. 14, 2014.

KOROISHI, E. H.; STEFFEN, V.; MAHFOUD, J. Fuzzy Control of Rotor System Using an Electromagnetic Actuator. Csndd 2012 - International Conference on Structural Nonlinear Dynamics and Diagnosis, v. 1, 2012.

LAM, T.; SCHUTTE, A.; UDWADIA, F. E. Constraint based control method for precision formation flight of spacecraft. Spaceflight Mechanics 2006 - AAS/AIAA Space Flight Mechnaics Meeting, January 22, 2006 - January 26, 2006, 2006, Tampa, FL, United states. Univelt Inc. p.343-359. 
LEI, S.; PALAZZOLO, A. Control of flexible rotor systems with active magnetic bearings. Journal of Sound and Vibration, v. 314, n. 1-2, p. 19-38, 2008.

LIN, Y.-H.; YU, H.-C. Active modal control of a flexible rotor. Mechanical Systems and Signal Processing, v. 18, n. 5, p. 1117-1131, 2004.

MORAIS, T. S., Contribuição ao Estudo de Máquinas Rotativas contendo não Linearidades. 2010. Tese de Doutorado (Engenharia Mecânica), Universidade Federal de Uberlândia, Uberlândia-MG.

MORAIS, T. S.; DER HAGOPIAN, J.; STEFFEN JR., V.; MAHFOUD, J. Modeling and Identification of Electromagnetic Actuator for the Control of Rotating Machinery. Shock and Vibration, v. 20, n. 1, 2013.

MYLAPILLI, H.; UDWADIA, F. E. A constrained motion approach to the synchronization of multiple coupled slave gyroscopes. 13th Biennial ASCE Aerospace Division International Conference on Engineering, Science, Construction, and Operations in Challenging Environments, Earth and Space 2012 and the 5th NASA/ASCE Workshop on Granular Materials in Space Exploration, April 15, 2012 - April 18, 2012, 2012, Pasadena, CA, United states. American Society of Civil Engineers (ASCE). p.1349-1360.

NELSON, H. D. A finite rotating shaft element using timoshenko beam theory. Trans. ASME - J. of Mechanical Design, v.102, n.4, p.793-803, 1980.

NICOLETTI, R. The proposed concept of active magnetic-pad journal bearings. Proc. $5^{\text {th }}$ Brazilian Conference on Dynamics, Control and Their Applications. Guraratinguetá, Brazil, p. 1-4, 2006.

OGATA, K. Engenharia de controle moderno. 4.ed. Upper Saddle River: Prentice Hall, 2001.

OPREA, R. A. A constrained motion perspective of railway vehicles collision. Multibody System Dynamics, Van Godewijckstraat 30, Dordrecht, 3311 GZ, Netherlands, v. 30, n. 1, p. 101-116, 2013.

PALAZZOLO, A. B.; JAGANNATHAN, S.; KASCAK, A. F.; MONTAGUE, G. T.; KIRALY, L. J. Hybrid active vibration control of rotorbearing systems using piezoelectric actuators. Journal of vibration, acoustics, stress, and reliability in design, v. 115, n. 1, p. 111-119, 1993.

PALAZZOLO, A. B.; LIN, R. R.; ALEXANDER, R. M.; KASCAK, A. F.; MONTAGUE, J. Test and theory for piezoelectric actuator-active vibration control of rotating machinery. Journal of Vibration and Acoustics-Transactions of the Asme, v. 113, n. 2, p. 167-175, 1991.

PENNESTRI, E.; PAOLO VALENTINI, P.; DE FALCO, D. An application of the UdwadiaKalaba dynamic formulation to flexible multibody systems. Journal of the Franklin Institute, Langford Lane, Kidlington, Oxford, OX5 1GB, United Kingdom, v. 347, n. 1, p. 173-194, 2010. 
PETERS, J.; MISTRY, M.; UDWADIA, F.; NAKANISHI, J.; SCHAAL, S. A unifying framework for robot control with redundant DOFs. Autonomous Robots, Van Godewijckstraat 30, Dordrecht, 3311 GZ, Netherlands, v. 24, n. 1, p. 1-12, 2008.

SCHWEITZER, G. Magnetic Bearings Applications, Concepts and Theory. Jsme International Journal Series Iii-Vibration Control Engineering Engineering for Industry, v. 33, n. 1, p. 13-18, 1990.

SCHWEITZER, G.; LANGE, R. Characteristics of a Magnetic Rotor Bearing for Active Vibration Control. First International Conference on Vibration in Rotating Machinery. 1976, Cambridge, UK. Paper N. C239/76

SIMOES, R. C.; STEFFEN, V. Modal active vibration control of a rotor using piezoelectric stack actuators. Journal of Vibration and Control, v. 13, n. 1, p. 45-64, 2007.

SOMEYA, T. Journal-Bearing Databook. 1.ed. Berlin: Springer Verlag, 1989.

TŮMA, J.; ŠIMEK, J.; ŠKUTA, J.; LOS, J. Active vibrations control of journal bearings with the use of piezoactuators. Mechanical Systems and Signal Processing, v. 36, n. 2, p. 618629, 2013.

UDWADIA, F. E. Optimal tracking control of nonlinear dynamical systems. Proceedings of the Royal Society A: Mathematical, Physical and Engineering Sciences, v. 464, n. 2097, p. 2341-2363, 2008.

UDWADIA, F. E.; KALABA, R. E. A New Perspective on Constrained Motion. Proceedings of the Royal Society of London Series a-Mathematical Physical and Engineering Sciences, v. 439, n. 1906, p. 407-410, 1992.

ULBRICH, H. Haben aktive Lagerungen Zukunft. In: Schwingungen in Rotierenden Maschinen II, 1993, Wiesbaden. Proceeding of SIRM II. Wiesbaden: Vieweg Verlag, p.1827, 1993.

VIVEROS, H, P.; NICOLETTI, R. Lateral Vibration Attenuation of Shafts Supported by Tilting-Pad Journal Bearing With Embedded Electromagnetic Actuators. Journal of Engineering for Gas Turbines and Power, v. 136, n. 4, p. 042503, 2014.

YU, H. C.; LIN, Y. H.; CHU, C. L. Robust modal vibration suppression of a flexible rotor. Mechanical Systems and Signal Processing, v. 21, n. 1, p. 334-347, 2007.

ZHAO, H.; ZHEN, S.; CHEN, Y.-H. Dynamic modeling and simulation of multi-body systems using the Udwadia-Kalaba theory. Chinese Journal of Mechanical Engineering, v. 26, n. 5, p. 839-850, 2013. 